\title{
Synthesis of a Small-Molecule Library with Skeletal Diversity from Hemslecin A via the Reaction-Discovery Strategy
}

Jian Ren, ${ }^{\dagger}+$ Xin Shi, $^{\dagger},{ }^{\dagger}$ Xiao-Nian Li, ${ }^{\dagger}$ Lai-Wei Li, ${ }^{\dagger}$ Jia Su, ${ }^{\dagger}$ Li-Dong Shao, ${ }^{*},{ }^{\dagger}$ Qin-Shi Zhao $*, \dagger$

${ }^{\dagger}$ State Key Laboratory of Phytochemistry and Plant Resources in West China, Kunming Institute of Botany, Chinese Academy of Sciences, Kunming 650204, People's Republic of China.

*University of Chinese Academy of Sciences, Beijing 10049, People's Republic of China.

\section{List of Supporting Information}

1. General Methods............................................................ 2

2. General Experimental Procedures and Spectroscopic Data of Compounds........... S3

3. Copies of ${ }^{1} \mathrm{H}$ and ${ }^{13} \mathrm{C}$ NMR Spectra of Compounds............................... 18

4. X-ray structure of compounds $(\mathbf{5}, \mathbf{6}, \mathbf{Q 2}, \mathbf{Q 4}, \mathbf{Q 5}, \mathbf{Q 6}, \mathbf{Q 7}, \mathbf{Q 8}, \mathbf{Q 9}) \ldots \ldots \ldots \ldots \ldots . . . . . .545$ 


\section{Supporting Information}

\section{General Information}

All reactions were carried out under an atmosphere of argon in dry flask, and were monitored by analytical thin-layer chromatography (TLC), which was visualized by ultraviolet light $(254 \mathrm{~nm})$. All solvents were obtained from commercial sources and were purified according to standard procedures. All reactions sensitive to air or moisture were carried out under argon or nitrogen atmosphere in dry and freshly distilled solvents under anhydrous conditions, unless otherwise noted. Purification of products was accomplished by flash column chromatography using silica gel (200 300 mesh).

All NMR spectra were recorded with a Bruker AVANCE III 400MHz or AVANCE III $600 \mathrm{MHz}\left({ }^{1} \mathrm{H} \mathrm{NMR}\right)$ spectrometer and $100 \mathrm{MHz}$ or $150 \mathrm{MHz}\left({ }^{13} \mathrm{C} \mathrm{NMR}\right)$ in $\mathrm{CDCl}_{3}$ : chemical shifts $(\delta)$ are given in ppm, coupling constants $(J)$ in $\mathrm{Hz}$, the solvent signals were used as references $\left(\mathrm{CDCl}_{3}: \delta_{\mathrm{C}}=77.0 \mathrm{ppm}\right.$; residual $\mathrm{CHCl}_{3}$ in $\left.\mathrm{CDCl}_{3}: \delta_{\mathrm{H}}=7.26 \mathrm{ppm}\right)$. Melting points were obtained on a WRX-4 apparatus (cover glass) and are uncorrected. HRMS(ESI) was taken on Agilent 6540 Q-TOF spectrometer. 


\section{Supporting Information}

\section{Experimental Procedures and Spectroscopic Data of Compounds}

\section{1 vicinal diol 2}

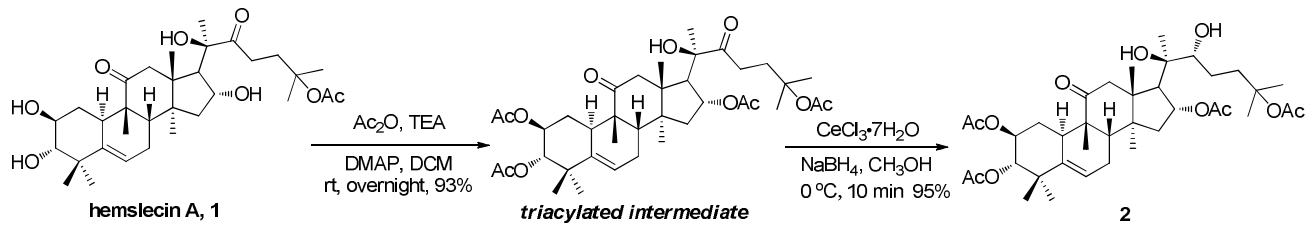

A mixture of hemslecin A (2 g, $3.6 \mathrm{mmol})$, dry $\mathrm{Et}_{3} \mathrm{~N}(2.6 \mathrm{~mL})$, acetic anhydride $(1.7$ $\mathrm{mL}$ ) and catalytic amount of DMAP in the dried DCM was stirred at rt overnight. The reaction mixture was then diluted with water and extracted with DCM. The extract was washed with brine, dried over anhydrous $\mathrm{Na}_{2} \mathrm{SO}_{4}$, filtered, and evaporated to give an oily residue. The residue was purified by column chromatography (petroleum ether/EtOAc = $1: 1)$ to afford triacylated intermediate $(2.28 \mathrm{~g}, 93 \%$ yield $)$ as a colorless foam. To a solution of the triacylated intermediate $(1.05 \mathrm{~g}, 1.5 \mathrm{mmol})$ in $\mathrm{CH}_{3} \mathrm{OH}(20 \mathrm{~mL})$ was added $\mathrm{CeCl}_{3} \cdot 7 \mathrm{H}_{2} \mathrm{O}(559 \mathrm{mg}, 1.5 \mathrm{mmol})$ and $\mathrm{NaBH}_{4}(58 \mathrm{mg}, 1.5 \mathrm{mmol})$ at $0{ }^{\circ} \mathrm{C}$ for $10 \mathrm{~min}$. The reaction mixture was quenched with saturated aqueous $\mathrm{NH}_{4} \mathrm{Cl}(10 \mathrm{~mL})$ and EtOAc (5 $\mathrm{mL}$ ), and evaporated to remove the organic layers. The combined aqueous was extracted with EtOAc $(40 \mathrm{~mL} \times 3)$. The combined organic layers were washed with brine, dried over anhydrous $\mathrm{Na}_{2} \mathrm{SO}_{4}$ and evaporated. The crude product was purified by column chromatography on silica gel (petroleum ether/EtOAc $=1: 1$ ) to give $\mathbf{2}$ as a white foam $\left(1.0 \mathrm{~g}, 95 \%\right.$ yield). ${ }^{1} \mathrm{H}$ NMR $\left(400 \mathrm{MHz}, \mathrm{CDCl}_{3}\right) \delta 5.74(\mathrm{~d}, J=5.0 \mathrm{~Hz}, 1 \mathrm{H}), 5.39$ (t, $J=$ $7.5 \mathrm{~Hz}, 1 \mathrm{H}), 4.99$ (td, $J=11.2,4.2 \mathrm{~Hz}, 1 \mathrm{H}), 4.66(\mathrm{~d}, J=10.0 \mathrm{~Hz}, 1 \mathrm{H}), 3.14(\mathrm{~s}, 1 \mathrm{H}), 3.10$ $(\mathrm{d}, J=15.3 \mathrm{~Hz}, 1 \mathrm{H}), 2.64-2.58(\mathrm{~m}, 2 \mathrm{H}), 2.41(\mathrm{~d}, J=11.9 \mathrm{~Hz}, 2 \mathrm{H}), 2.29(\mathrm{~s}, 1 \mathrm{H}), 2.04(\mathrm{~s}$, 3H), $2.03(\mathrm{~s}, 3 \mathrm{H}), 2.00(\mathrm{~s}, 2 \mathrm{H}), 1.97(\mathrm{~s}, 3 \mathrm{H}), 1.96(\mathrm{~s}, 3 \mathrm{H}), 1.93(\mathrm{~s}, 2 \mathrm{H}), 1.91-1.81(\mathrm{~m}, 2 \mathrm{H})$, 1.75-1.67 (m, 2H), 1.54-1.48 (m, 2H), $1.44(\mathrm{~s}, 3 \mathrm{H}), 1.43(\mathrm{~s}, 3 \mathrm{H}), 1.25(\mathrm{~s}, 4 \mathrm{H}), 1.21(\mathrm{~s}$, 3H), 1.07 (s, 3H), 1.04 (s, 3H), 1.02 (s, 3H), 0.95 (s, 3H). ${ }^{13} \mathrm{C}$ NMR (100 MHz, $\left.\mathrm{CDCl}_{3}\right) \delta$ $212.49,170.52,170.51,170.45,170.32,138.98,120.27,82.16,77.95,75.82,75.12,70.96$, $52.35,50.38,48.90,48.04,47.52,43.74,42.33,41.79,38.79,33.38,30.58,26.22,25.92$, 24.67, 24.38, 23.72, 22.58, 22.50, 21.39, 21.03, 20.89, 20.09, 19.80, 18.44. HRMS (ESI) 


\section{Supporting Information}

calcd. for $\mathrm{C}_{38} \mathrm{H}_{58} \mathrm{O}_{11} \mathrm{~K}(\mathrm{M}+\mathrm{K})^{+} 729.3611$, found 729.3612 .

\section{2 ketone 3}

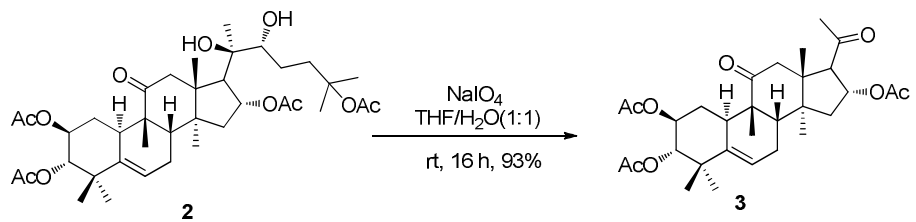

To a solution of $2(482 \mathrm{mg}, 0.7 \mathrm{mmol})$ in $\mathrm{THF} / \mathrm{H}_{2} \mathrm{O}(20 \mathrm{~mL}, 1: 1)$ was added $\mathrm{NaIO}_{4}$ (749 $\mathrm{mg}, 3.5 \mathrm{mmol}$ ) at $\mathrm{rt}$ for $16 \mathrm{~h}$. The reaction mixture was then diluted with water and extracted with EtOAc $(3 \times 15 \mathrm{~mL})$. The combined organic extract was washed with brine, dried over anhydrous $\mathrm{Na}_{2} \mathrm{SO}_{4}$ and evaporated. The crude product was purified by column chromatography on silica gel (petroleum ether/EtOAc $=2: 1$ ) to give $\mathbf{3}$ as a white foam (344 mg, 93\% yield). ${ }^{1} \mathrm{H}$ NMR (400 MHz, $\left.\mathrm{CDCl}_{3}\right) \delta 5.75(\mathrm{~d}, J=5.0 \mathrm{~Hz}, 1 \mathrm{H}), 5.61$ (t, $J=$ $7.6 \mathrm{~Hz}, 1 \mathrm{H}), 5.01(\mathrm{td}, J=11.0,4.2 \mathrm{~Hz}, 1 \mathrm{H}), 4.67$ (d, $J=10.0 \mathrm{~Hz}, 1 \mathrm{H}), 3.29$ (d, $J=6.6 \mathrm{~Hz}$, 1H), 3.22 (d, $J=14.4 \mathrm{~Hz}, 1 \mathrm{H}), 2.48-2.39$ (m, 3H), 2.14 (s, 3H), 2.05 (s, 3H), 2.02 (d, $J=$ $6.0 \mathrm{~Hz}, 1 \mathrm{H}), 1.99(\mathrm{~s}, 3 \mathrm{H}), 1.97(\mathrm{~s}, 3 \mathrm{H}), 1.94-1.82(\mathrm{~m}, 3 \mathrm{H}), 1.50(\mathrm{~d}, J=14.2 \mathrm{~Hz}, 1 \mathrm{H})$, 1.29-1.20 (m, 4H), $1.07(\mathrm{~s}, 3 \mathrm{H}), 1.04(\mathrm{~d}, J=4.3 \mathrm{~Hz}, 6 \mathrm{H}), 0.67(\mathrm{~s}, 3 \mathrm{H}) .{ }^{13} \mathrm{C}$ NMR (100 $\left.\mathrm{MHz}, \mathrm{CDCl}_{3}\right) \delta 210.59,205.85,170.41,170.34,170.28,139.00,120.00,77.80,74.64$ 70.83, 63.73, 49.41, 48.55, 48.30, 46.88, 43.17, 42.69, 41.76, 33.35, 31.33, 30.53, 24.34, 23.78, 22.49, 21.03, 20.98, 20.83, 20.02, 19.71, 18.65. HRMS (ESI) calcd. for $\mathrm{C}_{30} \mathrm{H}_{42} \mathrm{O}_{8} \mathrm{Na}(\mathrm{M}+\mathrm{Na})^{+}$553.2772, found 553.2775.

\section{3 intermediate $Q$}

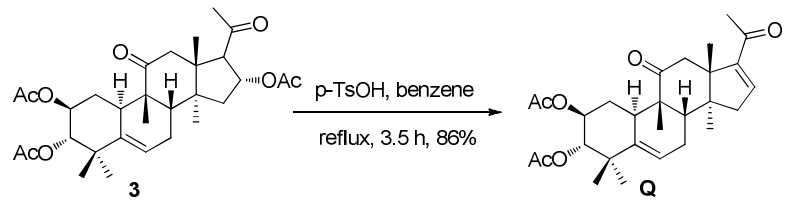

To a solution of $3(530 \mathrm{mg}, 1.0 \mathrm{mmol})$ in benzene $(20 \mathrm{~mL})$ was added p-Toluenesulfonic acid monohydrate $(57 \mathrm{mg}, 0.3 \mathrm{mmol})$ at $\mathrm{rt}$. The resulting mixture was refluxed at $80{ }^{\circ} \mathrm{C}$ for $3.5 \mathrm{~h}$, and then diluted with water and extracted with EtOAc. The extract was washed with saturated $\mathrm{NaHCO}_{3}$ (aq.) and brine, dried over anhydrous $\mathrm{Na}_{2} \mathrm{SO}_{4}$, 


\section{Supporting Information}

and evaporated. The crude product was purified by column chromatography on silica gel (petroleum ether/EtOAc $=2: 1)$ to give $\mathbf{Q}$ as a yellow foam $\left(406 \mathrm{mg}, 86 \%\right.$ yield). ${ }^{1} \mathrm{H}$ NMR (400 MHz, $\left.\mathrm{CDCl}_{3}\right) \delta 6.67(\mathrm{~s}, 1 \mathrm{H}), 5.75(\mathrm{~d}, J=5.7 \mathrm{~Hz}, 1 \mathrm{H}), 5.02(\mathrm{td}, J=11.2,4.4$ $\mathrm{Hz}, 1 \mathrm{H}), 4.65(\mathrm{~d}, J=10.0 \mathrm{~Hz}, 1 \mathrm{H}), 3.08(\mathrm{~d}, J=15.6 \mathrm{~Hz}, 1 \mathrm{H}), 2.97$ (d, $J=15.6 \mathrm{~Hz}, 1 \mathrm{H})$, $2.48(\mathrm{dd}, J=19.1,7.9 \mathrm{~Hz}, 1 \mathrm{H}), 2.35(\mathrm{~d}, J=12.9 \mathrm{~Hz}, 1 \mathrm{H}), 2.31-2.23(\mathrm{~m}, 4 \mathrm{H}), 2.21(\mathrm{~d}, J=$ $8.0 \mathrm{~Hz}, 1 \mathrm{H}), 2.15$ (dd, $J=17.1,3.2 \mathrm{~Hz}, 1 \mathrm{H}), 2.08-1.91(\mathrm{~m}, 8 \mathrm{H}), 1.26(\mathrm{q}, J=12.5 \mathrm{~Hz}, 1 \mathrm{H})$, 1.14 (s, 3H), 1.06 (s, 3H), 1.04 (s, 3H), 0.99 (s, 3H), 0.93 (s, 3H). ${ }^{13} \mathrm{C}$ NMR (100 MHz, $\left.\mathrm{CDCl}_{3}\right) \delta 212.14,196.20,170.53,170.13,151.06,143.77,138.85,119.78,78.20,71.00$, $52.41,49.54,48.41,44.18,42.53,41.71,41.49,33.98,30.87,26.91,24.47,23.71,22.77$, 22.14, 20.99, 20.95, 20.87, 19.79. HRMS (ESI) calcd. for $\mathrm{C}_{28} \mathrm{H}_{38} \mathrm{O}_{6} \mathrm{Na}(\mathrm{M}+\mathrm{Na})^{+}$ 493.2561, found 493.2566.

\section{4 epoxide 4}

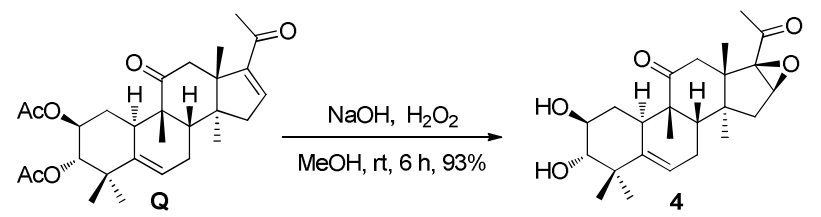

To a solution of $\mathbf{Q}(200 \mathrm{mg}, 0.42 \mathrm{mmol})$ in $\mathrm{CH}_{3} \mathrm{OH}(8 \mathrm{~mL})$ containing $10 \% \mathrm{NaOH}$ solution $(0.76 \mathrm{~mL}, 2.1 \mathrm{mmol})$ was added $30 \% \mathrm{H}_{2} \mathrm{O}_{2}$ solution $(1.5 \mathrm{~mL})$. The reaction mixture was stirred at $\mathrm{rt}$ for $6 \mathrm{~h}$, and then diluted with water and extracted with EtOAc. The combined organic extract was washed with brine, dried over anhydrous $\mathrm{Na}_{2} \mathrm{SO}_{4}$ and evaporated. The crude product was purified by column chromatography on silica gel $\left(\mathrm{DCM} / \mathrm{CH}_{3} \mathrm{OH}=20: 1\right)$ to give 4 as a white foam $\left(159 \mathrm{mg}, 93 \%\right.$ yield). ${ }^{1} \mathrm{H}$ NMR (400 $\left.\mathrm{MHz}, \mathrm{CDCl}_{3}\right) \delta 5.66(\mathrm{~d}, J=5.9 \mathrm{~Hz}, 1 \mathrm{H}), 3.81(\mathrm{~d}, J=3.2 \mathrm{~Hz}, 1 \mathrm{H}), 3.68(\mathrm{~d}, J=15.6 \mathrm{~Hz}$, 1H), 3.64-3.52 (m, 1H), 2.95 (d, $J=9.2 \mathrm{~Hz}, 1 \mathrm{H}), 2.54(\mathrm{~s}, 1 \mathrm{H}), 2.42-2.29(\mathrm{~m}, 4 \mathrm{H}), 2.00(\mathrm{~d}$, 4H, overlap), 1.90 (d, $J=7.8 \mathrm{~Hz}, 1 \mathrm{H}), 1.82$ (dd, $J=18.5,5.9 \mathrm{~Hz}, 1 \mathrm{H}), 1.68$ (dd, $J=13.2$, $3.8 \mathrm{~Hz}, 2 \mathrm{H}), 1.60$ (d, $J=13.1 \mathrm{~Hz}, 1 \mathrm{H}), 1.17$ (s, 3H), 1.16 (s, 3H), 1.09 (s, 3H), 0.94 (s, $3 \mathrm{H}), 0.89$ (s, 3H). ${ }^{13} \mathrm{C}$ NMR $\left(100 \mathrm{MHz}, \mathrm{CDCl}_{3}\right) \delta 211.74,205.37,140.89,118.31,80.89$, $72.65,71.06,66.94,58.19,48.14,47.85,45.27,41.81,40.90,38.50,34.16,33.50,25.88$, 24.70, 23.35, 21.32, 21.26, 21.05, 20.97. HRMS (ESI) calcd. for $\mathrm{C}_{24} \mathrm{H}_{34} \mathrm{O}_{5} \mathrm{~K}(\mathrm{M}+\mathrm{K})^{+}$ 


\section{Supporting Information}

441.2038, found 441.2036.

\section{$2.5 \alpha$-hydroxy epoxides 5}
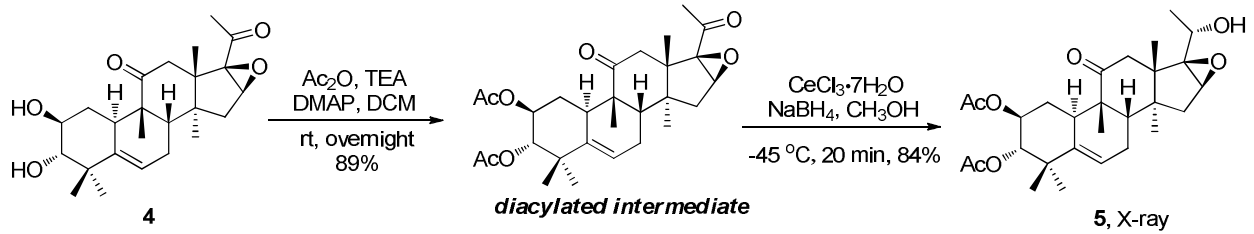

A mixture of $4(169 \mathrm{mg}, 0.42 \mathrm{mmol})$, $\operatorname{dry} \mathrm{Et}_{3} \mathrm{~N}(0.3 \mathrm{~mL})$, acetic anhydride $(120 \mu \mathrm{L})$ and catalytic amount of DMAP in DCM was stirred at rt overnight. The reaction mixture was then diluted with water and extracted with DCM, The extract was washed with brine, dried over anhydrous $\mathrm{Na}_{2} \mathrm{SO}_{4}$, filtered, and evaporated to give an oily residue. The residue was purified by column chromatography (petroleum ether/EtOAc $=5: 1$ ) to afford diacylated intermediate (182 mg, 89\% yield) as a white foam. To a solution of diacylated intermediate $(182 \mathrm{mg}, 0.37 \mathrm{mmol})$ in $\mathrm{CH}_{3} \mathrm{OH}(6 \mathrm{~mL})$ was added $\mathrm{CeCl}_{3} \cdot 7 \mathrm{H}_{2} \mathrm{O}(138 \mathrm{mg}$, $0.37 \mathrm{mmol})$ and $\mathrm{NaBH}_{4}(14 \mathrm{mg}, 0.37 \mathrm{mmol})$ at $-45{ }^{\circ} \mathrm{C}$ for $20 \mathrm{~min}$. The reaction mixture was quenched with saturated aqueous $\mathrm{NH}_{4} \mathrm{Cl}(5 \mathrm{~mL})$ and EtOAc $(4 \mathrm{~mL})$, and evaporated to remove the organic layers. The combined aqueous was extracted with EtOAc (15 $\mathrm{mL} \times 3$ ). The combined organic layers were washed with brine, dried over anhydrous $\mathrm{Na}_{2} \mathrm{SO}_{4}$ and evaporated. The crude product was purified by column chromatography on silica gel (petroleum ether / EtOAc $=2: 1)$ to give 5 as a white foam $(153 \mathrm{mg}, 84 \%$ yield). Colorless bulk crystal (recrystallized from petroleum ether/EtOAc); mp 289.2-289.4 ${ }^{\circ} \mathrm{C}$; ${ }^{1} \mathrm{H}$ NMR $\left(400 \mathrm{MHz}, \mathrm{CDCl}_{3}\right) \delta 5.70(\mathrm{~d}, J=5.4 \mathrm{~Hz}, 1 \mathrm{H}), 4.99(\mathrm{td}, J=11.2,4.1 \mathrm{~Hz}, 1 \mathrm{H})$, $4.63(\mathrm{~d}, J=10.0 \mathrm{~Hz}, 1 \mathrm{H}), 4.14-4.05(\mathrm{~m}, 1 \mathrm{H}), 3.52(\mathrm{~s}, 1 \mathrm{H}), 3.11(\mathrm{~d}, J=15.0 \mathrm{~Hz}, 1 \mathrm{H}), 2.66$ $(\mathrm{d}, J=14.9 \mathrm{~Hz}, 1 \mathrm{H}), 2.34(\mathrm{~d}, J=11.6 \mathrm{~Hz}, 2 \mathrm{H}), 2.02(\mathrm{~s}, 3 \mathrm{H}), 1.99(\mathrm{~d}, J=3.6 \mathrm{~Hz}, 1 \mathrm{H})$, 1.95 (s, 3H), 1.94-1.76 (m, 4H), 1.26-1.17 (m, 1H), 1.12-1.10 (d, 6H, overlap), 1.07 (s, $3 \mathrm{H}), 1.01(\mathrm{~s}, 3 \mathrm{H}), 0.99(\mathrm{~s}, 3 \mathrm{H}), 0.89(\mathrm{~s}, 3 \mathrm{H}) .{ }^{13} \mathrm{C} \mathrm{NMR}\left(100 \mathrm{MHz}, \mathrm{CDCl}_{3}\right) \delta 211.24$, $170.51,170.25,138.91,119.86,78.09,73.73,71.04,66.07,65.07,56.11,48.19,46.99$, $44.25,41.74,40.94,38.19,33.79,30.85,24.47,23.21,22.24,21.02,21.00,20.93,20.87$, 20.85, 18.50. HRMS (ESI) calcd. for $\mathrm{C}_{28} \mathrm{H}_{40} \mathrm{O}_{7} \mathrm{~K}(\mathrm{M}+\mathrm{K})^{+}$527.2406, found 527.2407. 


\section{Supporting Information}

2.6 Table 1 Optimization of the $\mathrm{Q1/Q2/6}$ ratio using different solvents and reaction conditions.

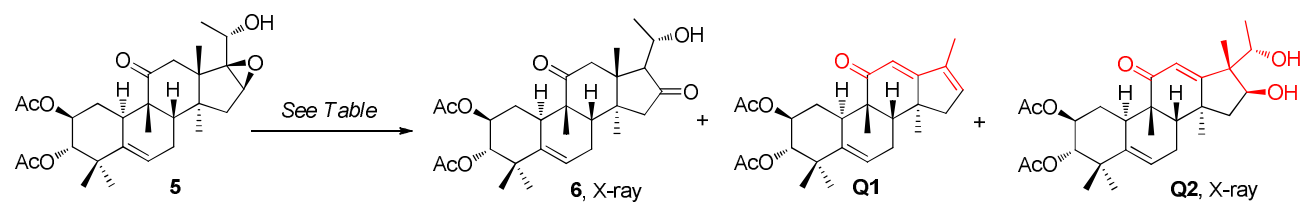

\begin{tabular}{cccccc}
\hline \multirow{2}{*}{ entry } & \multirow{2}{*}{ conditions } & solvent & \multicolumn{3}{c}{ yields $(\%)$} \\
\cline { 4 - 6 } & & $\mathrm{QCM}$ & 37 & 33 & $\mathbf{6}$ \\
\hline 1 & $\mathrm{BF}_{3} \cdot \mathrm{Et}_{2} \mathrm{O}, 0^{\circ} \mathrm{C}-\mathrm{rt}, 30 \mathrm{~min}$ & $\mathrm{DCM}$ & 15 & 70 \\
2 & $\mathrm{BF}_{3} \cdot \mathrm{Et}_{2} \mathrm{O}, 0^{\circ} \mathrm{C}-\mathrm{rt}, 30 \mathrm{~min}$ & $\mathrm{THF}$ & 12 & 17 & 11 \\
3 & $\mathrm{TFA}, 0^{\circ} \mathrm{C}-\mathrm{rt}, 30 \mathrm{~min}$ & $\mathrm{DCM}$ & 68 & 74 & 8 \\
4 & $\mathrm{TFA}, 0^{\circ} \mathrm{C}-\mathrm{rt}, 30 \mathrm{~min}$ & $\mathrm{THF}$ & 16 & 72 & $\mathrm{nd}$ \\
5 & $\mathrm{NaIO}_{4} / \mathrm{H}_{5} \mathrm{IO}_{6}, \mathrm{rt}, 72 \mathrm{~h}$ & $\mathrm{THF} / \mathrm{H}_{2} \mathrm{O}(1: 1, \mathrm{v} / \mathrm{v})$ & $\mathrm{nd}$ & 82 & \\
\hline
\end{tabular}

Procedure for Table (entry 1-2): To the solution of 5 (20 $\mathrm{mg}, 0.04 \mathrm{mmol}$ ) in corresponding solvents $(3 \mathrm{~mL})$ at $0{ }^{\circ} \mathrm{C}$ was added $\mathrm{BF}_{3} \cdot \mathrm{Et}_{2} \mathrm{O}(6 \mu \mathrm{L}, 0.48 \mathrm{mmol})$. After stirring at $\mathrm{rt}$ for $30 \mathrm{~min}$, the reaction mixture was quenched with saturated aqueous $\mathrm{NaHCO}_{3}(5 \mathrm{~mL})$, and extracted with $\mathrm{CH}_{2} \mathrm{Cl}_{2}(10 \mathrm{~mL} \times 3)$. The combined organic layers were sequentially washed with saturated aqueous $\mathrm{NaHCO}_{3}$, and brine, dried over $\mathrm{Na}_{2} \mathrm{SO}_{4}$ and evaporated to afford the crude product. The crude product was purified by column chromatography on silica gel (petroleum ether/EtOAc $=2: 1$ ) to give Q1, Q2 and 6 (See Table).

Procedure for Table (entry 3-4): To the solution of 5 (20 $\mathrm{mg}, 0.04 \mathrm{mmol})$ in corresponding solvents $(3 \mathrm{~mL})$ at $0{ }^{\circ} \mathrm{C}$ was added TFA $(9 \mu \mathrm{L}, 0.12 \mathrm{mmol})$. After stirring at $\mathrm{rt}$ for $30 \mathrm{~min}$, the reaction mixture was quenched with saturated aqueous $\mathrm{NaHCO}_{3}(5$ $\mathrm{mL})$, and extracted with $\mathrm{CH}_{2} \mathrm{Cl}_{2}(10 \mathrm{~mL} \times 3)$. The combined organic layers were sequentially washed with saturated aqueous $\mathrm{NaHCO}_{3}$, and brine, dried over $\mathrm{Na}_{2} \mathrm{SO}_{4}$ and evaporated to afford the crude product. The crude product was purified by column chromatography on silica gel (petroleum ether/EtOAc $=2: 1$ ) to give Q1, Q2 and 6 (See Table). 


\section{Supporting Information}

Procedure for Table (entry 5): To the solution of 5 (20 mg, $0.04 \mathrm{mmol})$ in $\mathrm{THF} / \mathrm{H}_{2} \mathrm{O}$ (3 $\mathrm{mL}, 1: 1)$ was added $\mathrm{H}_{5} \mathrm{IO}_{6}(45 \mathrm{mg}, 0.2 \mathrm{mmol})$ and $\mathrm{NaIO}_{4}(43 \mathrm{mg}, 0.2 \mathrm{mmol})$. After stirring at $\mathrm{rt}$ for $72 \mathrm{~h}$, the reaction mixture was quenched with saturated aqueous $\mathrm{NaHCO}_{3}$ $(5 \mathrm{~mL})$, and extracted with EtOAc $(10 \mathrm{~mL} \times 3)$. The combined organic layers were sequentially washed with saturated aqueous $\mathrm{NaHCO}_{3}$, and brine, dried over $\mathrm{Na}_{2} \mathrm{SO}_{4}$ and evaporated to afford the crude product. The crude product was purified by column chromatography on silica gel (petroleum ether/EtOAc $=1: 1)$ to give $\mathbf{Q 2}(16 \mathrm{mg}, 82 \%$ yield).

Compound Q1: ${ }^{1} \mathrm{H}$ NMR (400 MHz, $\left.\mathrm{CDCl}_{3}\right) \delta 6.14$ (s, 1H), 5.75 (s, 2H), 5.07 (td, $J=$ 11.6, $4.5 \mathrm{~Hz}, 1 \mathrm{H}), 4.70$ (d, $J=10.0 \mathrm{~Hz}, 1 \mathrm{H}), 2.59$ (d, $J=13.3 \mathrm{~Hz}, 1 \mathrm{H}), 2.53-2.44(\mathrm{~m}, 1 \mathrm{H})$, 2.38 (dt, $J=12.4,4.2 \mathrm{~Hz}, 1 \mathrm{H}), 2.28$ (d, $J=16.2 \mathrm{~Hz}, 1 \mathrm{H}), 2.21$ (d, $J=17.0 \mathrm{~Hz}, 1 \mathrm{H}), 2.05$ (s, 3H), 2.01 (d, $J=7.2 \mathrm{~Hz}, 2 \mathrm{H}), 1.98$ (s, 3H), 1.84 (s, 3H), 1.40 (dd, $J=25.0,12.5 \mathrm{~Hz}$, $1 \mathrm{H}), 1.15(\mathrm{~s}, 3 \mathrm{H}), 1.11(\mathrm{~s}, 3 \mathrm{H}), 1.06(\mathrm{~s}, 3 \mathrm{H}), 1.00(\mathrm{~s}, 3 \mathrm{H}) .{ }^{13} \mathrm{C} \mathrm{NMR}\left(100 \mathrm{MHz}, \mathrm{CDCl}_{3}\right) \delta$ 202.06, 176.19, 170.63, 170.26, 140.48, 140.12, 138.89, 119.55, 114.51, 78.31, 71.08, $48.51,47.46,46.84,45.20,41.79,33.92,30.79,25.09,24.77,24.50,22.35,21.07,20.93$, 20.87, 12.18. HRMS (ESI) calcd. for $\mathrm{C}_{26} \mathrm{H}_{34} \mathrm{O}_{5} \mathrm{Na}(\mathrm{M}+\mathrm{Na})^{+} 449.2298$, found 449.2302.

Compound Q2: Colorless acicular crystal (recrystallized from petroleum ether/EtOAc); mp 134.5-136.7 ${ }^{\circ} \mathrm{C} ;{ }^{1} \mathrm{H}$ NMR (400 MHz, $\left.\mathrm{CDCl}_{3}\right) \delta 5.80(\mathrm{~s}, 1 \mathrm{H}), 5.75(\mathrm{~d}, J=5.4 \mathrm{~Hz}, 1 \mathrm{H})$, $5.03(\mathrm{td}, J=11.5,4.4 \mathrm{~Hz}, 1 \mathrm{H}), 4.71(\mathrm{~d}, J=10.1 \mathrm{~Hz}, 1 \mathrm{H}), 4.47(\mathrm{dd}, J=10.3,6.3 \mathrm{~Hz}, 1 \mathrm{H})$, $3.90(\mathrm{q}, J=6.2 \mathrm{~Hz}, 1 \mathrm{H}), 2.54(\mathrm{~d}, J=12.8 \mathrm{~Hz}, 1 \mathrm{H}), 2.50-2.42(\mathrm{~m}, 1 \mathrm{H}), 2.36(\mathrm{dt}, J=12.4$, $4.2 \mathrm{~Hz}, 1 \mathrm{H}), 2.17$ (dd, $J=11.6,6.3 \mathrm{~Hz}, 1 \mathrm{H}), 2.05$ (s, 3H), 2.02 (d, $J=6.3 \mathrm{~Hz}, 1 \mathrm{H}), 1.99$ (s, 3H), $1.86(\mathrm{~d}, J=7.1 \mathrm{~Hz}, 2 \mathrm{H}), 1.44-1.38(\mathrm{~m}, 1 \mathrm{H}), 1.27$ (s, 2H), 1.25 (d, $J=2.3 \mathrm{~Hz}, 3 \mathrm{H})$, $1.15(\mathrm{~s}, 3 \mathrm{H}), 1.10$ (s, 6H), 1.05 (s, 3H), 0.98 (s, 3H). ${ }^{13} \mathrm{C} \mathrm{NMR}\left(100 \mathrm{MHz}, \mathrm{CDCl}_{3}\right) \delta$ $202.04,170.56,170.35,139.75,122.99,119.84,78.00,73.18,72.72,71.02,53.73,50.37$, $46.65,45.35,44.27,41.73,34.34,30.85,29.68,24.67,24.42,22.38,21.99,21.08,21.05$, 20.89, 19.05, 18.93. HRMS (ESI) calcd. for $\mathrm{C}_{28} \mathrm{H}_{40} \mathrm{O}_{7} \mathrm{~K}(\mathrm{M}+\mathrm{K})^{+} 527.2406$, found 527.2411 . 


\section{Supporting Information}

Compound 6: Colorless acicular crystal (recrystallized from petroleum ether/EtOAc); mp 258.1-259.3 ${ }^{\circ} \mathrm{C} ;{ }^{1} \mathrm{H}$ NMR (400 MHz, $\left.\mathrm{CDCl}_{3}\right) \delta 5.78(\mathrm{~d}, J=5.6 \mathrm{~Hz}, 1 \mathrm{H}), 5.01(\mathrm{td}, J=11.5$, $4.4 \mathrm{~Hz}, 1 \mathrm{H}), 4.69$ (d, $J=10.1 \mathrm{~Hz}, 1 \mathrm{H}), 4.30$ (s, 1H), 3.97-3.94 (m, 1H), 3.18 (d, $J=14.7$ Hz, 1H), 2.47 (m, 3H), 2.32-2.20 (m, 1H), 2.18-2.10 (m, 3H), 2.06 (m, 3H), 1.98 (s, 3H), $1.95-1.83(\mathrm{~m}, 2 \mathrm{H}), 1.32-1.25(\mathrm{~m}, 1 \mathrm{H}), 1.20$ (d, 6H, overlap), 1.13 (s, 3H), 1.05 (d, $J=9.5$ $\mathrm{Hz}, 6 \mathrm{H}), 0.86(\mathrm{~s}, 3 \mathrm{H}) .{ }^{13} \mathrm{C}$ NMR $\left(100 \mathrm{MHz}, \mathrm{CDCl}_{3}\right) \delta 221.07,210.40,170.50,170.29$, 139.35, 119.76, 77.78, 70.81, 66.21, 61.36, 49.83, 49.53, 46.86, 46.34, 43.74, 42.51, $41.85,33.39,30.61,24.36,24.06,22.60,21.48,21.01,20.88,20.00,19.00,18.39$. HRMS (ESI) calcd. for $\mathrm{C}_{28} \mathrm{H}_{40} \mathrm{O}_{7} \mathrm{~K}(\mathrm{M}+\mathrm{K})^{+}$527.2406, found 527.2406.

\subsection{Compound Q3 and Q4}
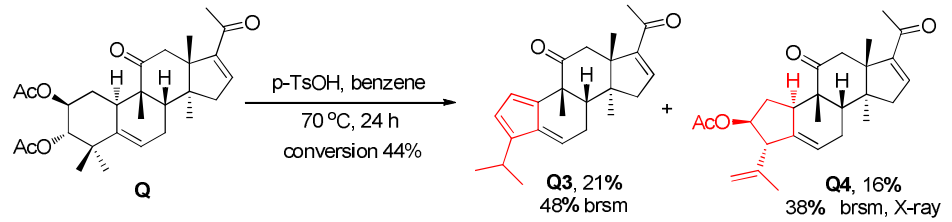

To a solution of $\mathbf{Q}(1.22 \mathrm{~g}, 2.59 \mathrm{mmol})$ in benzene $(25 \mathrm{~mL})$ was added p-Toluenesulfonic acid monohydrate $(590 \mathrm{mg}, 3.1 \mathrm{mmol})$ at $\mathrm{rt}$. The resulting mixture was stirred at $70{ }^{\circ} \mathrm{C}$ for $24 \mathrm{~h}$, and then diluted with water and extracted with EtOAc. The extract was washed with saturated $\mathrm{NaHCO}_{3}$ (aq.) and brine, dried over anhydrous $\mathrm{Na}_{2} \mathrm{SO}_{4}$, and evaporated to afford the crude product. The crude product was purified by column chromatography on silica gel (petroleum ether/EtOAc $=5: 1$ ) to give $\mathbf{Q 3}$ as a yellow foam (184 mg, 21\% yield, 48\% brsm) and $\mathbf{Q} 4$ as a yellow solid (167 mg, 16\% yield, 38\% brsm).

Compound Q3: ${ }^{1} \mathrm{H}$ NMR $\left(600 \mathrm{MHz}, \mathrm{CDCl}_{3}\right) \delta 6.69(\mathrm{~s}, 1 \mathrm{H}), 6.64(\mathrm{~d}, J=10.0 \mathrm{~Hz}, 1 \mathrm{H})$, $5.66(\mathrm{dd}, J=9.9,6.0 \mathrm{~Hz}, 1 \mathrm{H}), 5.60(\mathrm{~s}, 1 \mathrm{H}), 3.11(\mathrm{~d}, J=16.4 \mathrm{~Hz}, 1 \mathrm{H}), 2.99(\mathrm{dt}, J=13.7$, $6.8 \mathrm{~Hz}, 1 \mathrm{H}), 2.88$ (d, $J=11.9 \mathrm{~Hz}, 2 \mathrm{H}), 2.84(\mathrm{~d}, J=16.4 \mathrm{~Hz}, 1 \mathrm{H}), 2.76(\mathrm{~d}, J=5.8 \mathrm{~Hz}, 1 \mathrm{H})$, 2.46 (d, $J=17.3 \mathrm{~Hz}, 1 \mathrm{H}), 2.27$ (s, 3H), 2.16 (dd, $J=17.3,3.1 \mathrm{~Hz}, 1 \mathrm{H}), 1.32$ (s, 3H), 1.12 (d, $J=6.8 \mathrm{~Hz}, 3 \mathrm{H}), 1.06(\mathrm{~d}, J=6.9 \mathrm{~Hz}, 3 \mathrm{H}), 1.02(\mathrm{~s}, 3 \mathrm{H}), 0.83(\mathrm{~s}, 3 \mathrm{H}) .{ }^{13} \mathrm{C}$ NMR $(150$ $\left.\mathrm{MHz}, \mathrm{CDCl}_{3}\right) \delta 211.37,196.19,150.68,148.23,145.84,143.88,131.06,125.72,122.71$, 


\section{Supporting Information}

$120.74,51.52,49.96,49.53,47.51,45.13,41.59,38.70,27.99,27.28,26.98,23.73,22.85$, 22.48, 18.56. HRMS (ESI) calcd. for $\mathrm{C}_{24} \mathrm{H}_{31} \mathrm{O}_{2} \mathrm{Na}(\mathrm{M}+\mathrm{H})^{+}$351.2319, found 351.2322.

Compound Q4: yellow acicular crystal (recrystallized from petroleum ether/EtOAc); mp 242.7-243.6 ${ }^{\circ} \mathrm{C} ;{ }^{1} \mathrm{H}$ NMR $\left(600 \mathrm{MHz}, \mathrm{CDCl}_{3}\right) \delta 6.67(\mathrm{~d}, J=1.2 \mathrm{~Hz}, 1 \mathrm{H}), 5.49(\mathrm{~s}, 1 \mathrm{H})$, $5.00(\mathrm{dd}, J=15.2,8.2 \mathrm{~Hz}, 1 \mathrm{H}), 4.77$ (s, 2H), $3.14(\mathrm{dd}, J=5.1,2.3 \mathrm{~Hz}, 1 \mathrm{H}), 3.10(\mathrm{~d}, J=$ $16.3 \mathrm{~Hz}, 1 \mathrm{H}), 2.90$ (d, $J=16.3 \mathrm{~Hz}, 1 \mathrm{H}), 2.57-2.53(\mathrm{~m}, 1 \mathrm{H}), 2.44-2.37$ (m, 1H), 2.29 (d, 5H, overlap), 2.20 (dd, $J=17.0,3.2 \mathrm{~Hz}, 1 \mathrm{H}), 2.09-2.03$ (m, 2H), 2.01 (s, 3H), 1.62 (s, $3 \mathrm{H}), 1.49(\mathrm{dd}, J=21.6,11.9 \mathrm{~Hz}, 1 \mathrm{H}), 1.11(\mathrm{~s}, 3 \mathrm{H}), 1.10$ (s, 3H), 0.96 (s, 3H). ${ }^{13} \mathrm{C}$ NMR $\left(151 \mathrm{MHz}, \mathrm{CDCl}_{3}\right) \delta 213.27,196.21,170.76,151.27,144.25,143.65,137.67,118.77$, $113.18,75.17,57.33,51.33,49.82,48.50,44.57,43.09,41.08,40.98,33.06,26.92,24.40$, 22.90, 21.06, 19.86, 19.00, 18.61. HRMS (ESI) calcd. for $\mathrm{C}_{26} \mathrm{H}_{34} \mathrm{O}_{4} \mathrm{Na}(\mathrm{M}+\mathrm{Na})^{+}$ 433.2349, found 433.2352 .

\subsection{Compound 9}

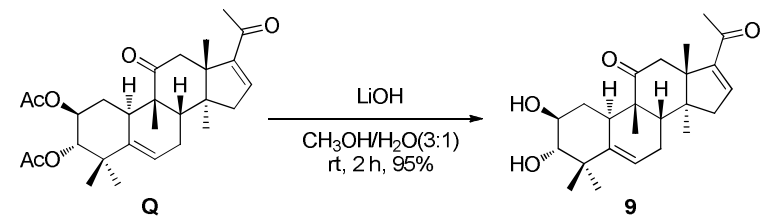

To a solution of $\mathbf{Q}(256 \mathrm{mg}, 0.54 \mathrm{mmol})$ in $\mathrm{CH}_{3} \mathrm{OH} / \mathrm{H}_{2} \mathrm{O}(20 \mathrm{~mL}, 3: 1)$ was added $\mathrm{LiOH}(39 \mathrm{mg}, 1.62 \mathrm{mmol})$ at $\mathrm{rt}$. The resulting mixture was stirred at $\mathrm{rt}$ for $2 \mathrm{~h}$, and then diluted with water and extracted with EtOAc. The extract was washed with brine, dried over anhydrous $\mathrm{Na}_{2} \mathrm{SO}_{4}$ and evaporated to afford the crude product. The crude product was purified by column chromatography on silica gel (petroleum ether/EtOAc $=1: 1$ ) to give 9 as a white foam $\left(199 \mathrm{mg}, 95 \%\right.$ yield). ${ }^{1} \mathrm{H}$ NMR (400 MHz, $\left.\mathrm{CDCl}_{3}\right) \delta 6.68(\mathrm{~s}, 1 \mathrm{H})$, $5.70(\mathrm{~d}, J=5.7 \mathrm{~Hz}, 1 \mathrm{H}), 3.64-3.47(\mathrm{~m}, 1 \mathrm{H}), 3.04(\mathrm{~d}, J=15.5 \mathrm{~Hz}, 1 \mathrm{H}), 2.98(\mathrm{~d}, J=11.5$ Hz, 1H), 2.95 (d, $J=5.5 \mathrm{~Hz}, 1 \mathrm{H}), 2.75$ (s, 1H), 2.61 (s, 1H), 2.46 (dd, $J=18.9,7.7 \mathrm{~Hz}$, 1H), 2.28 (d, 5H, overlap), $2.16(\mathrm{~m}, 2 \mathrm{H}$, overlap), $2.05(\mathrm{dd}, J=8.9,5.0 \mathrm{~Hz}, 1 \mathrm{H})$, 2.01-1.83 (m, 2H, overlap), 1.17 (s, 3H), 1.14 (s, 3H), 1.05 (s, 3H), 0.92 (s, 3H), 0.89 (s, 3H). ${ }^{13} \mathrm{C}$ NMR $\left(101 \mathrm{MHz}, \mathrm{CDCl}_{3}\right) \delta 213.10,196.42,150.99,144.16,140.61,118.56$, 


\section{Supporting Information}

$80.86,71.09,52.40,49.59,48.49,44.19,42.55,41.78,41.50,34.46,33.57,26.88,24.71$, 23.63, 22.73, 21.11, 21.07, 19.94. HRMS (ESI) calcd. for $\mathrm{C}_{24} \mathrm{H}_{34} \mathrm{O}_{4} \mathrm{Na}(\mathrm{M}+\mathrm{Na})^{+}$ 409.2349, found 409.2350.

\section{$2.9 \alpha$-hydroxyl ketone 10}

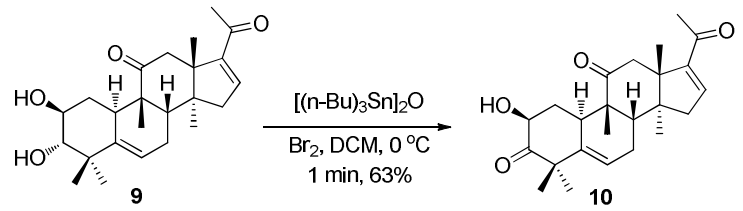

To a solution of $9(50 \mathrm{mg}, 0.13 \mathrm{mmol})$ in dry DCM $(5 \mathrm{~mL})$ at $0{ }^{\circ} \mathrm{C}$, $\left[(\mathrm{n}-\mathrm{Bu})_{3} \mathrm{Sn}\right]_{2} \mathrm{O}(66$ $\mu \mathrm{L}, 0.13 \mathrm{mmol})$ and bromine $(7 \mu \mathrm{L}, 0.13 \mathrm{mmol})$ were added. After stirring at $0{ }^{\circ} \mathrm{C}$ for 1 min, $\mathrm{NEt}_{3}(0.10 \mathrm{~mL})$ was added, the solvents were removed under diminished pressure, and the residue was purified by column chromatography on silica gel (petroleum ether/EtOAc/formic acid $=20: 10: 1)$ to give $\mathbf{1 0}$ as a white foam $(31 \mathrm{mg}, 63 \%$ yield $) .{ }^{1} \mathrm{H}$ NMR (400 MHz, $\left.\mathrm{CDCl}_{3}\right) \delta 6.70(\mathrm{~d}, J=1.8 \mathrm{~Hz}, 1 \mathrm{H}), 5.76(\mathrm{~d}, J=5.9 \mathrm{~Hz}, 1 \mathrm{H}), 4.41(\mathrm{dd}, J$ $=12.8,6.0 \mathrm{~Hz}, 1 \mathrm{H}), 3.57(\mathrm{~s}, 1 \mathrm{H}), 3.14(\mathrm{~d}, J=15.6 \mathrm{~Hz}, 1 \mathrm{H}), 3.05(\mathrm{~d}, J=15.8 \mathrm{~Hz}, 1 \mathrm{H})$, $2.65(\mathrm{~d}, J=12.8 \mathrm{~Hz}, 1 \mathrm{H}), 2.54-2.49(\mathrm{~m}, 1 \mathrm{H}), 2.47$ (dd, $J=8.4,5.3 \mathrm{~Hz}, 1 \mathrm{H}), 2.29$ (s, 4H), $2.25(\mathrm{~d}, J=8.0 \mathrm{~Hz}, 1 \mathrm{H}), 2.18(\mathrm{dd}, J=17.0,3.4 \mathrm{~Hz}, 1 \mathrm{H}), 2.02(\mathrm{dd}, J=19.7,5.1 \mathrm{~Hz}, 1 \mathrm{H})$, 1.31 (s, 3H), 1.24-1.20 (m, 4H, overlap), 1.14 (s, 6H), 0.95 (s, 3H). ${ }^{13} \mathrm{C}$ NMR (100 MHz, $\left.\mathrm{CDCl}_{3}\right) \delta 213.15,212.21,196.33,150.93,143.91,140.14,119.84,71.62,52.32,50.29$, $49.62,48.51,44.22,42.50,41.30,36.32,34.27,28.71,26.92,23.77,22.78,21.21,20.96$, 19.85. HRMS (ESI) calcd. for $\mathrm{C}_{24} \mathrm{H}_{32} \mathrm{O} 4 \mathrm{Na}(\mathrm{M}+\mathrm{Na})+407.2193$, found 407.2194.

\subsection{Compound Q5}
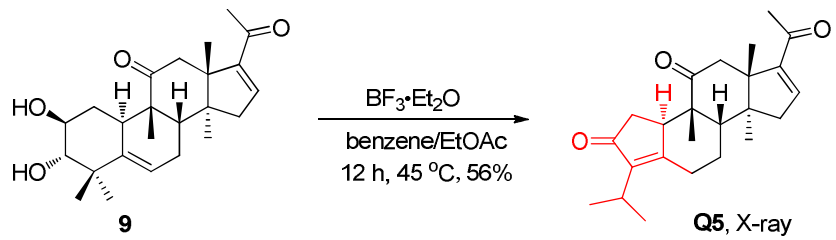

To a solution of 9 (40 mg, $0.1 \mathrm{mmol})$ in benzene/EtOAc $(8 \mathrm{~mL}, 50: 1)$ was added $\mathrm{BF}_{3} \cdot \mathrm{Et}_{2} \mathrm{O}(62 \mu \mathrm{L}, 0.5 \mathrm{mmol})$ at $\mathrm{rt}$. The resulting mixture was stirred at $45^{\circ} \mathrm{C}$ for $12 \mathrm{~h}$, and then the reaction mixture was quenched with saturated aqueous $\mathrm{NaHCO}_{3}(5 \mathrm{~mL})$, and 


\section{Supporting Information}

extracted with EtOAc $(15 \mathrm{~mL} \times 3)$. The combined organic layers were sequentially washed with saturated aqueous $\mathrm{NaHCO}_{3}$, and brine, dried over $\mathrm{Na}_{2} \mathrm{SO}_{4}$ and evaporated to afford the crude product. The crude product was purified by column chromatography on silica gel (petroleum ether/EtOAc $=3: 1)$ to give $\mathbf{Q 5}$ as a white foam $(21 \mathrm{mg}, 56 \%$ yield) . Colorless acicular crystal (recrystallized from $n$-hexane/EtOAc); mp 157.2-159 ${ }^{\circ} \mathrm{C} ;{ }^{1} \mathrm{H}$ NMR $\left(600 \mathrm{MHz}, \mathrm{CDCl}_{3}\right) \delta 6.71(\mathrm{~d}, J=1.3 \mathrm{~Hz}, 1 \mathrm{H}), 3.05(\mathrm{~d}, J=5.7 \mathrm{~Hz}, 1 \mathrm{H}), 2.97(\mathrm{~d}, J=$ $18.3 \mathrm{~Hz}, 1 \mathrm{H}), 2.83$ (d, $J=18.4 \mathrm{~Hz}, 1 \mathrm{H}), 2.79-2.71(\mathrm{~m}, 3 \mathrm{H}), 2.62-2.55$ (m, 1H), 2.40 (d, $J$ $=17.2 \mathrm{~Hz}, 1 \mathrm{H}), 2.32(\mathrm{~d}, J=6.2 \mathrm{~Hz}, 1 \mathrm{H}), 2.33-2.31(\mathrm{~m}, 1 \mathrm{H}), 2.29(\mathrm{~s}, 3 \mathrm{H}), 2.28-2.25(\mathrm{~m}$, 1H), 1.93-1.84 (m, 1H), 1.84-1.76 (m, 1H), 1.17 (s, 3H), 1.15 (d, J=3.4 Hz, 3H), 1.14 (d, $J=3.4 \mathrm{~Hz}, 3 \mathrm{H}), 1.13(\mathrm{~s}, 3 \mathrm{H}), 1.01(\mathrm{~s}, 3 \mathrm{H}) .{ }^{13} \mathrm{C} \mathrm{NMR}\left(150 \mathrm{MHz}, \mathrm{CDCl}_{3}\right) \delta 215.35,208.53$, $196.03,170.67,151.77,145.33,143.16,50.14,49.72,49.04,46.07,44.00,43.33,42.35$, $38.28,26.86,25.16,24.66,23.22,22.41,21.67,20.57,20.40,20.12$. HRMS (ESI) calcd. for $\mathrm{C}_{24} \mathrm{H}_{33} \mathrm{O}_{3}(\mathrm{M}+\mathrm{H})^{+} 369.2424$, found 369.2429 .

\subsection{Compound Q6}

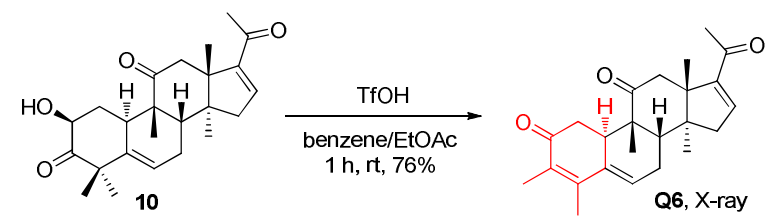

To a solution of $10(26 \mathrm{mg}, 0.07 \mathrm{mmol})$ in benzene/EtOAc ( $5 \mathrm{ml}, 50: 1)$ was added $\mathrm{TfOH}(31 \mu \mathrm{L}, 0.34 \mathrm{mmol})$ at $\mathrm{rt}$. The resulting mixture was stirred at $\mathrm{rt}$ for $1 \mathrm{~h}$, and then the reaction mixture was quenched with saturated aqueous $\mathrm{NaHCO}_{3}(5 \mathrm{~mL})$, and extracted with EtOAc $(10 \mathrm{~mL} \times 3)$. The combined organic layers were sequentially washed with saturated aqueous $\mathrm{NaHCO}_{3}$, and brine, dried over $\mathrm{Na}_{2} \mathrm{SO}_{4}$ and evaporated to afford the crude product. The crude product was purified by column chromatography on silica gel (petroleum ether/EtOAc $=3: 1)$ to give $\mathbf{Q 6}$ as a white foam $(19 \mathrm{mg}, 76 \%$ yield). Colorless acicular crystal (recrystallized from $n$-hexane/EtOAc); mp 232.4-234.8 ${ }^{\circ} \mathrm{C} ;{ }^{1} \mathrm{H}$ NMR (400 MHz, $\left.\mathrm{CDCl}_{3}\right) \delta 6.68(\mathrm{~d}, J=1.1 \mathrm{~Hz}, 1 \mathrm{H}), 6.36-6.26(\mathrm{~m}, 1 \mathrm{H}), 3.09(\mathrm{~d}, J=15.5$ $\mathrm{Hz}, 1 \mathrm{H}), 2.91$ (d, $J=15.6 \mathrm{~Hz}, 1 \mathrm{H}), 2.72-2.61$ (m, 2H, overlap), 2.54 (dd, $J=15.2,3.8 \mathrm{~Hz}$, 1H), 2.34-2.30 (m, 2H), $2.28(\mathrm{~s}, 3 \mathrm{H}), 2.25-2.14(\mathrm{~m}, 3 \mathrm{H}), 2.03(\mathrm{~s}, 3 \mathrm{H}), 1.85(\mathrm{~s}, 3 \mathrm{H}), 1.17$ 


\section{Supporting Information}

(s, 3H), 1.06 (s, 3H), 0.95 (s, 3H). ${ }^{13} \mathrm{C}$ NMR (100 MHz, $\left.\mathrm{CDCl}_{3}\right) \delta 211.34,198.85,196.17$, $151.09,148.39,143.63,133.68,131.14,127.13,52.23,49.63,48.54,44.19,42.77,40.93$, 38.55, 36.70, 26.92, 24.64, 22.74, 20.41, 19.31, 16.41, 11.86. HRMS (ESI) calcd. for $\mathrm{C}_{24} \mathrm{H}_{31} \mathrm{O}_{3}(\mathrm{M}+\mathrm{H})^{+}$367.2268, found 367.2271.

\subsection{Table 2 Condition Screening for C(sp3)-H Oxidation of C30-methyl Group}

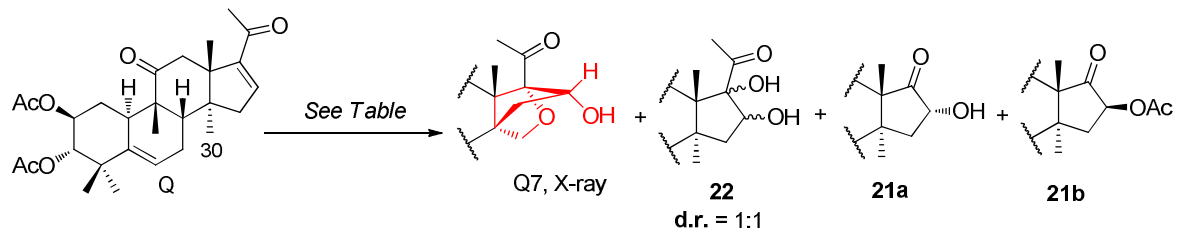

\begin{tabular}{cccccc}
\hline \multirow{2}{*}{ entry } & \multirow{2}{*}{ conditions } & solvent & \multicolumn{3}{c}{ yields(\%) } \\
\cline { 4 - 5 } & & & $\mathbf{2 1 a} / \mathbf{2 1 b}$ & $\mathbf{2 2}$ \\
\hline 1 & $\mathrm{KMnO}_{4}, \mathrm{HCOOH}$ & acetone $/ \mathrm{H}_{2} \mathrm{O}(4: 1, \mathrm{v} / \mathrm{v})$ & 39 & $5 / \mathrm{nd}$ & 45 \\
2 & $\mathrm{KMnO}_{4}, \mathrm{HCOOH}$ & acetone $/ \mathrm{H}_{2} \mathrm{O}(2: 1, \mathrm{v} / \mathrm{v})$ & 40 & $25 / \mathrm{nd}$ & 35 \\
3 & $\mathrm{KMnO}_{4}, \mathrm{HCOOH}$ & acetone $/ \mathrm{H}_{2} \mathrm{O}(1: 1, \mathrm{v} / \mathrm{v})$ & 42 & $15 / 9$ & 12 \\
4 & $\mathrm{KMnO}_{4}, \mathrm{HCOOH}$ & acetone $/ \mathrm{H}_{2} \mathrm{O}(1: 2, \mathrm{v} / \mathrm{v})$ & 54 & $\mathrm{nd} / 25$ & $\mathrm{nd}$ \\
5 & $\mathrm{KMnO}_{4}, \mathrm{HCOOH}$ & $18-$ crown-6(1 equiv $) /$ acetone & 37 & $\mathrm{nd} / \mathrm{nd}$ & 51 \\
6 & $\mathrm{KMnO}_{4}, \mathrm{HCOOH}$ & $\mathrm{CH}_{3} \mathrm{CN} / \mathrm{H}_{2} \mathrm{O}(1: 2, \mathrm{v} / \mathrm{v})$ & 36 & $24 / 17$ & 11 \\
\hline
\end{tabular}

Procedure for Table (entry 1-4, 6): To solution of $\mathbf{Q}(50 \mathrm{mg}, 0.11 \mathrm{mmol})$ and $\mathrm{HCOOH}$ (21 $\mu \mathrm{L}, 0.55 \mathrm{mmol})$ in corresponding solvent $(2 \mathrm{~mL})$ of corresponding ratio listed in Table at $0{ }^{\circ} \mathrm{C}$ was added gradually a solution of $\mathrm{KMnO}_{4}(49 \mathrm{mg}, 0.33 \mathrm{mmol})$ in corresponding solvent $(2 \mathrm{~mL})$ of corresponding ratio listed in Table. Upon completion of the addition, the reaction was stirred at $\mathrm{rt}$ for 10 min and quenched with a $10 \%$ aqueous solution of $\mathrm{Na}_{2} \mathrm{~S}_{2} \mathrm{O}_{3}$ $(5 \mathrm{~mL})$. Acetone was removed under vacuum, and the aqueous layer was extracted with EtOAc $(10 \mathrm{~mL} \times 3)$. The organic layer was washed with saturated aqueous $\mathrm{NaHCO}_{3}$, and brine, dried over $\mathrm{Na}_{2} \mathrm{SO}_{4}$ and evaporated to afford the crude product. The crude product was purified by column chromatography on silica gel (petroleum ether/EtOAc $=2: 1$ ) to give Q7, 22, 21a and 21b (see table).

Procedure for Table 2 (entry 5): A mixture of $\mathbf{Q}(50 \mathrm{mg}, 0.11 \mathrm{mmol})$, HCOOH (21 $\mu \mathrm{L}$, $0.55 \mathrm{mmol})$ and 18 -crown- $6(24 \mathrm{mg}, 0.11 \mathrm{mmol})$ in acetone $(2 \mathrm{~mL})$ at $0{ }^{\circ} \mathrm{C}$ was added gradually a solution of $\mathrm{KMnO}_{4}(49 \mathrm{mg}, 0.33 \mathrm{mmol})$ in acetone $(2 \mathrm{~mL})$. Upon completion 


\section{Supporting Information}

of the addition, the reaction was stirred at rt for $10 \mathrm{~min}$ and quenched with a $10 \%$ aqueous solution of $\mathrm{Na}_{2} \mathrm{~S}_{2} \mathrm{O}_{3}(5 \mathrm{~mL})$. Acetone was removed under vacuum, and the aqueous layer was extracted with EtOAc $(10 \mathrm{~mL} \times 3)$. The organic layer was washed with saturated aqueous $\mathrm{NaHCO}_{3}$, and brine, dried over $\mathrm{Na}_{2} \mathrm{SO}_{4}$ and evaporated to afford the crude product. The crude product was purified by column chromatography on silica gel (petroleum ether/EtOAc $=2: 1$ ) to give Q7, 22, 21a and 21b (see table).

Compound Q7: Colorless bulk crystal (recrystallized from petroleum ether/EtOAc); mp 157.4-158.7 ${ }^{\circ} \mathrm{C} ;{ }^{1} \mathrm{H}$ NMR $\left(400 \mathrm{MHz}, \mathrm{CDCl}_{3}\right) \delta 5.73(\mathrm{~d}, J=6.0 \mathrm{~Hz}, 1 \mathrm{H}), 5.01(\mathrm{td}, J=11.3$, $4.5 \mathrm{~Hz}, 1 \mathrm{H}), 4.71(\mathrm{~d}, J=9.2 \mathrm{~Hz}, 1 \mathrm{H}), 4.65(\mathrm{~d}, J=10.2 \mathrm{~Hz}, 1 \mathrm{H}), 4.29$ (dd, $J=8.5,3.8 \mathrm{~Hz}$, 1H), 3.72 (d, $J=8.5 \mathrm{~Hz}, 1 \mathrm{H}), 3.25$ (d, $J=14.4 \mathrm{~Hz}, 1 \mathrm{H}$ ), 2.55-2.52 (t, 2H, overlap), 2.38 (dd, $J=18.6,7.0 \mathrm{~Hz}, 1 \mathrm{H}), 2.21$ (s, 3H), 2.08-2.05 (d, 4H, overlap), 2.01 (d, $J=4.9 \mathrm{~Hz}$, 1H), 1.96 (s, 3H), 1.90 (d, $J=7.2 \mathrm{~Hz}, 1 \mathrm{H}), 1.82(\mathrm{dt}, J=12.0,4.1 \mathrm{~Hz}, 1 \mathrm{H}), 1.42(\mathrm{~d}, J=$ 13.0, 1H), 1.23 (q, $J=12.4 \mathrm{~Hz}, 1 \mathrm{H}), 1.11(\mathrm{~s}, 3 \mathrm{H}), 1.08$ (s, 3H), 1.05 (s, 3H), 0.93 (s, 3H). ${ }^{13} \mathrm{C}$ NMR $\left(100 \mathrm{MHz}, \mathrm{CDCl}_{3}\right) \delta 209.75,206.42,170.35,170.18,139.70,119.01,93.70$, 77.64, 75.32, 75.13, 70.69, 54.92, 53.64, 48.64, 43.77, 42.16, 41.84, 40.36, 34.48, 31.14, $29.20,24.38,23.03,22.39,20.89,20.78,19.47,15.42$. HRMS (ESI) calcd. for $\mathrm{C}_{28} \mathrm{H}_{38} \mathrm{O}_{8} \mathrm{Na}(\mathrm{M}+\mathrm{Na})^{+} 525.2459$, found 527.2463.

Compound 22: HRMS (ESI) calcd. for $\mathrm{C}_{28} \mathrm{H}_{40} \mathrm{O}_{8} \mathrm{Na}(\mathrm{M}+\mathrm{Na})^{+}$527.2615, found 527.2616.

Compound 21a: ${ }^{1} \mathrm{H}$ NMR $\left(600 \mathrm{MHz}, \mathrm{CDCl}_{3}\right) \delta 5.76(\mathrm{~d}, J=5.2 \mathrm{~Hz}, 1 \mathrm{H}), 5.01(\mathrm{td}, J=$ 11.5, 4.4 Hz, 1H), 4.66 (d, $J=10.0 \mathrm{~Hz}, 1 \mathrm{H}), 4.47(\mathrm{~d}, J=9.2 \mathrm{~Hz}, 1 \mathrm{H}), 3.00(\mathrm{~d}, J=15.1$ $\mathrm{Hz}, 1 \mathrm{H}), 2.44-2.40$ (m, 2H, overlap), 2.35 (d, $J=15.1 \mathrm{~Hz}, 1 \mathrm{H}), 2.26-2.18(\mathrm{~m}, 1 \mathrm{H})$, 2.10-2.02 (m, 5H, overlap), 1.97 (s, 3H), 1.86 (d, $J=12.3 \mathrm{~Hz}, 1 \mathrm{H}), 1.73$ (d, $J=13.7 \mathrm{~Hz}$, 1H), 1.24 (q, $J=12.5 \mathrm{~Hz}, 2 \mathrm{H}), 1.12(\mathrm{~s}, 3 \mathrm{H}), 1.05$ (s, 3H), 1.04 (s, 3H), $1.02(\mathrm{~s}, 3 \mathrm{H}), 0.99$ (s, 3H). ${ }^{13} \mathrm{C}$ NMR $\left(150 \mathrm{MHz}, \mathrm{CDCl}_{3}\right) \delta 215.73,210.33,170.49,170.23,139.12,119.45$, $77.87,71.39,70.83,54.88,49.52,42.91,42.60,41.78,41.44,40.60,33.44,30.63,24.36$, 22.30, 22.00, 20.97, 20.84, 20.22, 19.92, 19.26. HRMS (ESI) calcd. for $\mathrm{C}_{26} \mathrm{H}_{36} \mathrm{O}_{7} \mathrm{Na}(\mathrm{M}$ 


\section{Supporting Information}

$+\mathrm{Na})^{+} 483.2353$, found 483.2354 .

Compound 21b: ${ }^{1} \mathrm{H}$ NMR $\left(600 \mathrm{MHz}, \mathrm{CDCl}_{3}\right) \delta 5.78(\mathrm{~d}, J=5.6 \mathrm{~Hz}, 1 \mathrm{H}), 5.55(\mathrm{~s}, 1 \mathrm{H})$, $5.02(\mathrm{td}, J=11.4,4.4 \mathrm{~Hz}, 1 \mathrm{H}), 4.68$ (d, $J=10.0 \mathrm{~Hz}, 1 \mathrm{H}), 3.19$ (d, $J=14.8 \mathrm{~Hz}, 1 \mathrm{H}), 2.48$ (dd, $J=16.5,10.3 \mathrm{~Hz}, 2 \mathrm{H}$ ), 2.30 (d, $J=14.8 \mathrm{~Hz}, 1 \mathrm{H}$ ), 2.19-2.11 (m, 6H, overlap), 2.06 (s, $3 \mathrm{H}), 1.97$ (s, 3H), $1.94(\mathrm{dd}, J=12.9,5.2 \mathrm{~Hz}, 1 \mathrm{H}), 1.88(\mathrm{dt}, J=12.1,3.8 \mathrm{~Hz}, 1 \mathrm{H}), 1.30$ (s, $3 \mathrm{H}), 1.27$ (d, $J=12.5 \mathrm{~Hz}, 1 \mathrm{H}), 1.14(\mathrm{~s}, 3 \mathrm{H}), 1.06(\mathrm{~s}, 3 \mathrm{H}), 1.04(\mathrm{~s}, 3 \mathrm{H}), 0.86(\mathrm{~s}, 3 \mathrm{H}) .{ }^{13} \mathrm{C}$ NMR $\left(150 \mathrm{MHz}, \mathrm{CDCl}_{3}\right) \delta 209.60,209.52,170.47,170.21,170.18,139.46,119.64$, $79.27,77.74,70.74,49.88,47.59,46.83,44.09,43.43,41.83,40.87,33.34,30.58,24.32$, 23.41, 22.52, 20.96, 20.84, 20.58, 19.97, 19.60, 17.30. HRMS (ESI) calcd. for $\mathrm{C}_{28} \mathrm{H}_{38} \mathrm{O}_{8} \mathrm{Na}(\mathrm{M}+\mathrm{Na})^{+}$525.2459, found 525.2463.

\subsection{3 hemiacetal 23}

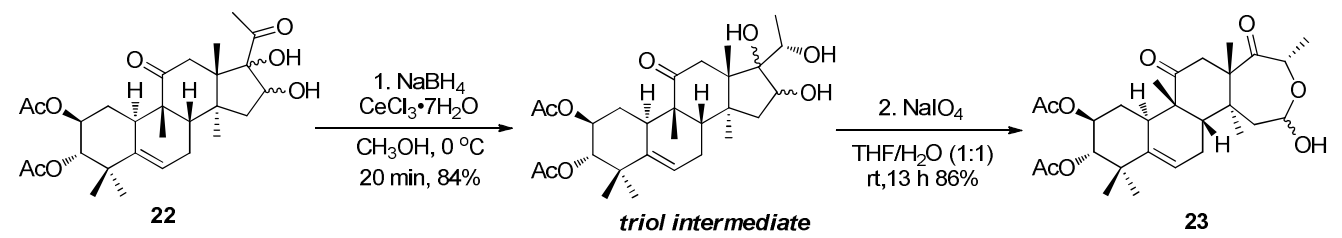

To the solution of $22(65 \mathrm{mg}, 0.13 \mathrm{mmol})$ in $\mathrm{CH}_{3} \mathrm{OH}(3 \mathrm{~mL})$ was added $\mathrm{CeCl}_{3} \cdot 7 \mathrm{H}_{2} \mathrm{O}$ (48 mg, $0.13 \mathrm{mmol})$ and $\mathrm{NaBH}_{4}(5 \mathrm{mg}, 0.13 \mathrm{mmol})$ at $0{ }^{\circ} \mathrm{C}$ for $20 \mathrm{~min}$. The reaction mixture was quenched with saturated aqueous $\mathrm{NH}_{4} \mathrm{Cl}(5 \mathrm{~mL})$ and EtOAc $(5 \mathrm{~mL})$, and evaporated to remove the organic layers. The combined aqueous was extracted with EtOAc $(10 \mathrm{~mL} \times 3)$. The combined organic layers were washed with brine, dried over anhydrous $\mathrm{Na}_{2} \mathrm{SO}_{4}$ and evaporated. The crude product was purified by column chromatography on silica gel (petroleum ether/EtOAc $=1: 1$ ) to give triol intermediate as a white foam (55 mg, 84\% yield). To a solution of triol intermediate (55 mg, $0.1 \mathrm{mmol})$ in $\mathrm{THF} / \mathrm{H}_{2} \mathrm{O}(3 \mathrm{ml}, 1: 1)$ was added $\mathrm{NaIO}_{4}(107 \mathrm{mg}, 0.5 \mathrm{mmol})$ at $\mathrm{rt}$ for $13 \mathrm{~h}$. The reaction mixture was then diluted with water and extracted with EtOAc $(3 \times 10 \mathrm{ml})$. The combined organic extract was washed with brine, dried over anhydrous $\mathrm{Na}_{2} \mathrm{SO}_{4}$ and evaporated. The crude product was purified by column chromatography on silica gel (petroleum ether/EtOAc $=2: 1$ ) to give 23 as a white foam (47 mg, 86\% yield). HRMS (ESI) calcd. 


\section{Supporting Information}

for $\mathrm{C}_{28} \mathrm{H}_{40} \mathrm{O}_{8} \mathrm{Na}(\mathrm{M}+\mathrm{Na})^{+}$527.2615, found 527.2615.

\subsection{Lactone Q8}

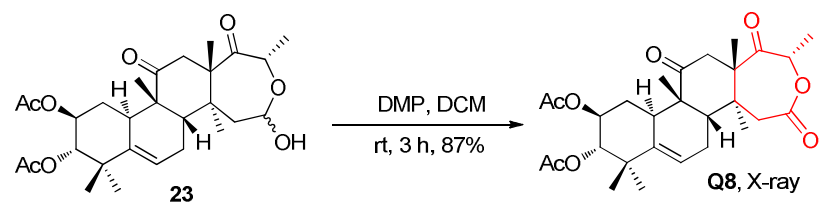

To solution of 23 (47 mg, $0.11 \mathrm{mmol})$ in DCM (2 mL) at was added DMP (68 $\mathrm{mg}, 0.16$ $\mathrm{mmol}$ ) at $\mathrm{rt}$. The resulting mixture was stirred at $\mathrm{rt}$ for $3 \mathrm{~h}$, and then the reaction mixture was quenched with $10 \%$ aqueous solution of $\mathrm{Na}_{2} \mathrm{~S}_{2} \mathrm{O}_{3}(5 \mathrm{~mL})$, and extracted with DCM $(10 \mathrm{~mL} \times 3)$. The combined organic layers were sequentially washed with saturated aqueous $\mathrm{NaHCO}_{3}$, and brine, dried over $\mathrm{Na}_{2} \mathrm{SO}_{4}$ and evaporated to afford the crude product. The crude product was purified by column chromatography on silica gel (petroleum ether/EtOAc $=2: 1$ ) to give $\mathbf{Q 8}$ as a white foam ( $41 \mathrm{mg}, 87 \%$ yield). Colorless acicular crystal recrystallized from petroleum ether/EtOAc; mp 298-299.2 ${ }^{\circ} \mathrm{C} ;{ }^{1} \mathrm{H}$ NMR $\left(400 \mathrm{MHz}, \mathrm{CDCl}_{3}\right) \delta 5.72(\mathrm{~d}, J=4.0 \mathrm{~Hz}, 1 \mathrm{H}), 5.15$ (q, $\left.J=6.0 \mathrm{~Hz}, 1 \mathrm{H}\right), 5.00$ (td, $J=11.2$, $4.3 \mathrm{~Hz}, 1 \mathrm{H}), 4.67$ (d, $J=10.0 \mathrm{~Hz}, 1 \mathrm{H}), 3.39$ (d, $J=15.1 \mathrm{~Hz}, 1 \mathrm{H}), 3.09$ (d, $J=14.9 \mathrm{~Hz}$, 1H), $2.83(\mathrm{~d}, J=14.9 \mathrm{~Hz}, 1 \mathrm{H}), 2.51(\mathrm{~d}, J=12.5 \mathrm{~Hz}, 1 \mathrm{H}), 2.43(\mathrm{dd}, J=19.7,7.2 \mathrm{~Hz}, 1 \mathrm{H})$, 2.36-2.27 (m, 1H), 2.24 (d, $J=15.1 \mathrm{~Hz}, 1 \mathrm{H}), 2.05$ (s, 3H), 1.97 (s, 3H), 1.88 (d, $J=7.3$ $\mathrm{Hz}, 1 \mathrm{H}), 1.77$ (dd, $J=8.2,4.2 \mathrm{~Hz}, 1 \mathrm{H}), 1.41$ (d, $J=6.2 \mathrm{~Hz}, 3 \mathrm{H}), 1.28-1.23(\mathrm{~m}, 4 \mathrm{H}$, overlap), 1.13 (s, 3H), 1.03 (s, 6H), 1.00 (s, 3H). $\left.{ }^{13} \mathrm{C} \mathrm{NMR} \mathrm{(100} \mathrm{MHz,} \mathrm{CDCl}_{3}\right) \delta 210.60$, $201.73,171.07,170.47,170.15,138.93,119.11,77.61,70.60,70.34,57.97,50.45,43.64$, $41.60,41.47,41.23,40.87,34.29,30.69,24.14,22.35,22.31,20.94,20.84,20.03,18.90$, 17.65, 14.98. HRMS (ESI) calcd. for $\mathrm{C}_{28} \mathrm{H}_{38} \mathrm{O}_{8} \mathrm{~K}(\mathrm{M}+\mathrm{K})^{+} 541.2198$, found 541.2201.

\subsection{Compound Q9}

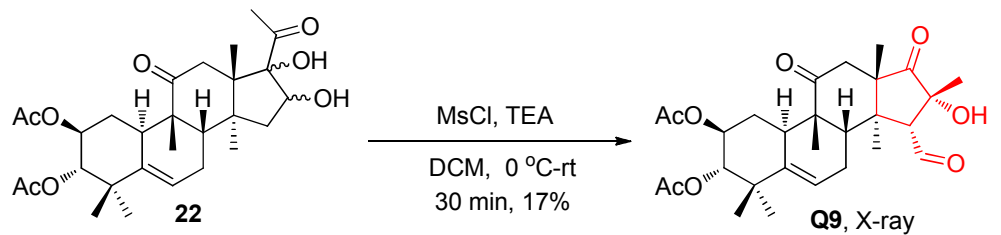

To the solution of $22(35 \mathrm{mg}, 0.07 \mathrm{mmol})$ in DCM $(3 \mathrm{~mL})$ was added TEA ( $48 \mu \mathrm{L}$, 


\section{Supporting Information}

$0.35 \mathrm{mmol})$ and $\mathrm{MsCl}(9 \mu \mathrm{L}, 0.11 \mathrm{mmol})$ at $0{ }^{\circ} \mathrm{C}$. The resulting mixture was stirred at $\mathrm{rt}$ for $30 \mathrm{~min}$, and then diluted with water and extracted with EtOAc. The extract was washed with brine, dried over anhydrous $\mathrm{Na}_{2} \mathrm{SO}_{4}$ and evaporated to afford the crude product. The crude product was purified by column chromatography on silica gel (petroleum ether/EtOAc $=2: 1$ ) to give $\mathbf{Q 9}$ as a white foam (6 $\mathrm{mg}, 17 \%$ yield). Colorless acicular crystal recrystallized from petroleum ether/EtOAc; mp 274.7-276 ${ }^{\circ} \mathrm{C} ;{ }^{1} \mathrm{H}$ NMR $\left(400 \mathrm{MHz}, \mathrm{CDCl}_{3}\right) \delta 9.99(\mathrm{~d}, J=3.8 \mathrm{~Hz}, 1 \mathrm{H}), 5.74(\mathrm{~d}, J=5.9 \mathrm{~Hz}, 1 \mathrm{H}), 5.06-4.92(\mathrm{~m}, 1 \mathrm{H})$, $4.66(\mathrm{~d}, J=10.0 \mathrm{~Hz}, 1 \mathrm{H}), 3.09$ (d, $J=15.6 \mathrm{~Hz}, 1 \mathrm{H}), 2.75-2.63(\mathrm{~m}, 2 \mathrm{H}), 2.42(\mathrm{~m}, 3 \mathrm{H}$, overlap), 2.12 (d, $J=7.6 \mathrm{~Hz}, 1 \mathrm{H}), 2.05$ (s, 3H), 2.01 (d, $J=6.2 \mathrm{~Hz}, 1 \mathrm{H}), 1.98(\mathrm{~s}, 3 \mathrm{H})$, 1.95 (s, 1H), 1.52 (s, 3H), 1.48 (s, 3H), 1.25 (s, 1H), 1.14 (s, 3H), 1.05 (s, 6H), 1.02 (s, $3 \mathrm{H}) .{ }^{13} \mathrm{C}$ NMR $\left(100 \mathrm{MHz}, \mathrm{CDCl}_{3}\right) \delta 215.98,209.08,203.81,170.48,170.27,139.15$, $119.23,79.02,77.83,70.83,62.23,55.81,49.75,46.45,43.02,41.78,41.12,33.93,30.65$, $27.99,24.38,23.31,22.12,21.00,20.85,20.58,20.01,15.68$. HRMS (ESI) calcd. for $\mathrm{C}_{28} \mathrm{H}_{38} \mathrm{O}_{8} \mathrm{Na}(\mathrm{M}+\mathrm{Na})^{+} 525.2459$, found 525.2457. 


\section{Supporting Information}

\section{Copies of ${ }^{1} \mathrm{H}$ and ${ }^{13} \mathrm{C}$ NMR Spectra of Compounds}
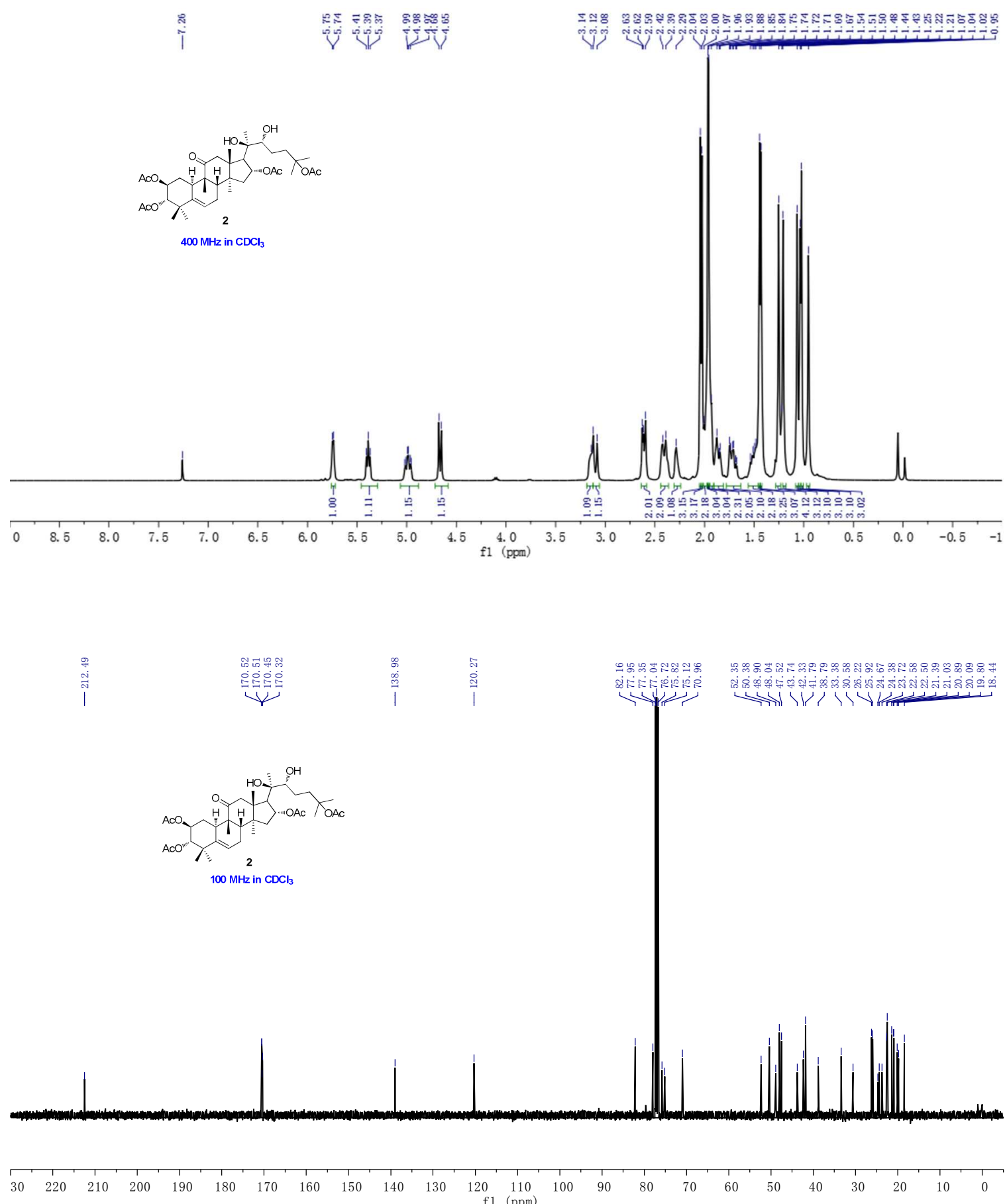


\section{Supporting Information}
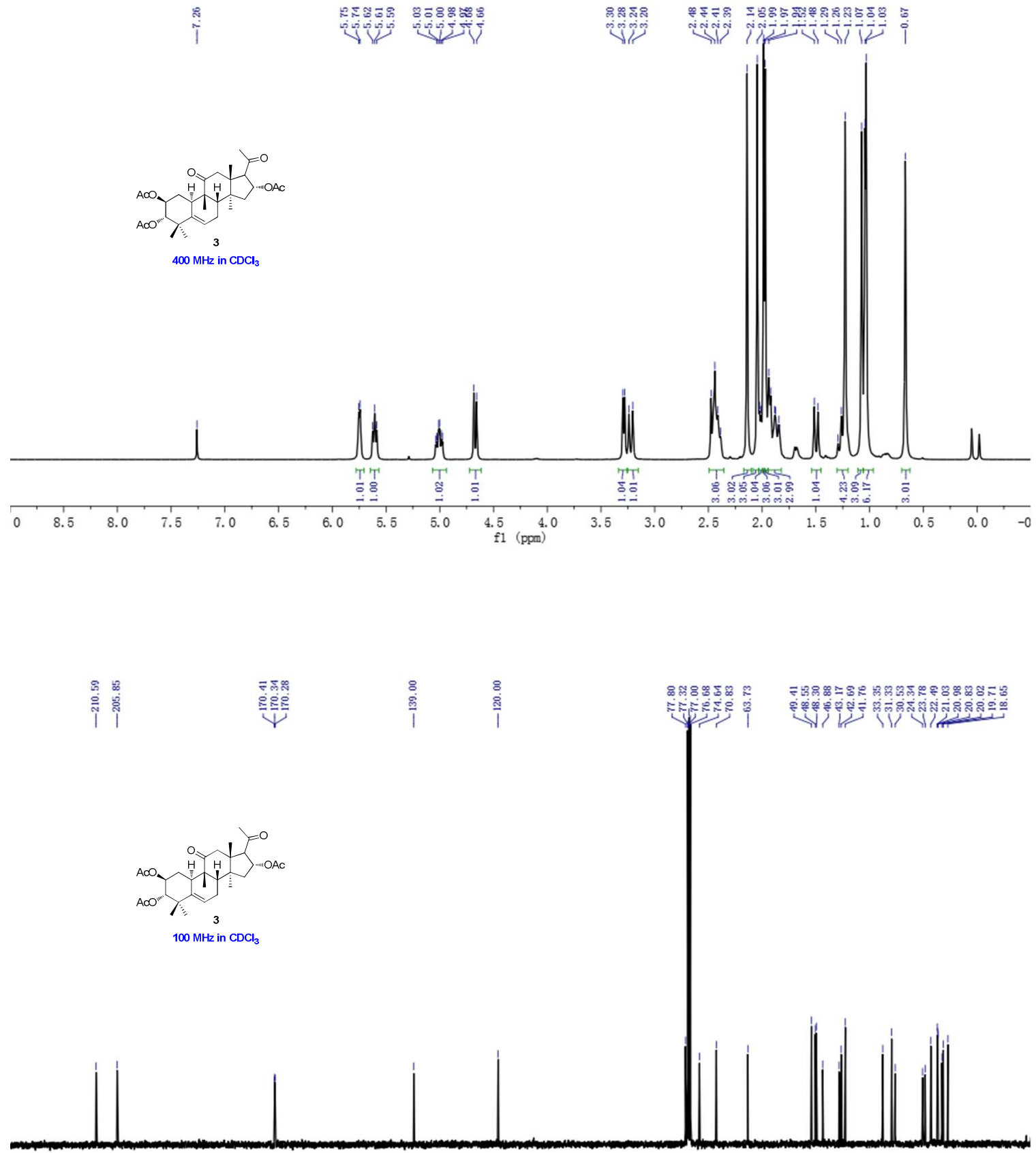

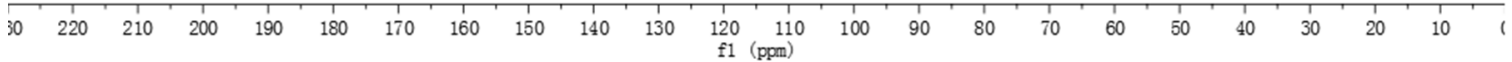




\section{Supporting Information}

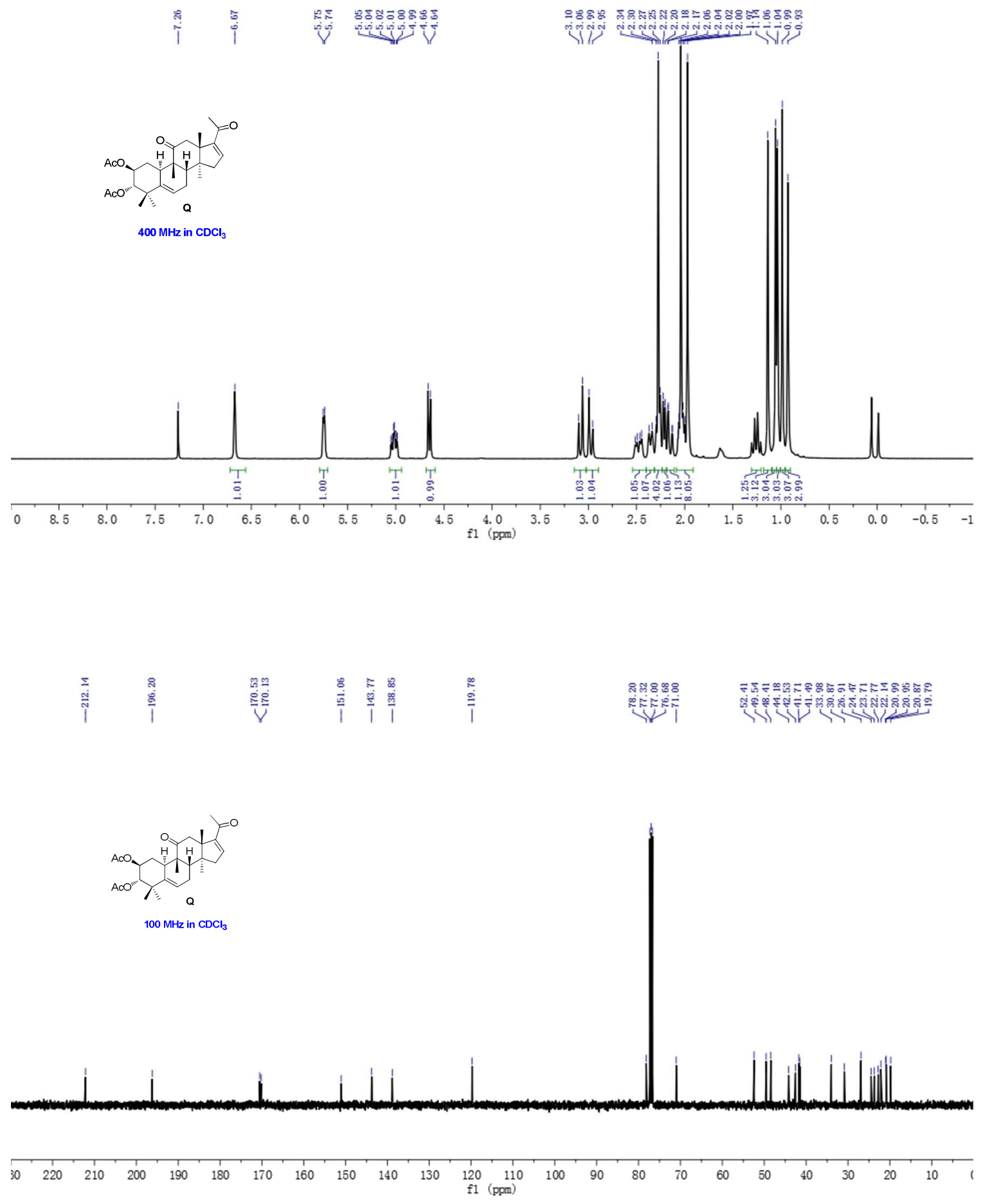




\section{Supporting Information}

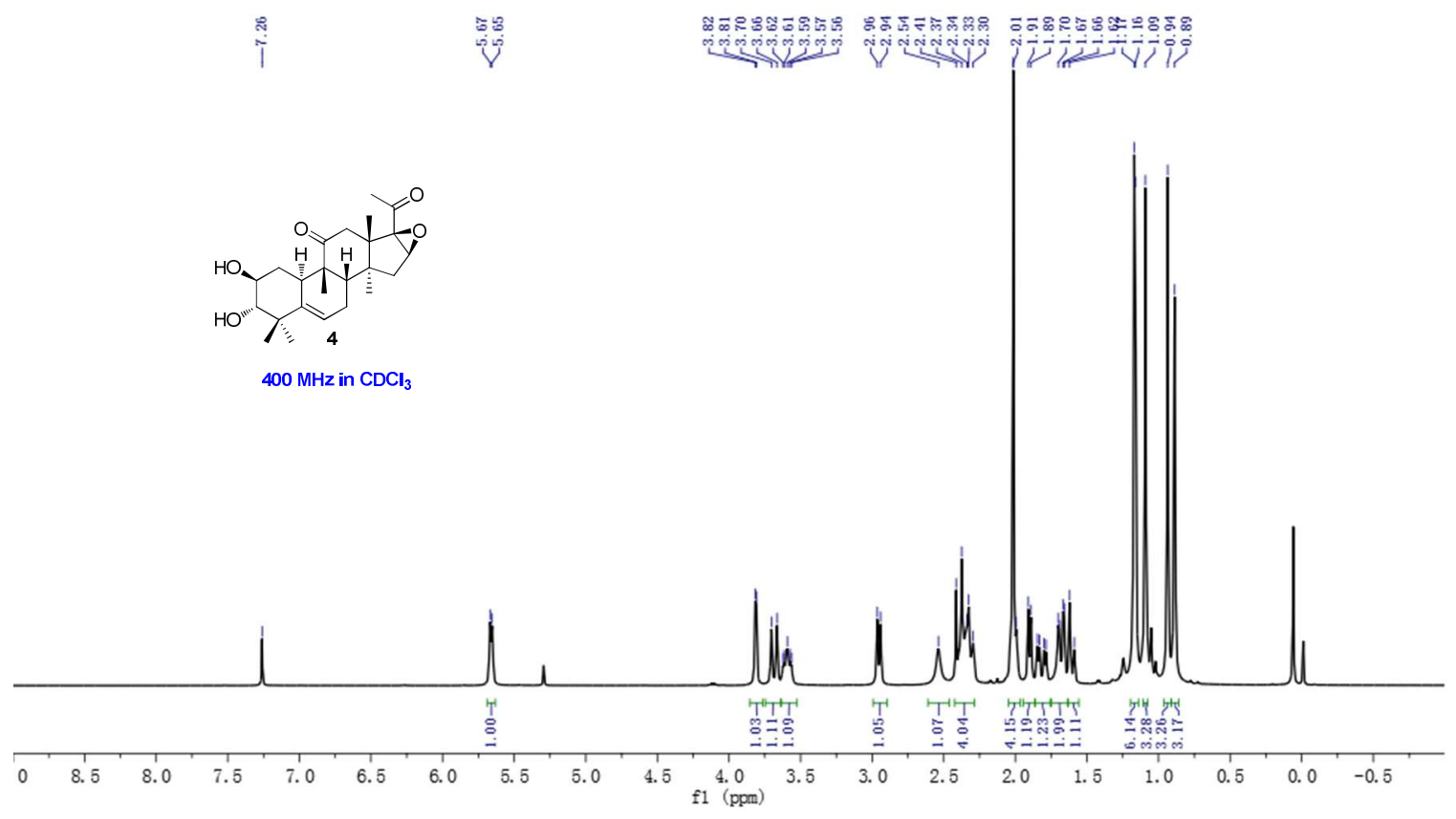

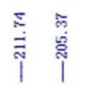

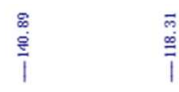

$\stackrel{\overrightarrow{0}}{\stackrel{\infty}{1}}$
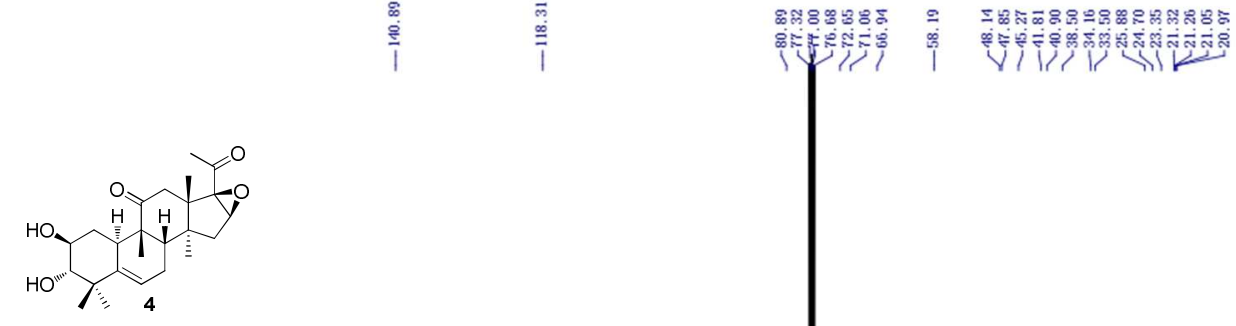

$100 \mathrm{MHz}$ in $\mathrm{CDCl}_{3}$

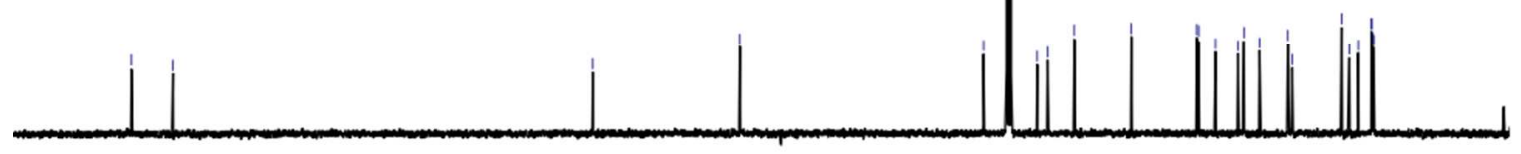

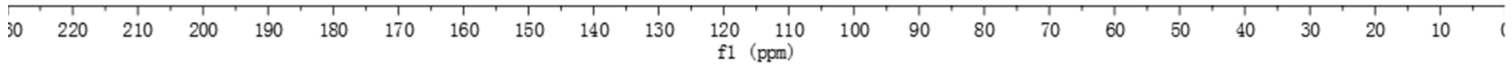




\section{Supporting Information}

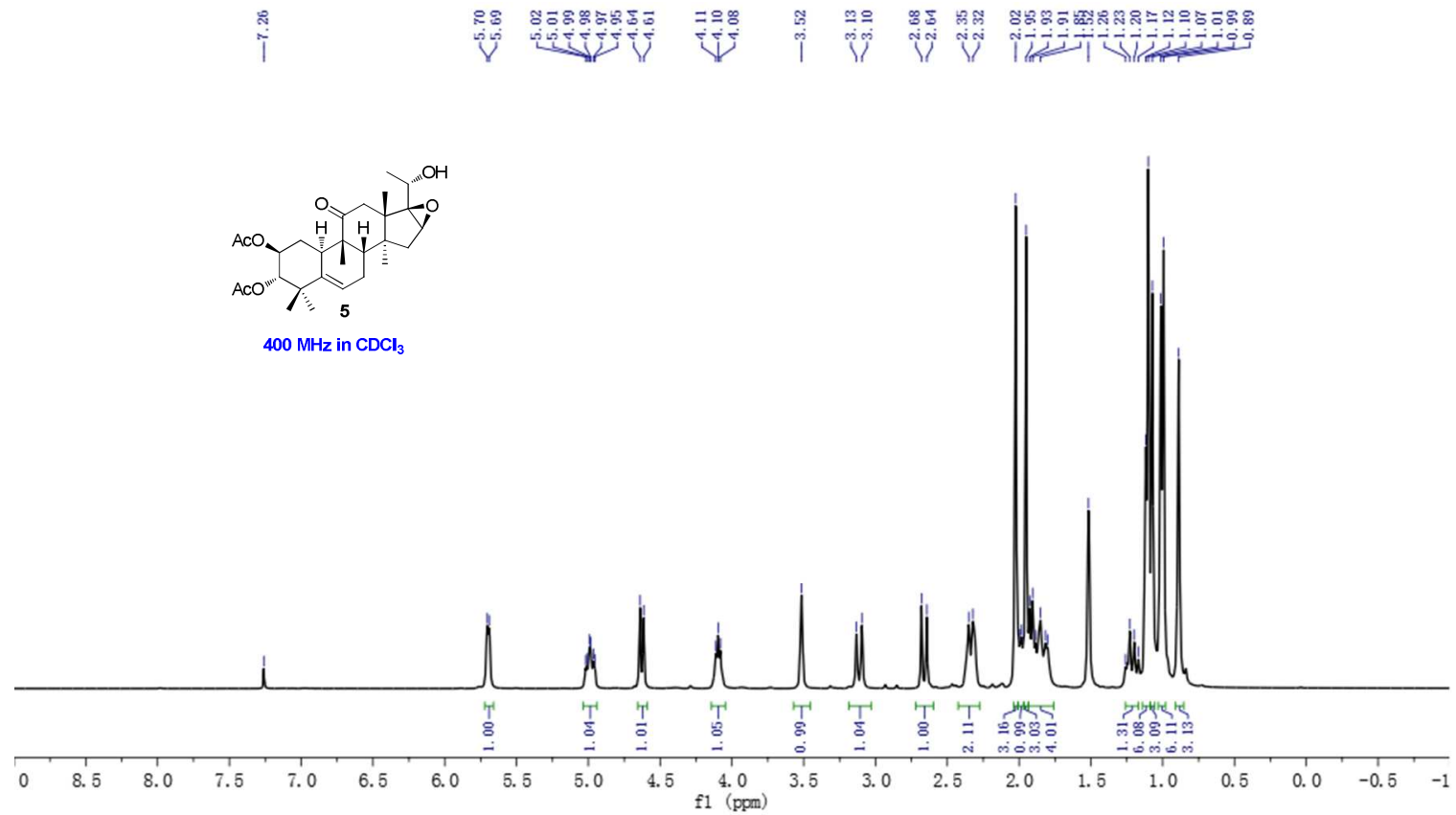

$\stackrel{\text { స్ }}{\stackrel{\text { I }}{1}}$
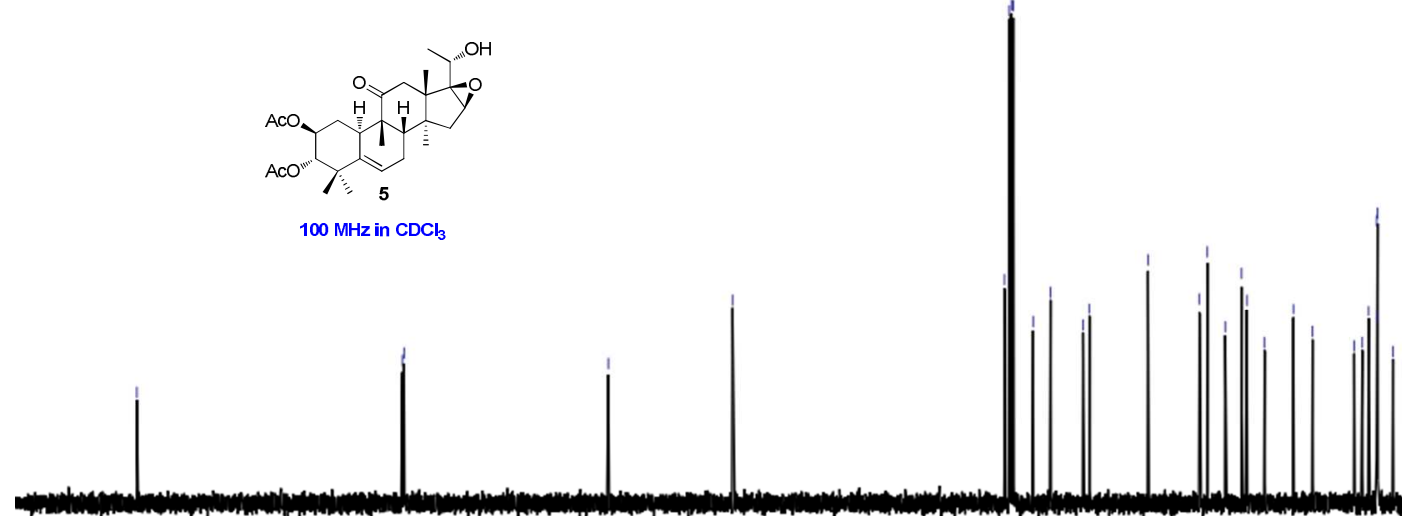

30
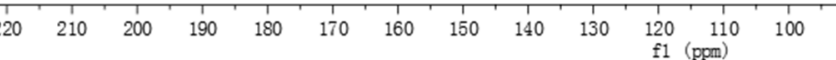

80

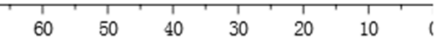




\section{Supporting Information}
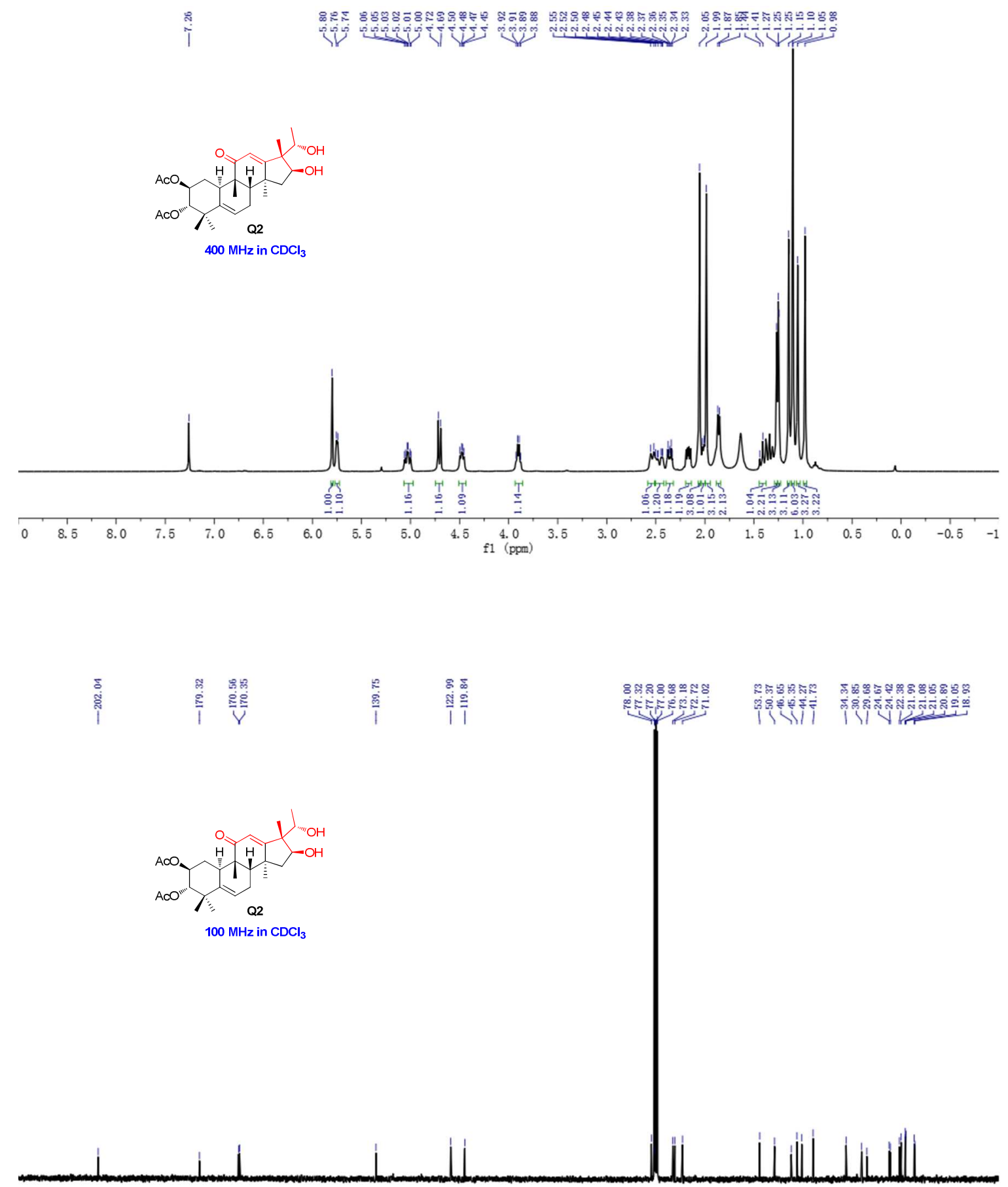

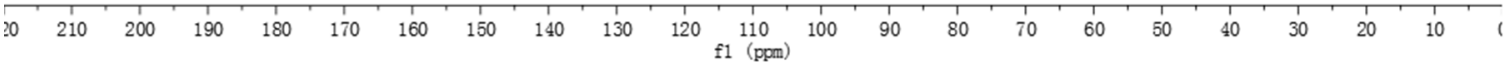




\section{Supporting Information}
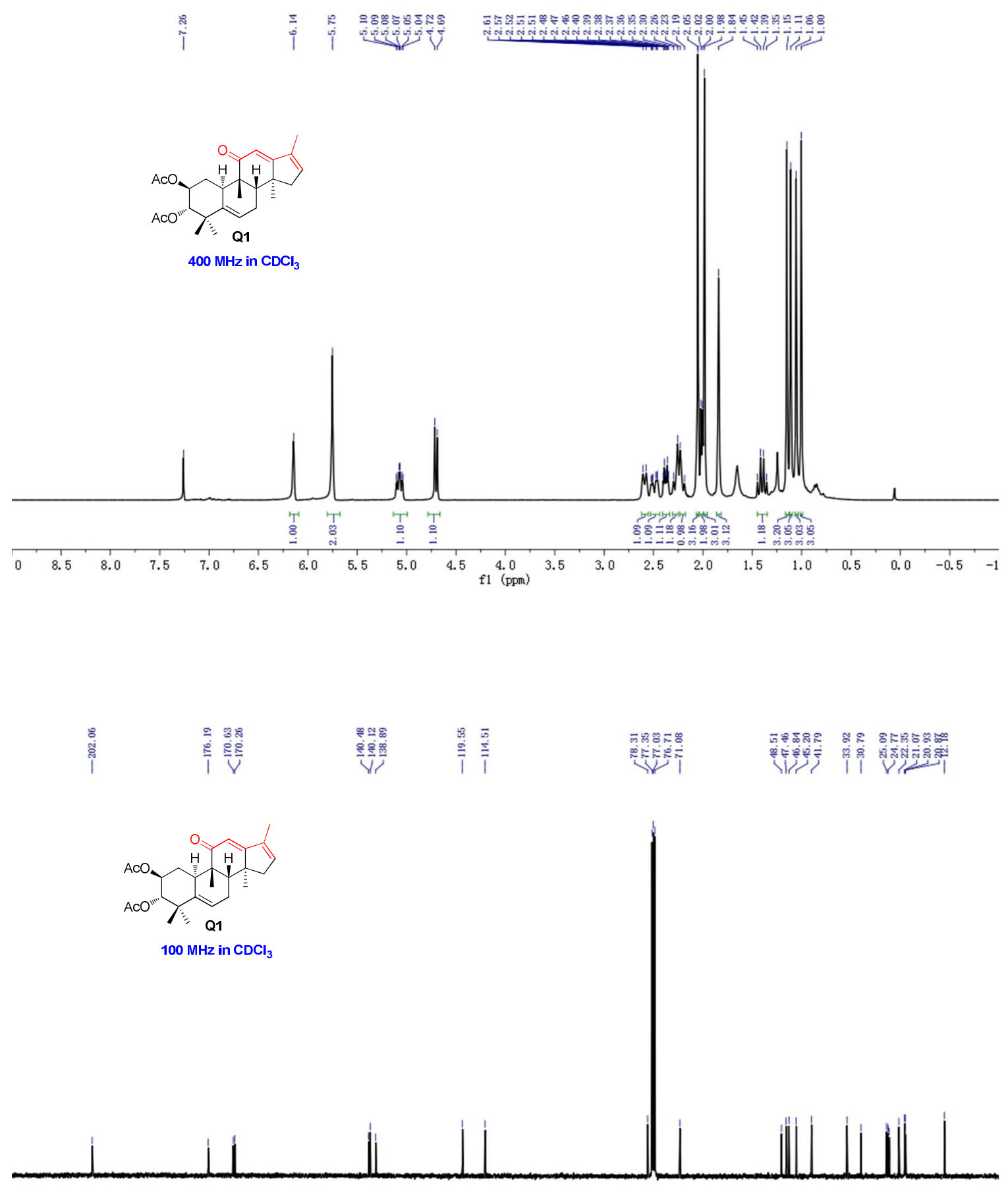

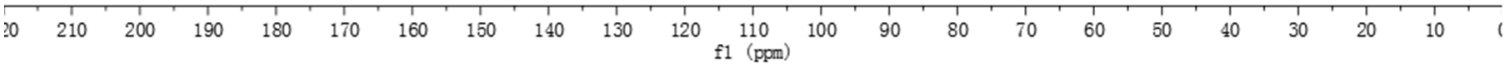




\section{Supporting Information}

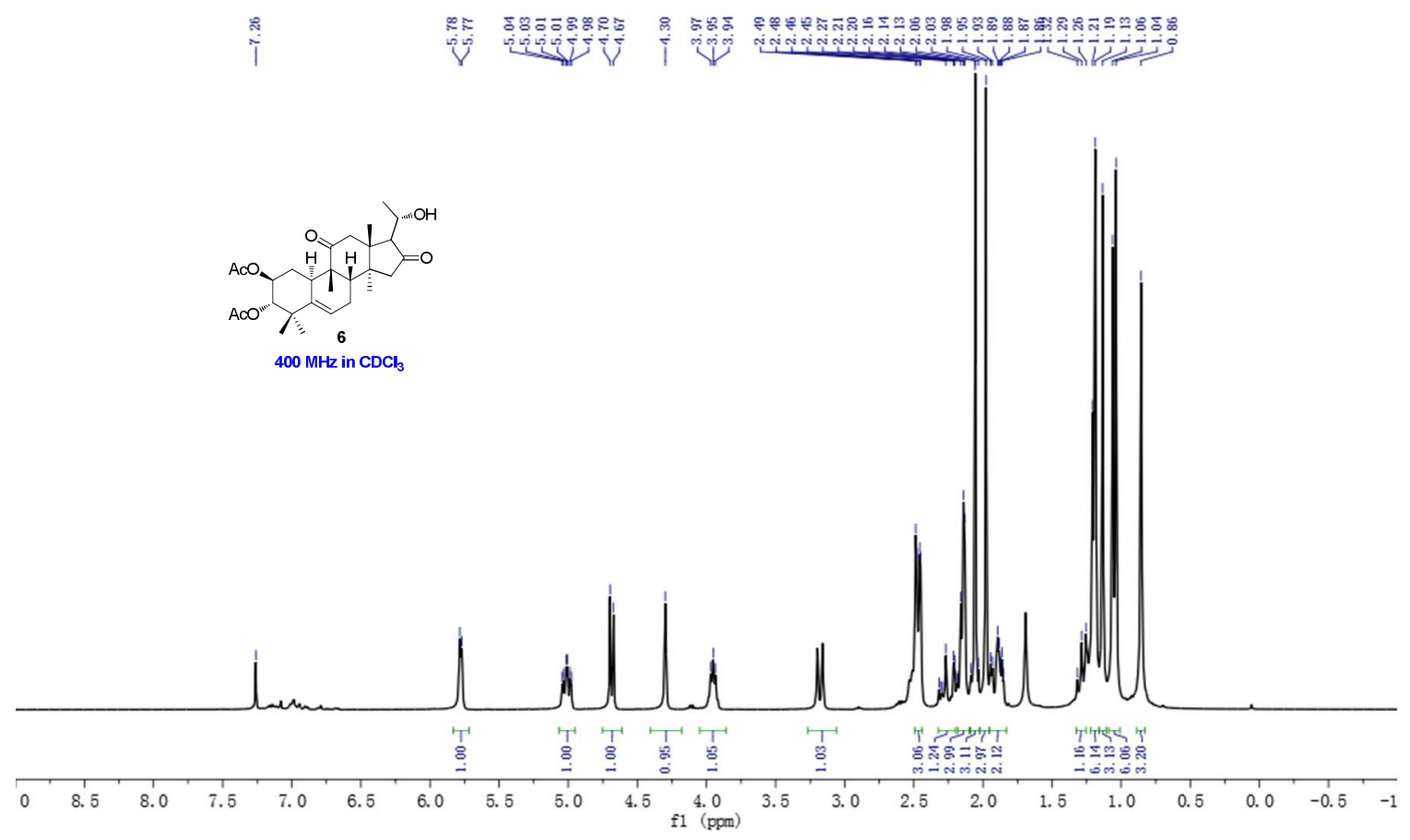

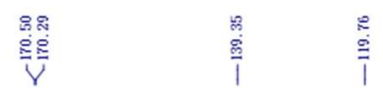
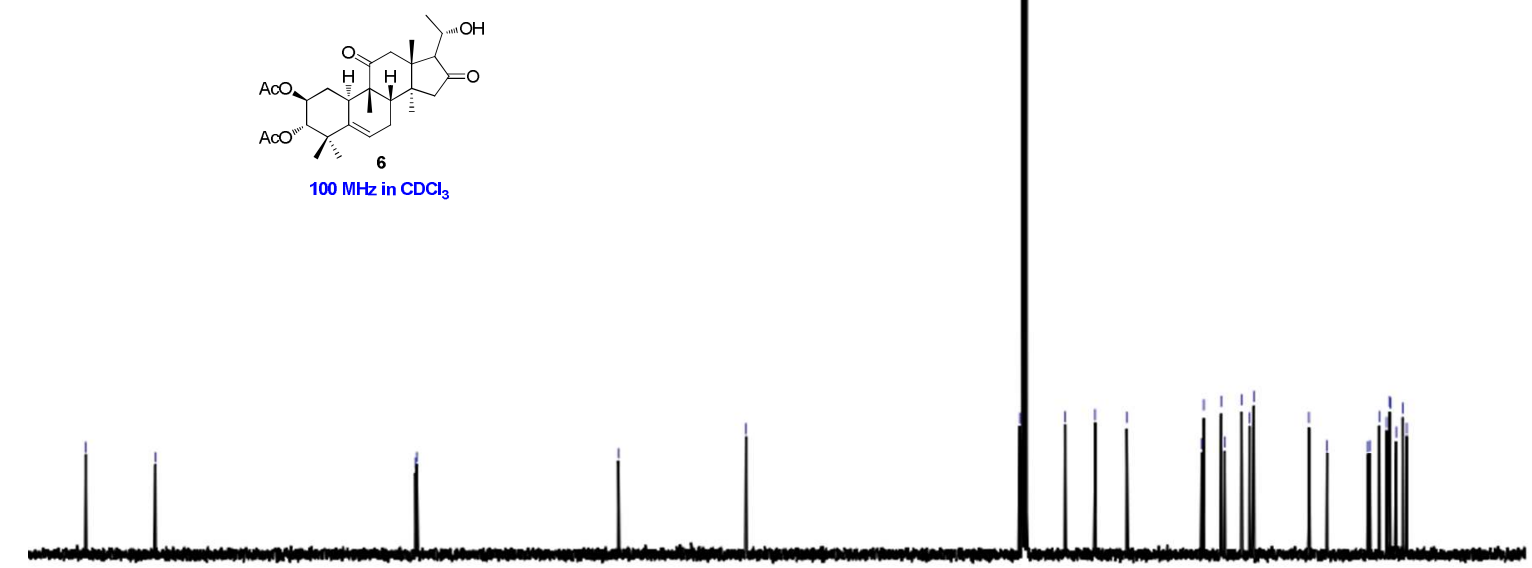

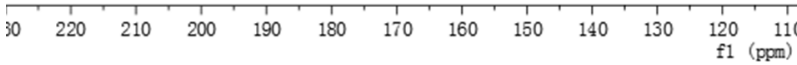

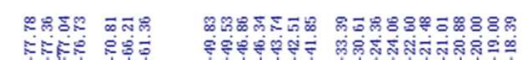

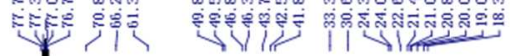




\section{Supporting Information}
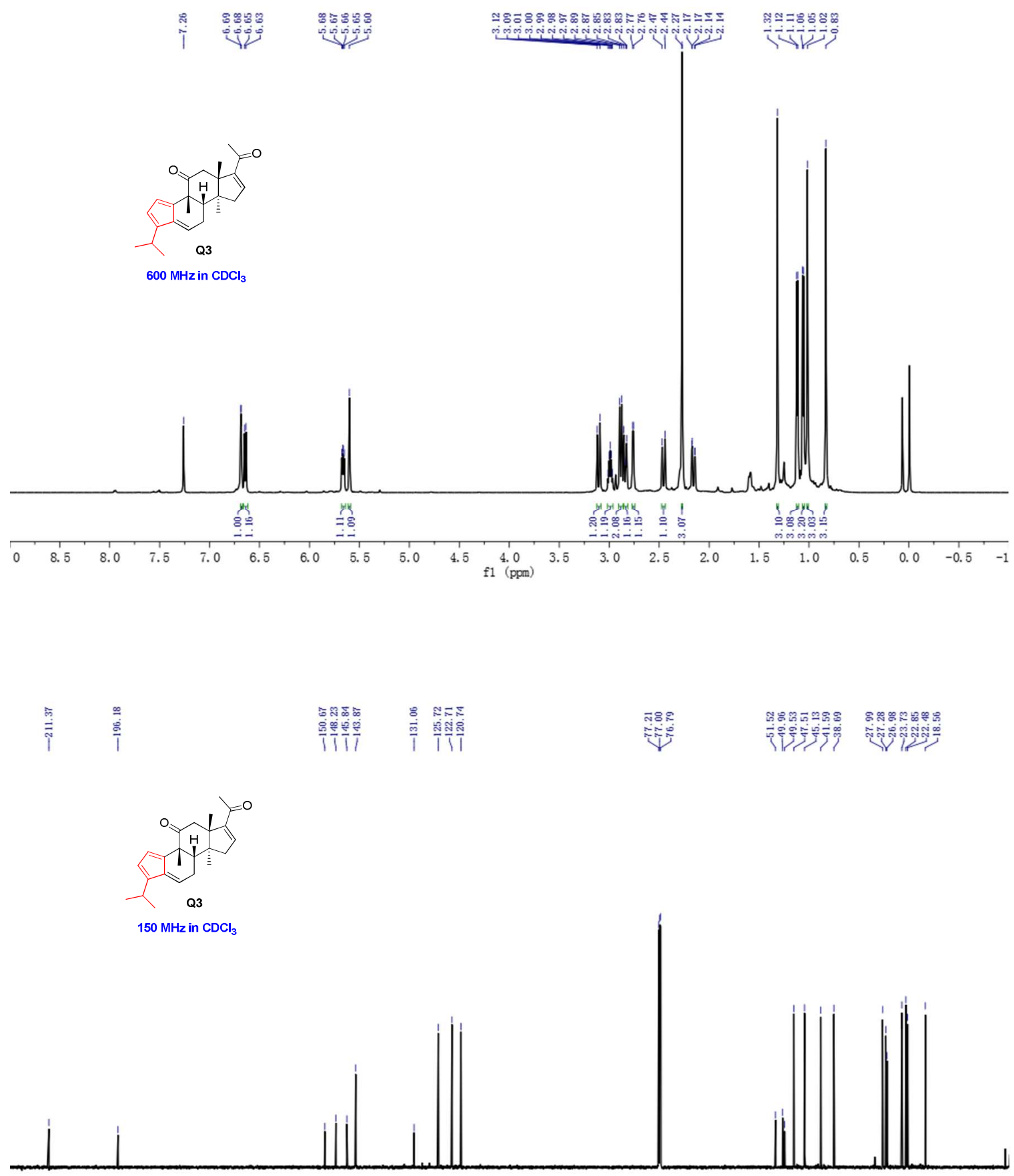

\begin{tabular}{|l|lllllllllllllllllllllll}
\hline 20 & 210 & 200 & 190 & 180 & 170 & 160 & 150 & 140 & 130 & 120 & 110 & 100 & 90 & 80 & 70 & 60 & 50 & 40 & 30 & 20 & 10 & 1
\end{tabular} 


\section{Supporting Information}

${ }^{1} \mathrm{H}-{ }^{-1} \mathrm{H}$ COSY spectrum of Compund $\mathbf{Q 3}$

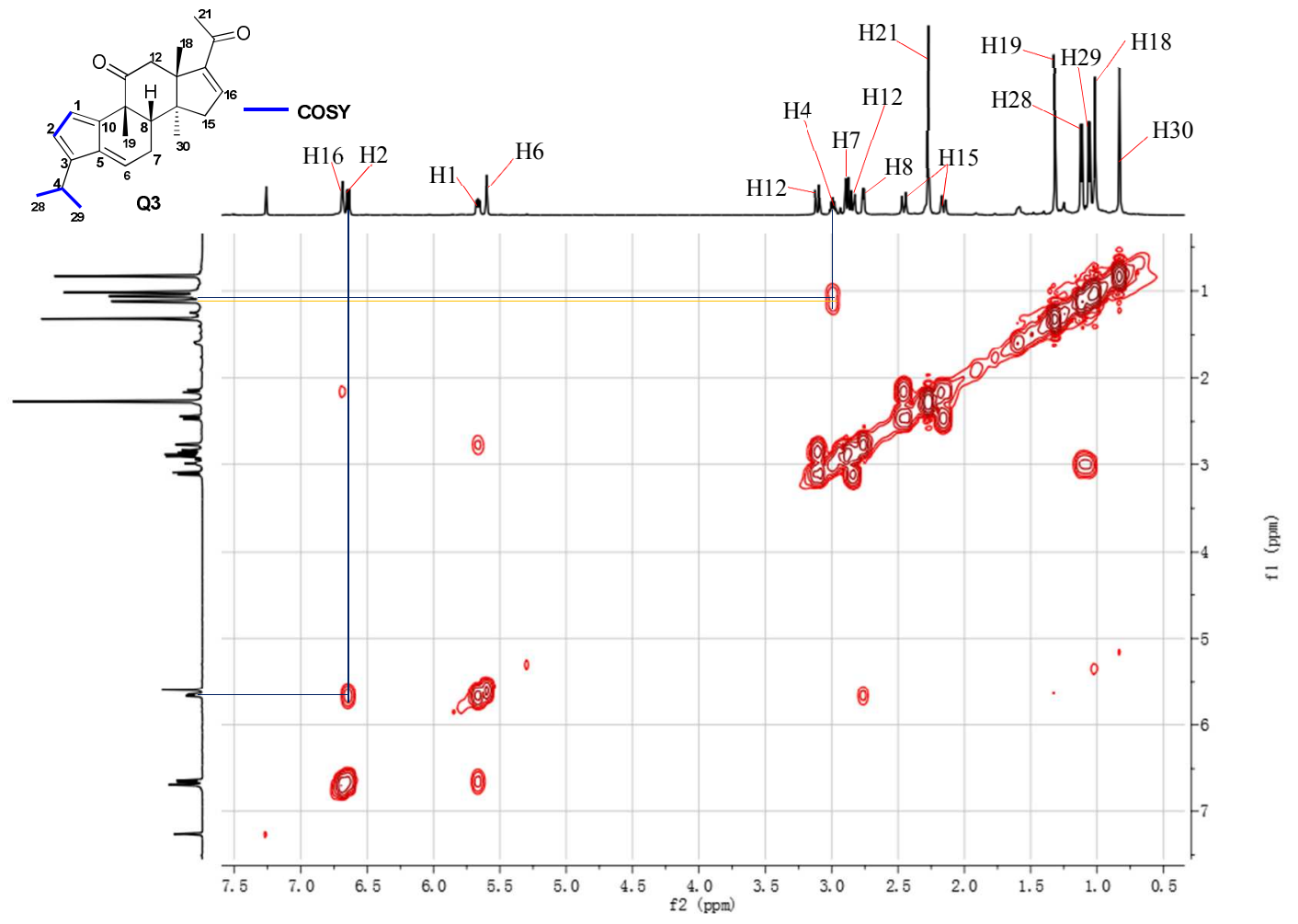

HSQC spectrum of Compund Q3

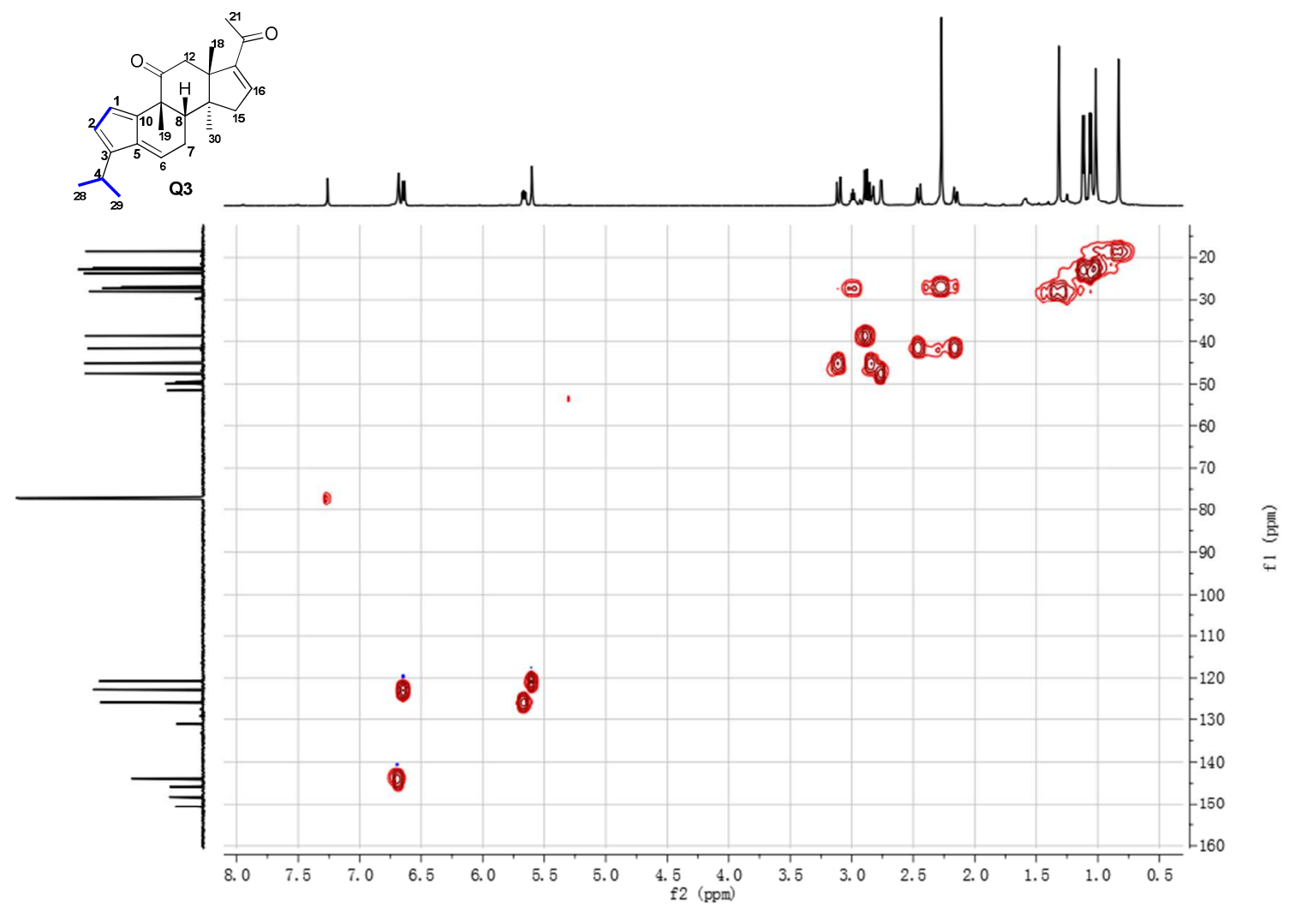




\section{Supporting Information}

HMBC spectrum of Compund Q3

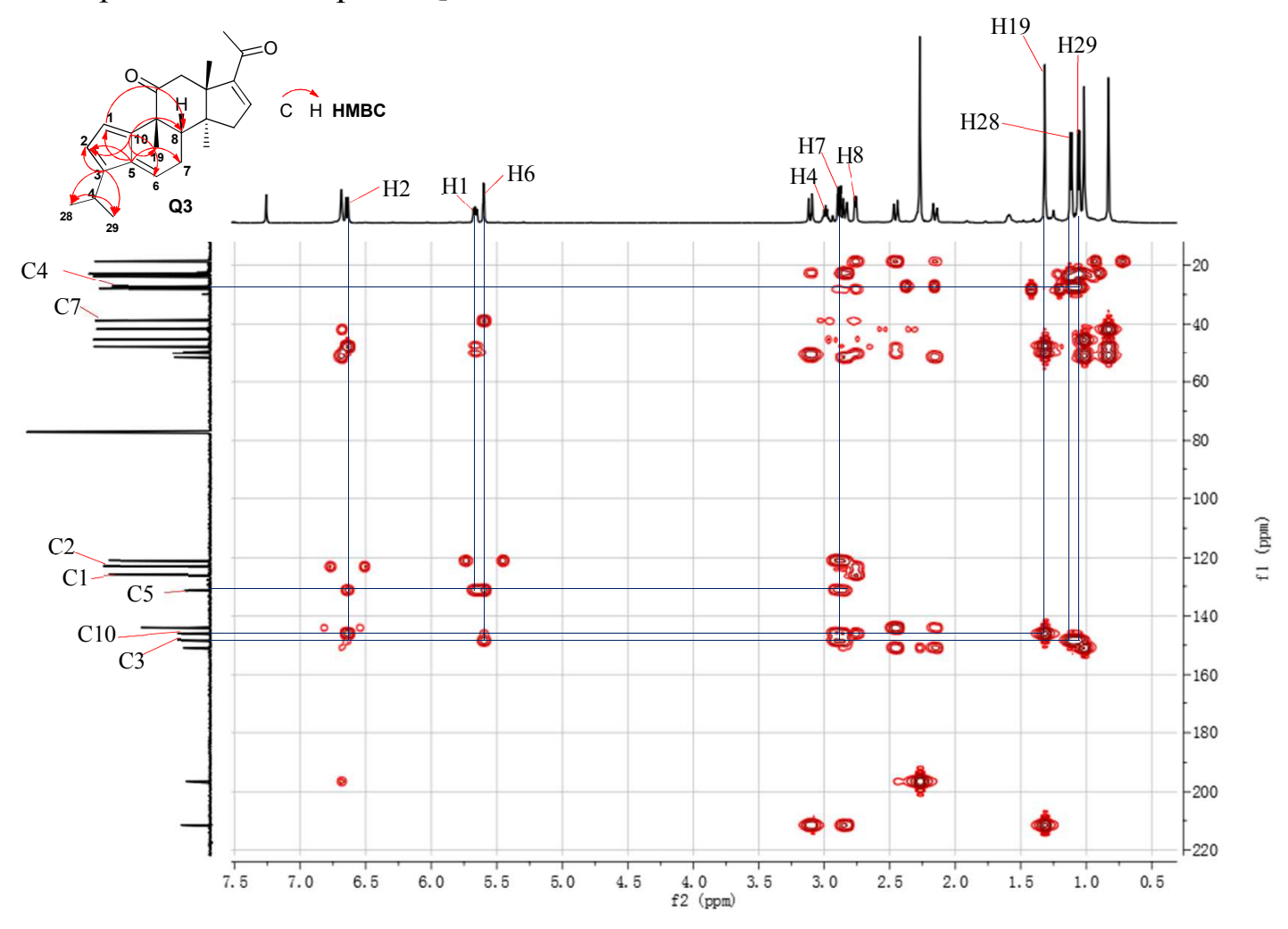

ROESY spectrum of Compund Q3

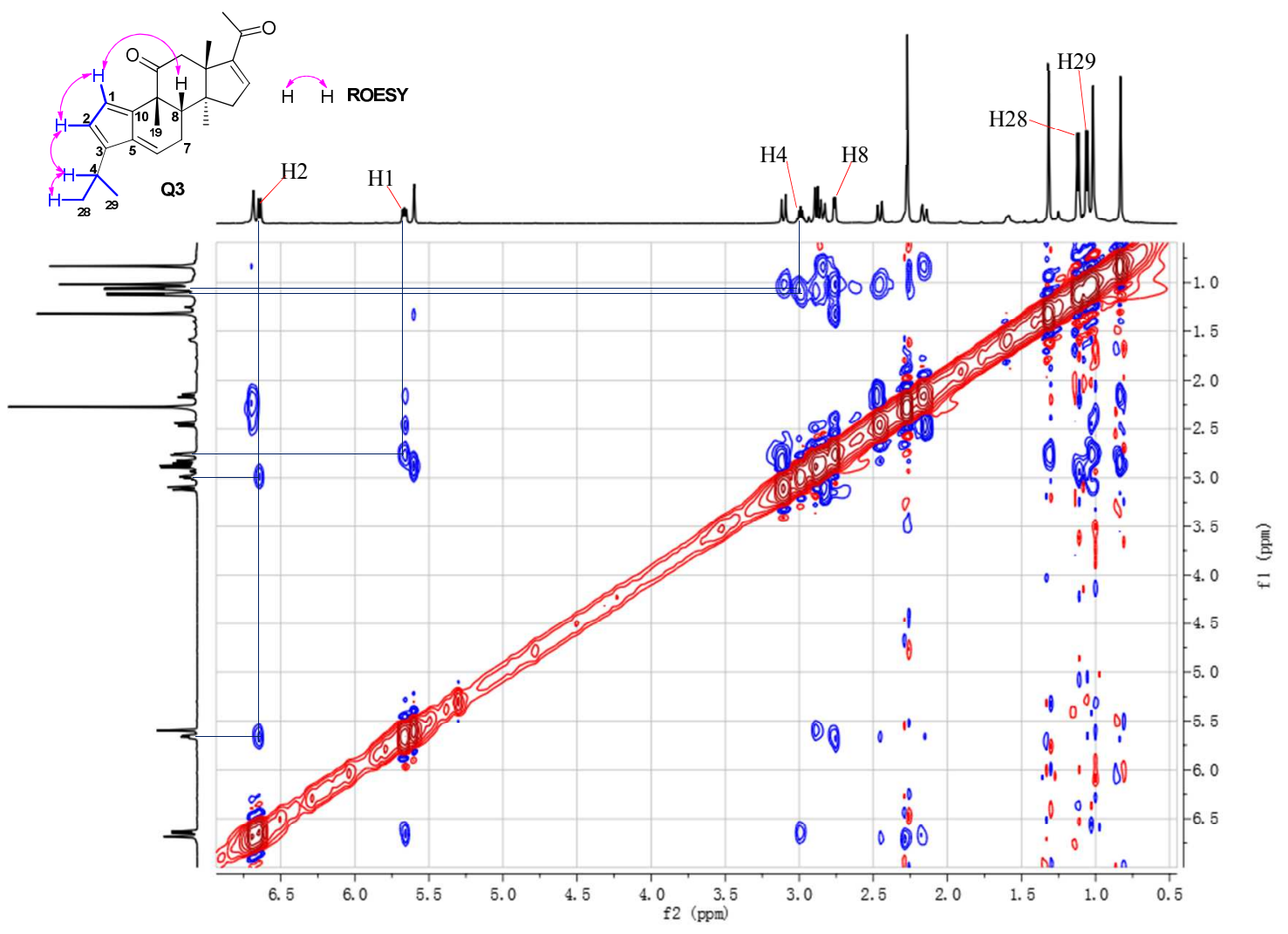




\section{Supporting Information}
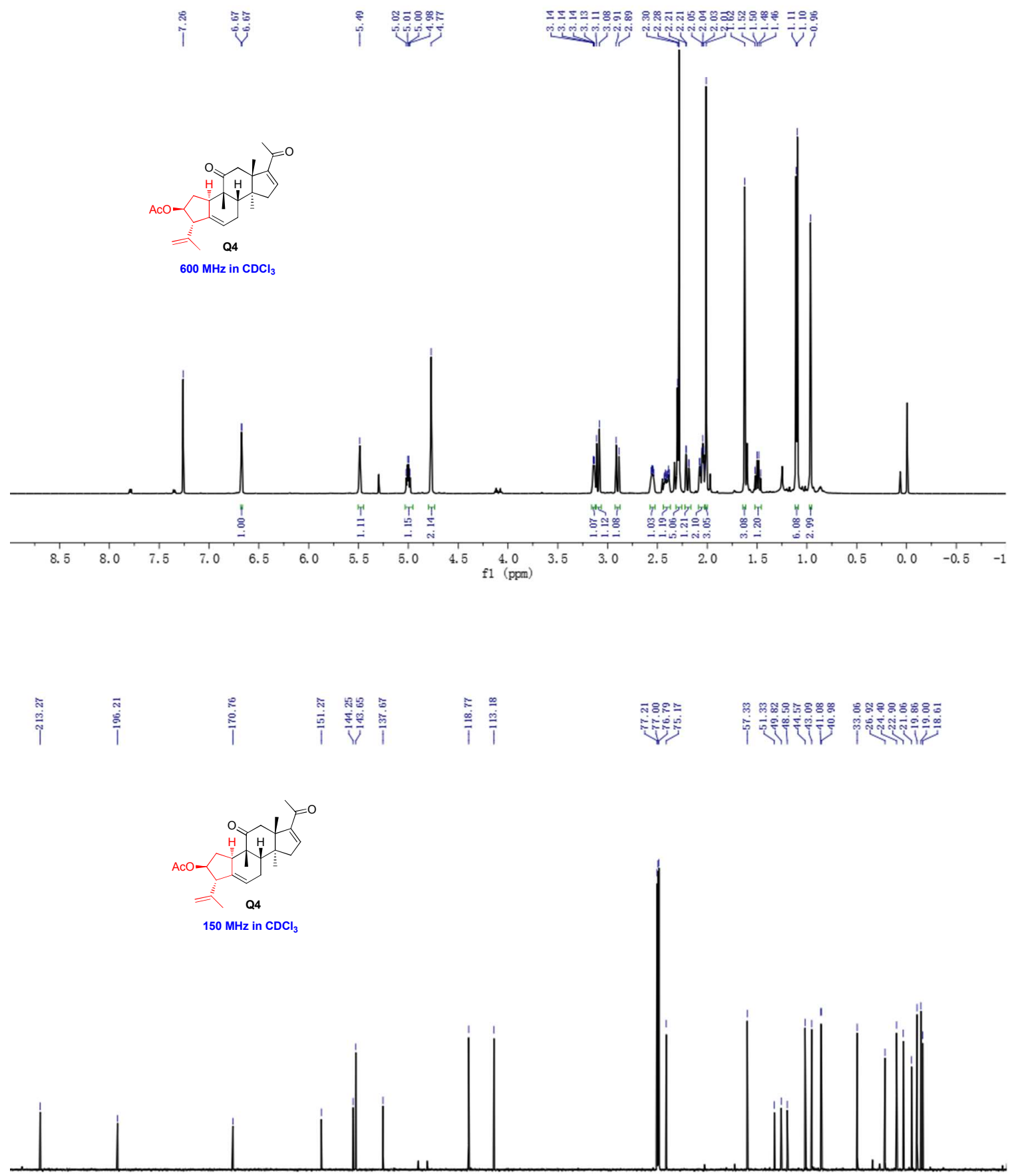

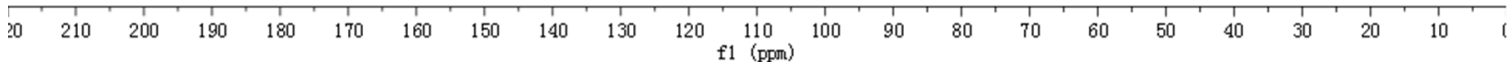




\section{Supporting Information}
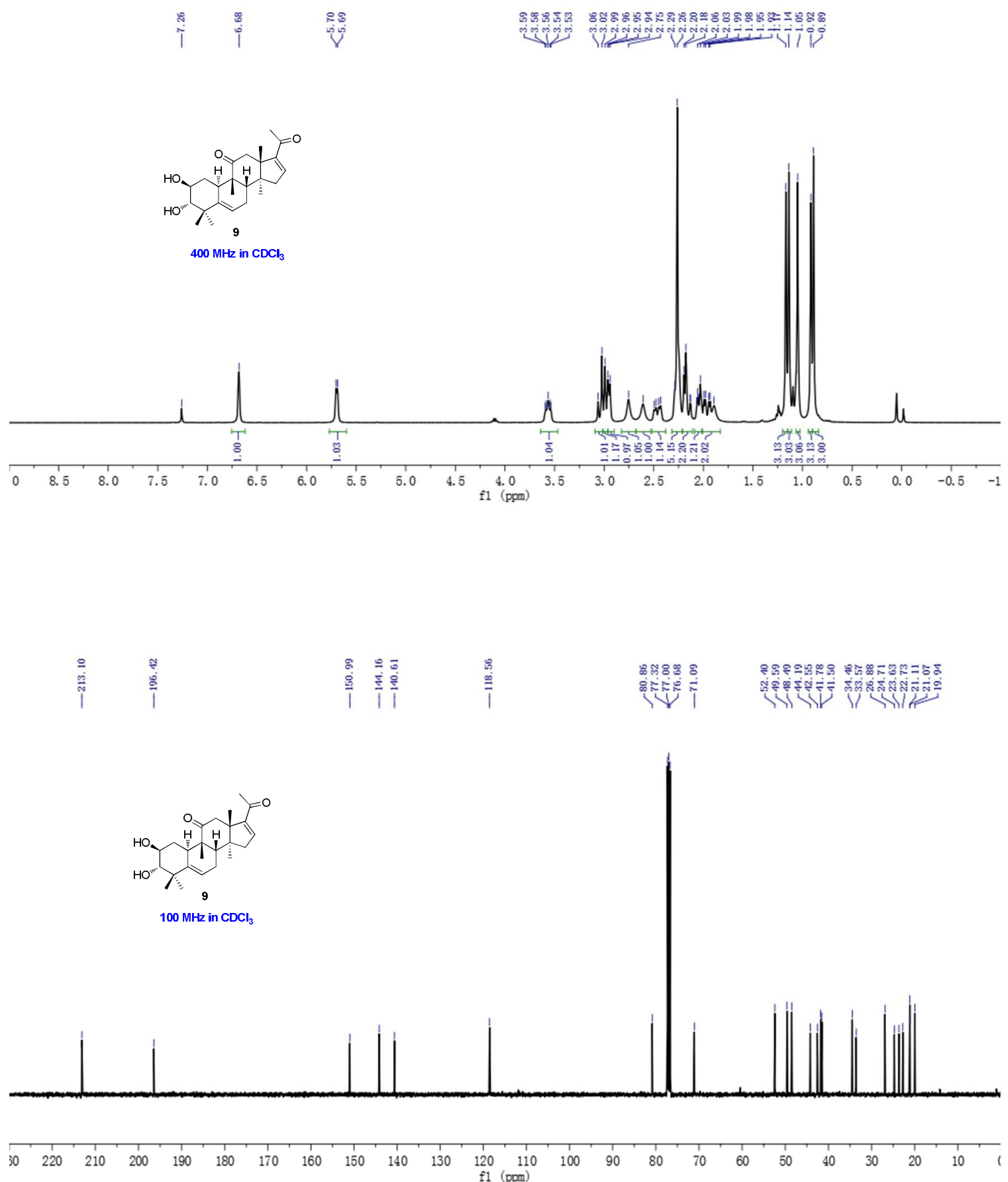


\section{Supporting Information}
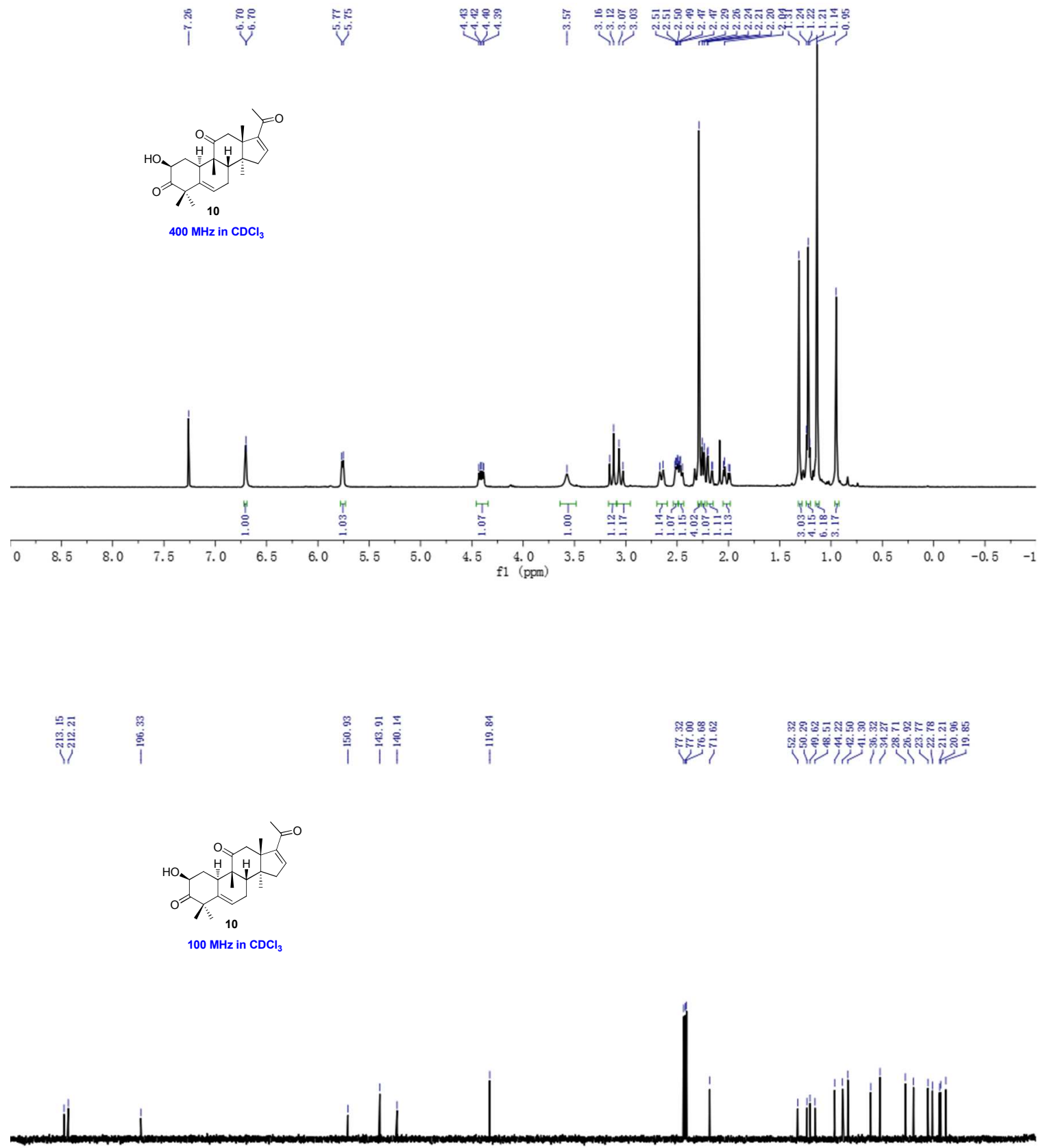

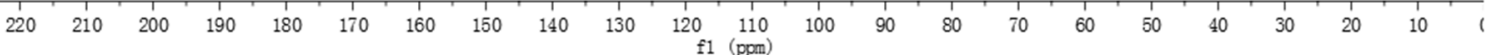




\section{Supporting Information}

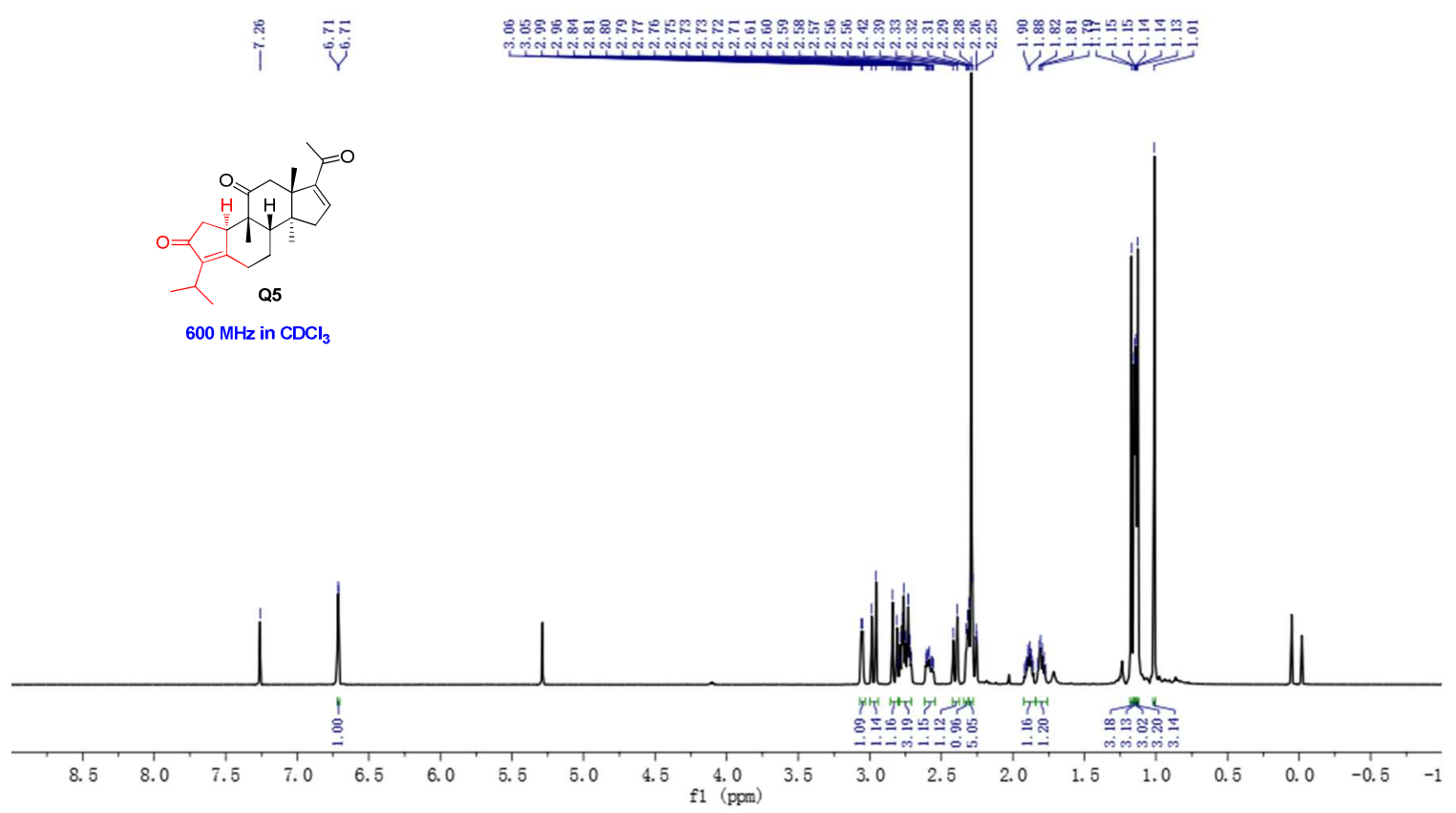

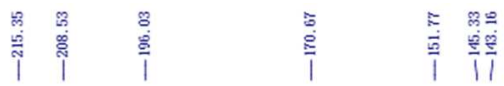

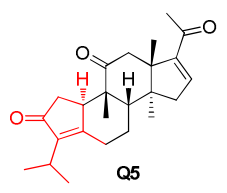

$150 \mathrm{MHz}$ in $\mathrm{CDCl}_{3}$
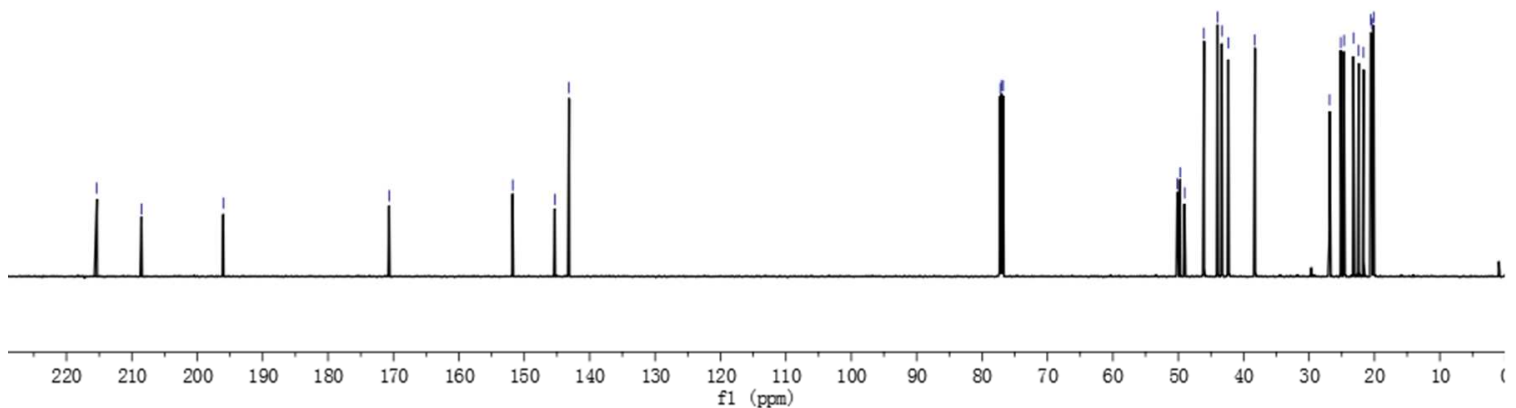


\section{Supporting Information}
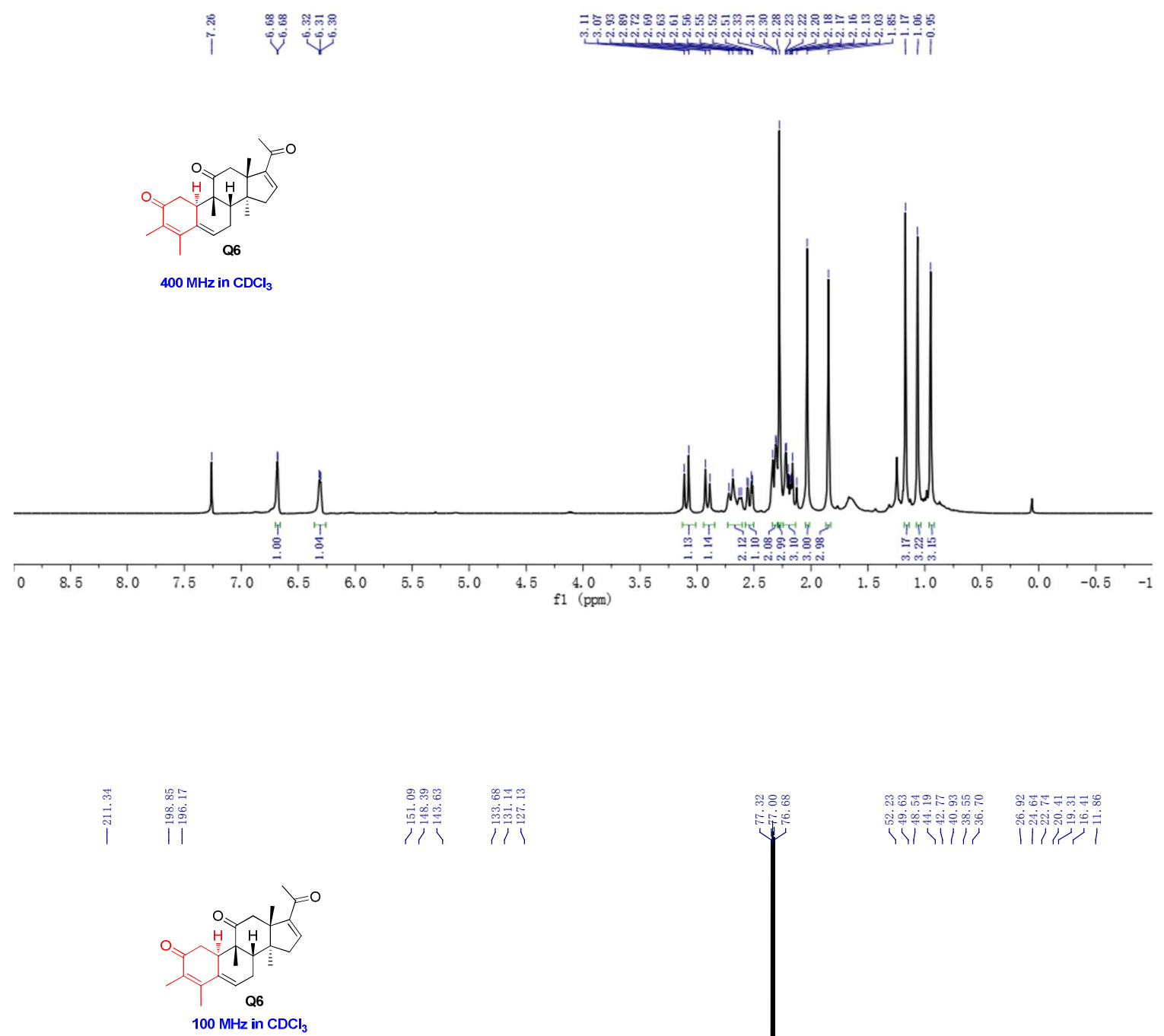

f1 (ppm)
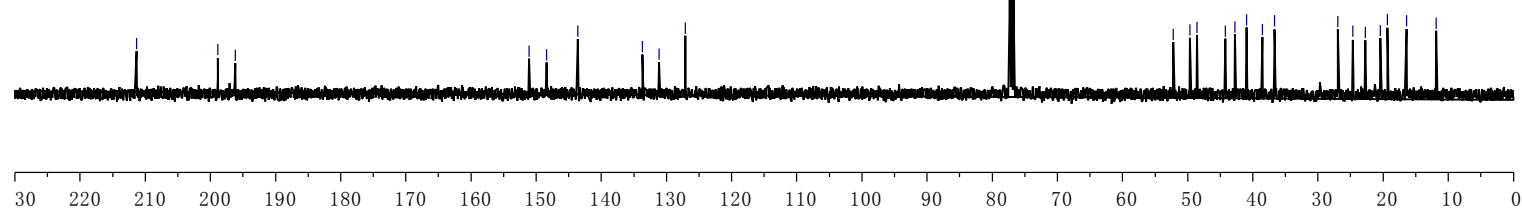

f1 (ppm) 


\section{Supporting Information}
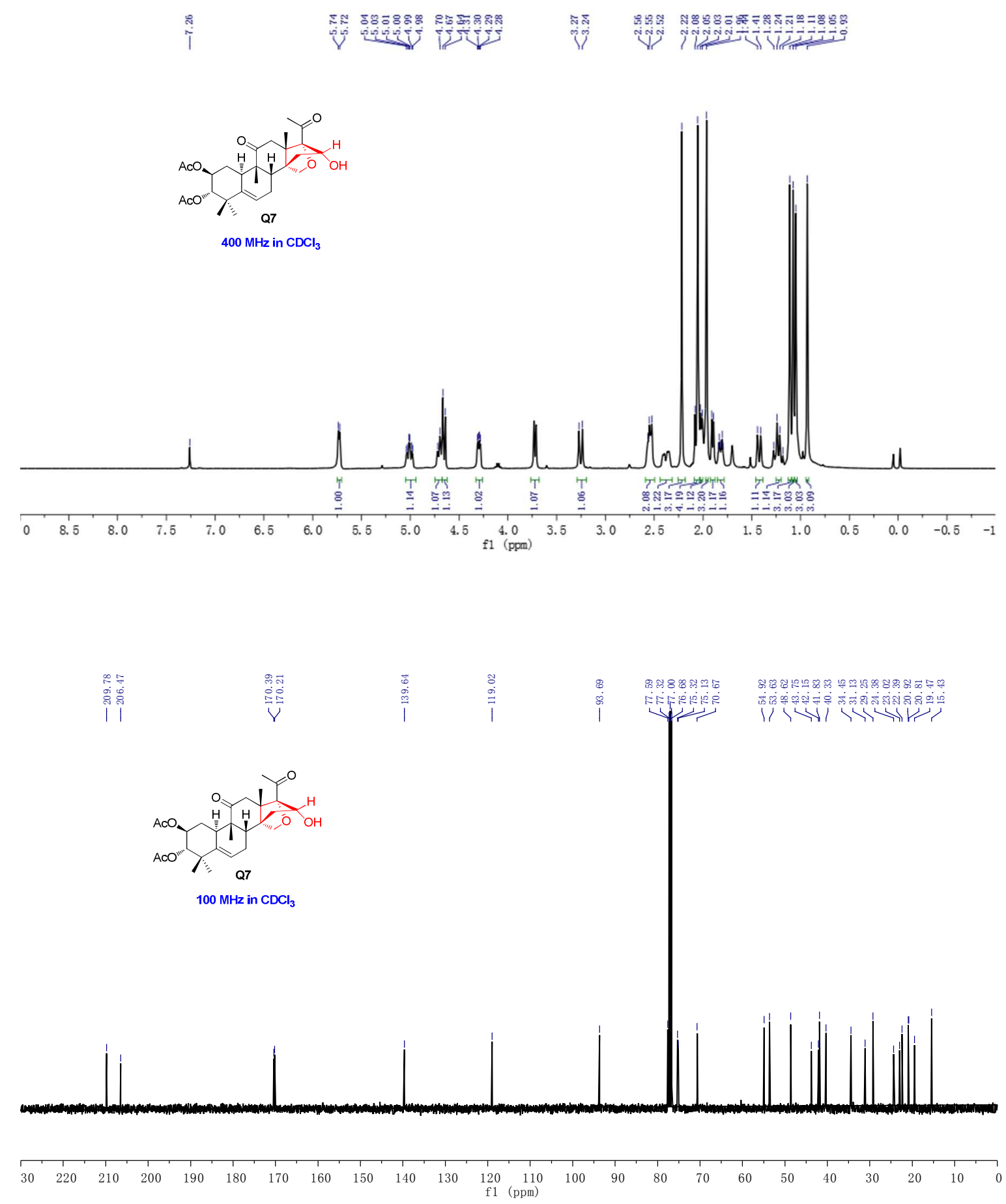


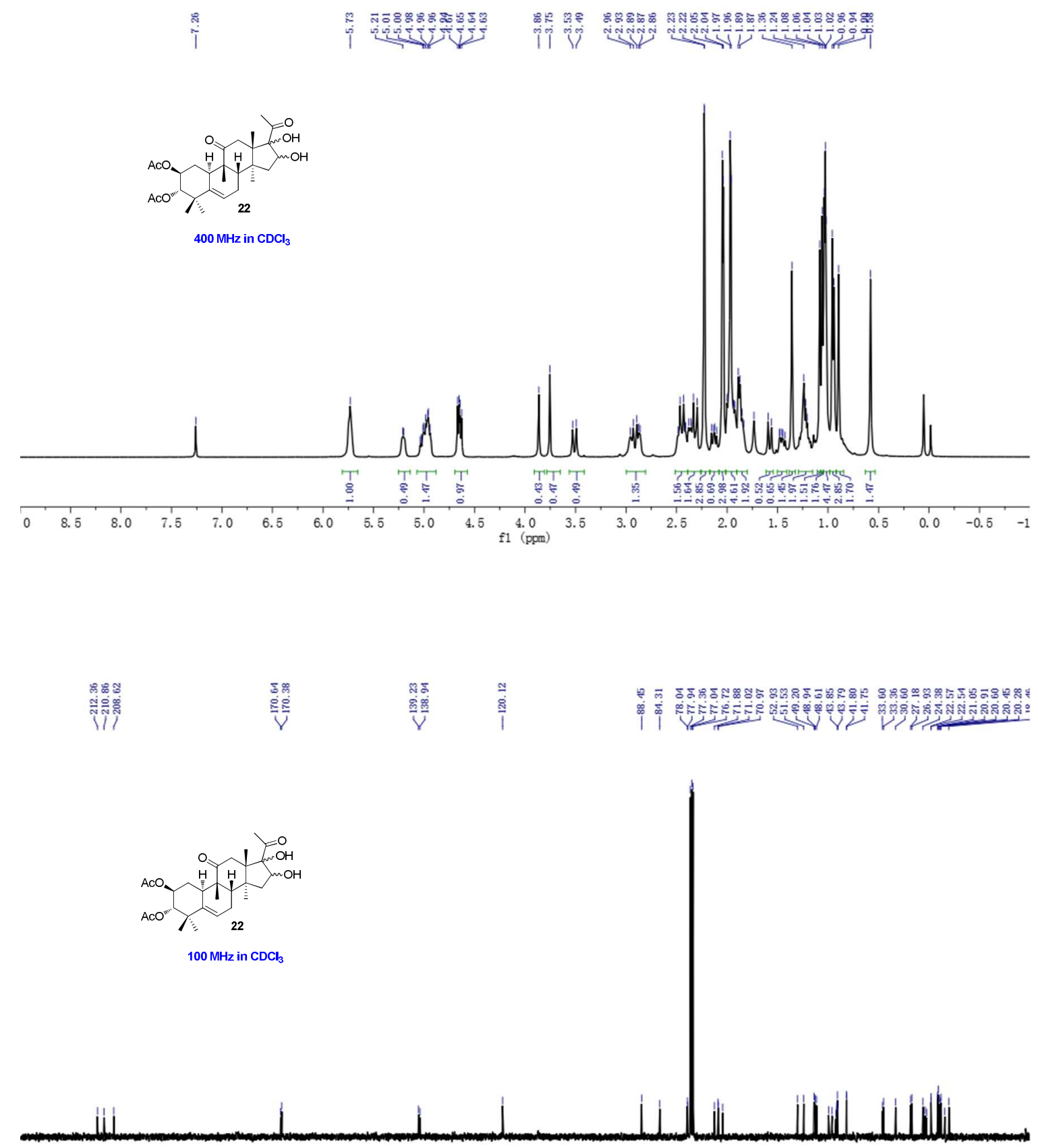

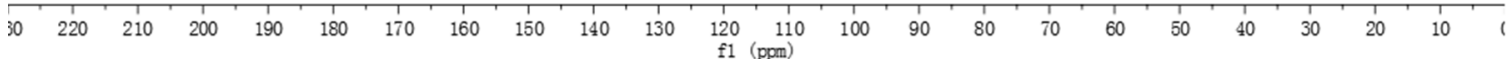




\section{Supporting Information}

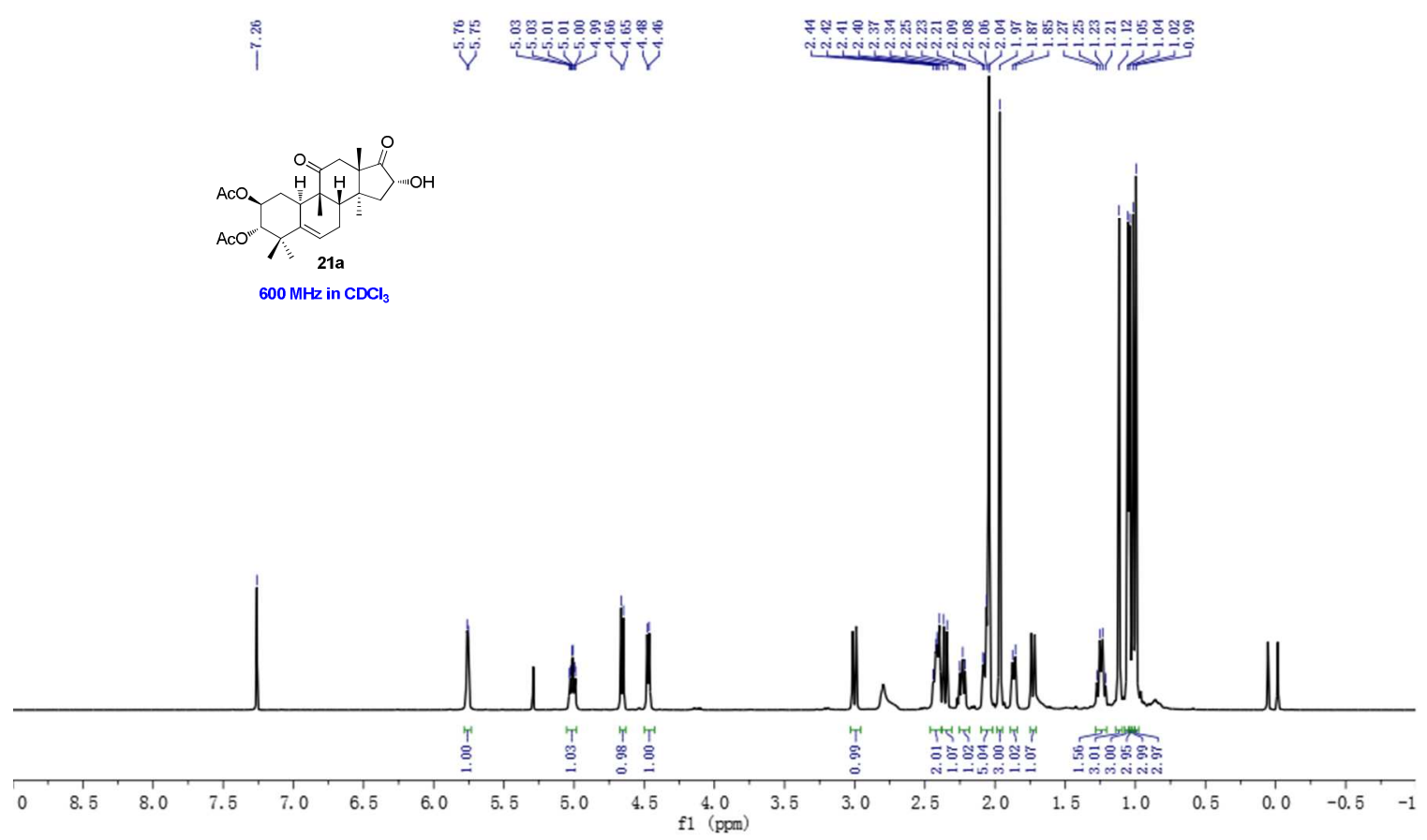

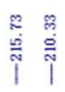
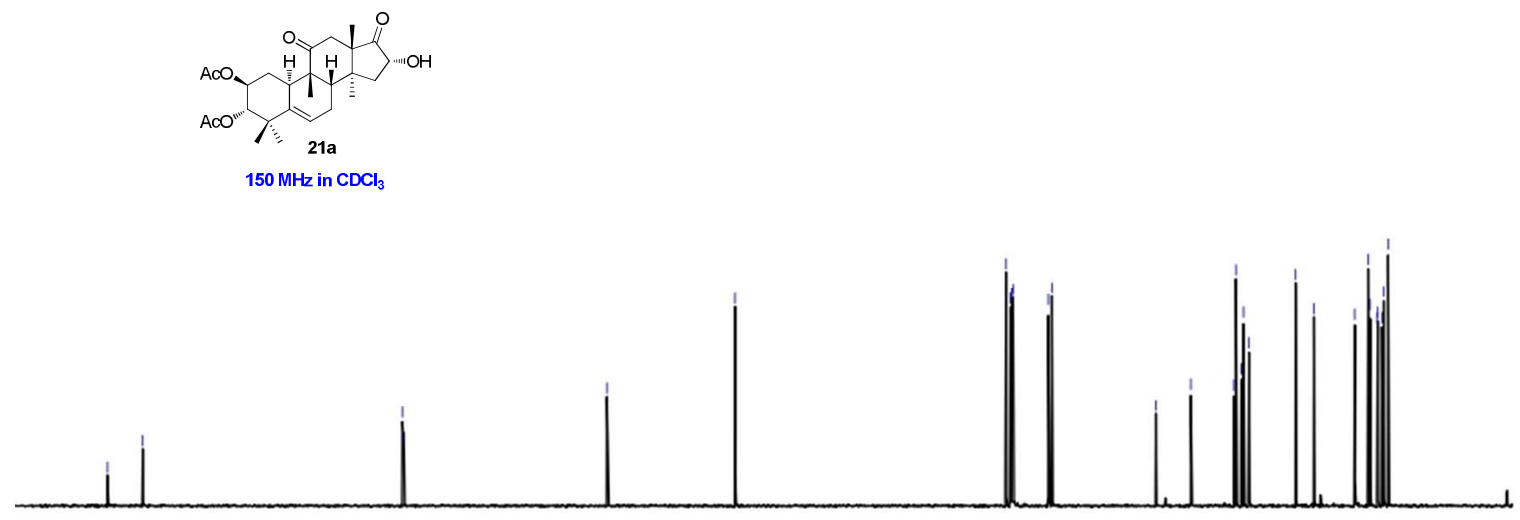

$\begin{array}{lllllllllllllllllllllllllllllllllllll}220 & 210 & 200 & 190 & 180 & 170 & 160 & 150 & 140 & 130 & 120 & 110 & 100 & 90 & 80 & 70 & 60 & 50 & 40 & 30 & 20 & 10 & 1\end{array}$ 


\section{Supporting Information}

${ }^{1} \mathrm{H}-{ }^{1} \mathrm{H}$ COSY spectrum of Compund 21a

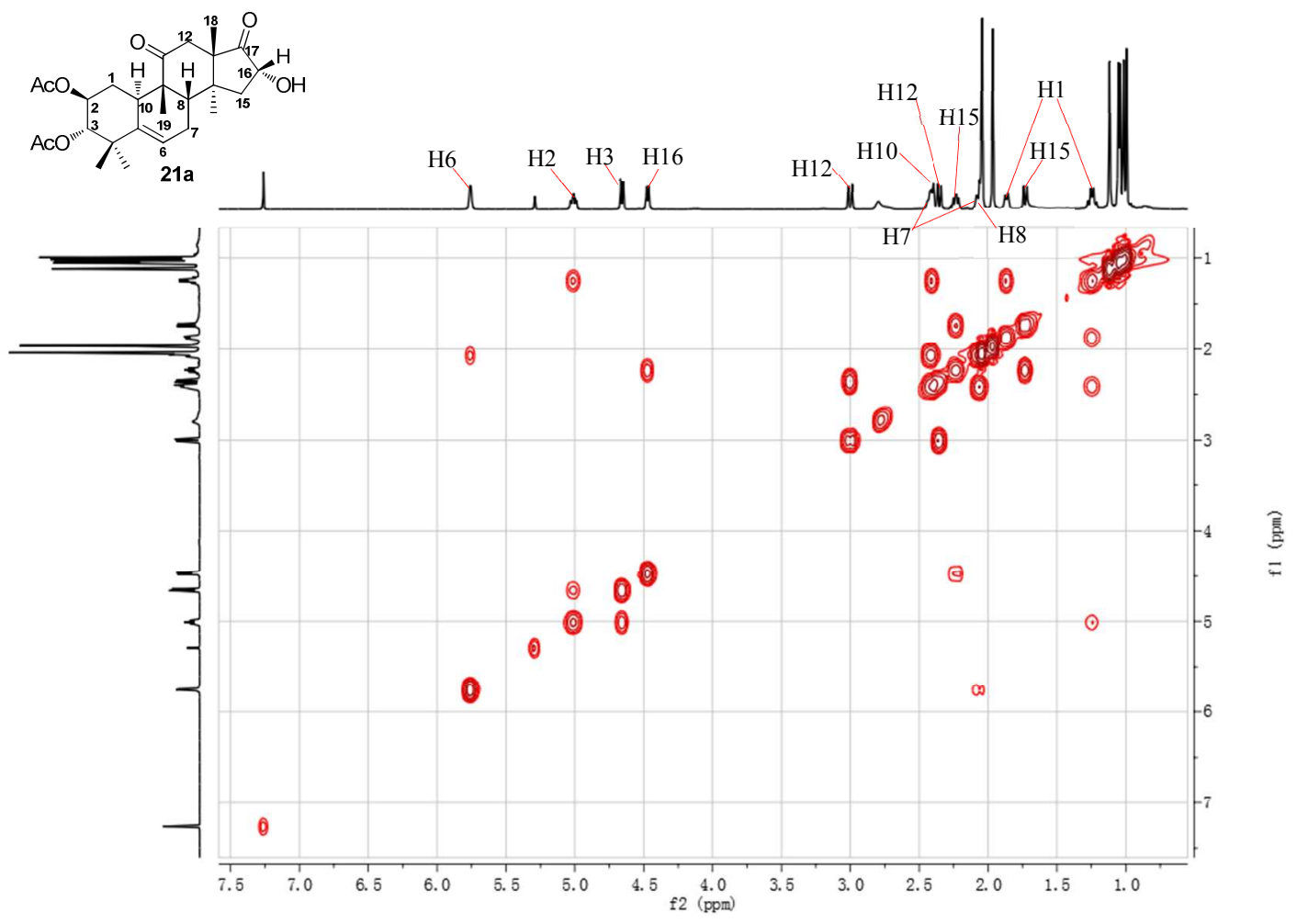

HSQC spectrum of Compund 21a

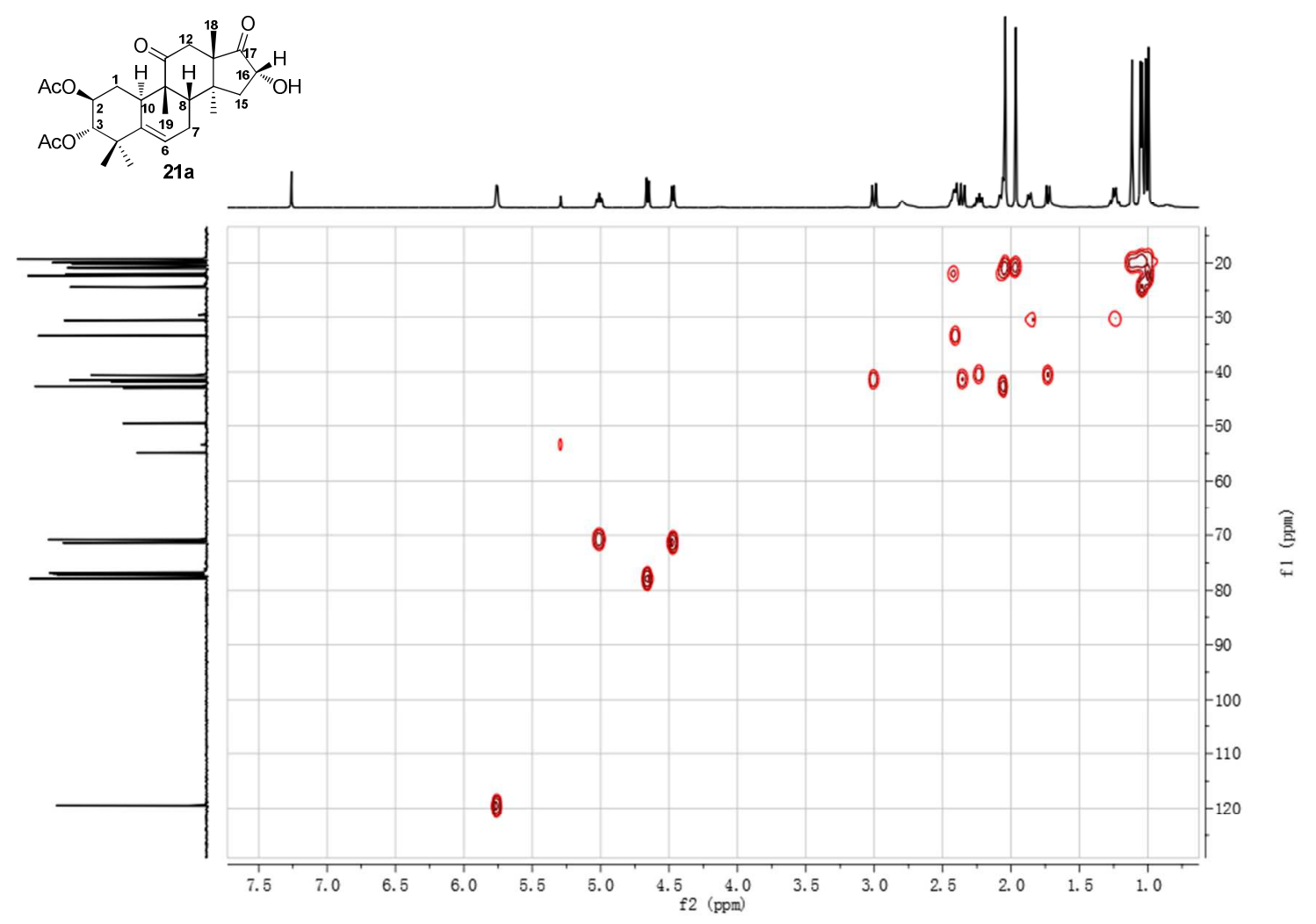




\section{Supporting Information}

HMBC spectrum of Compund 21a

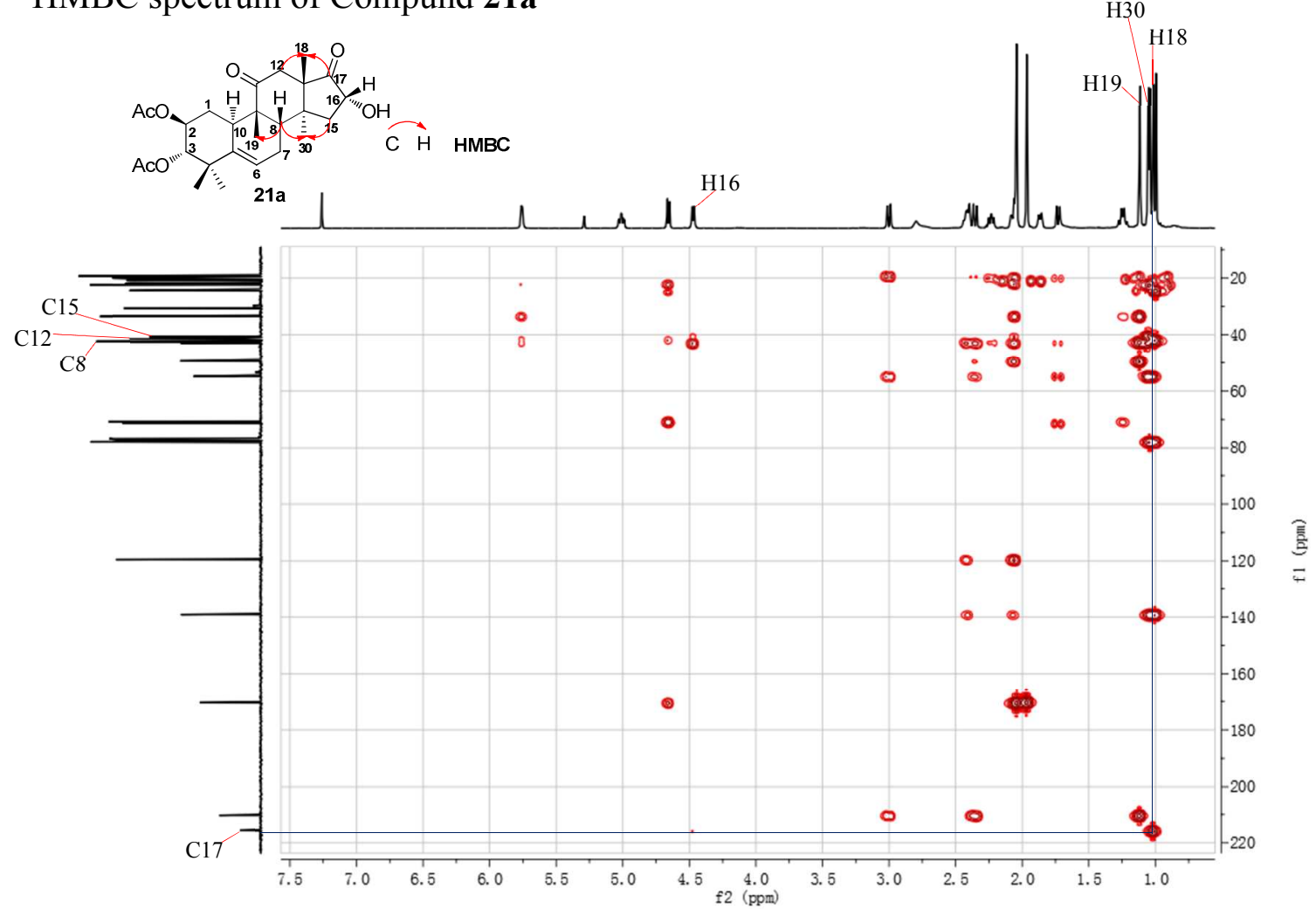

ROESY spectrum of Compund 21a

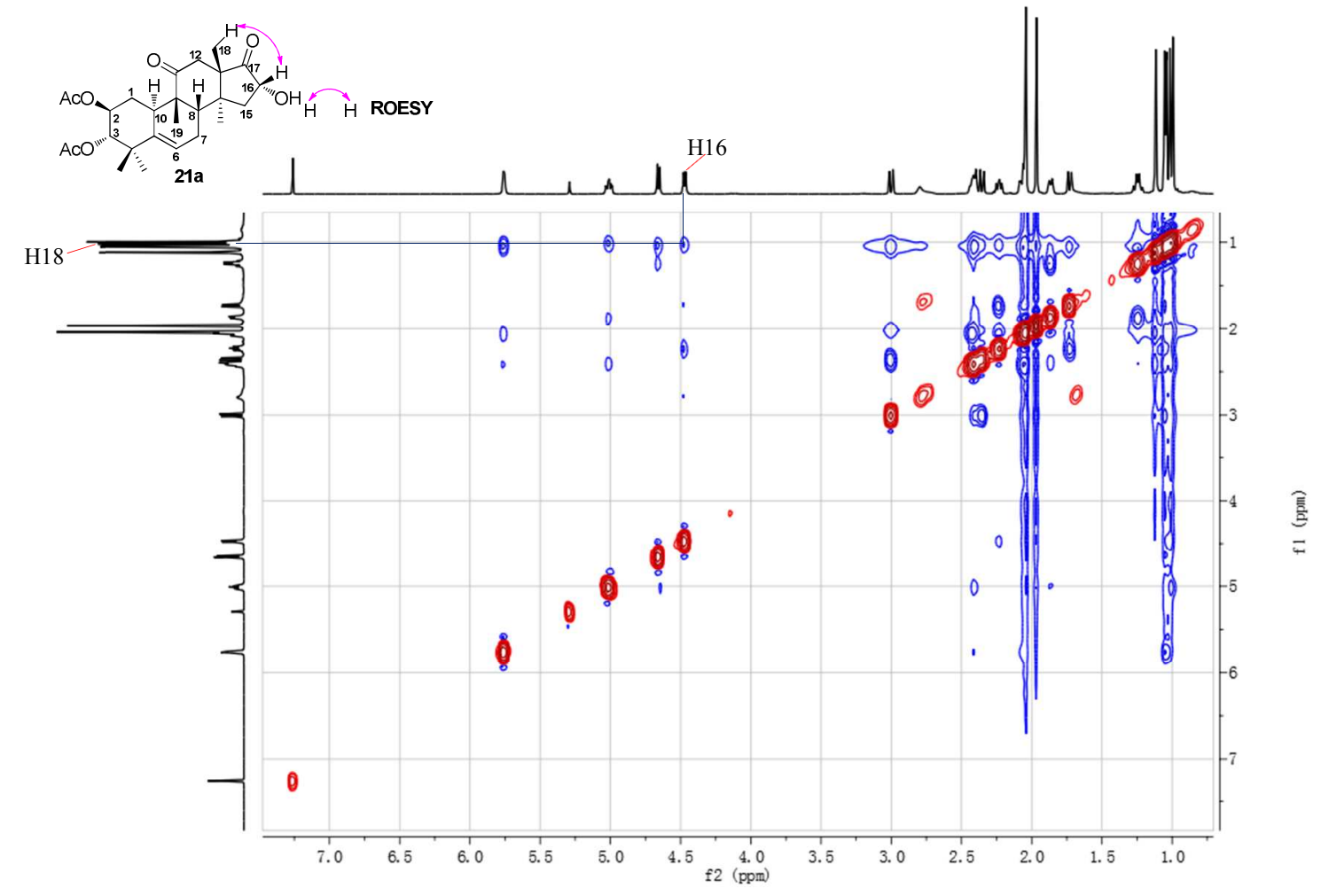




\section{Supporting Information}

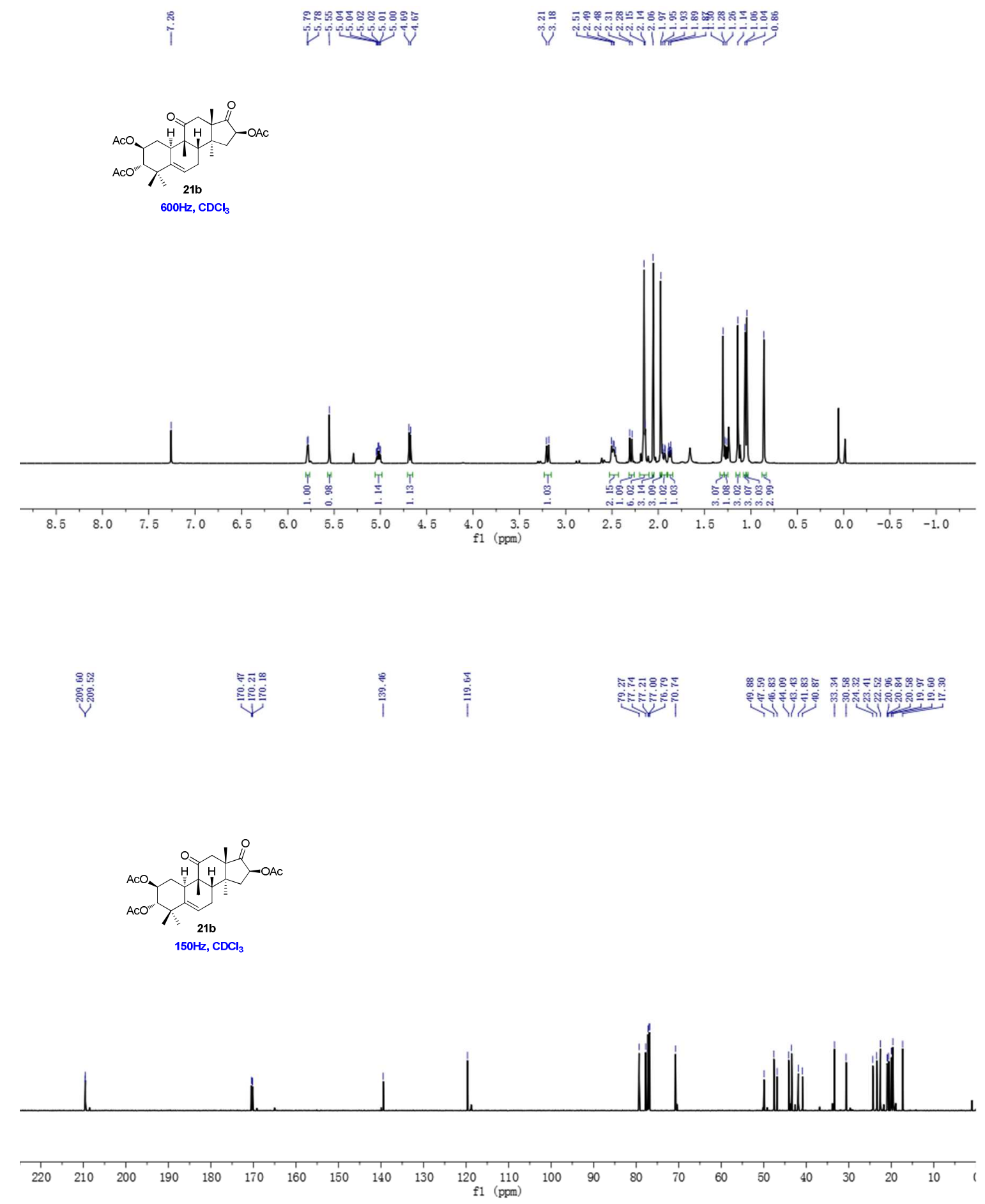




\section{Supporting Information}

${ }^{1} \mathrm{H}-{ }^{1} \mathrm{H}$ COSY spectrum of Compund $\mathbf{2 1 b}$

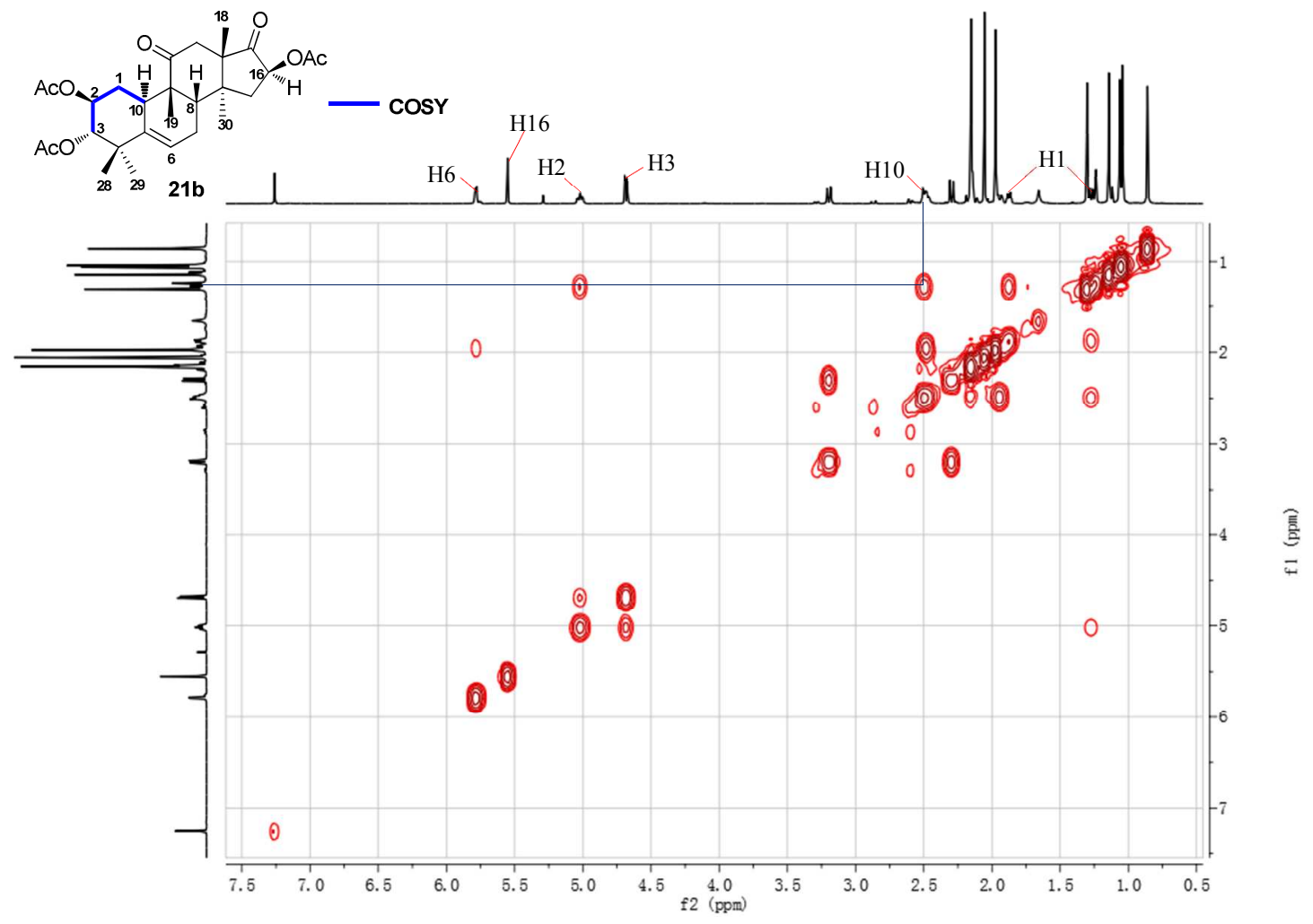

HMQC spectrum of Compund 21b

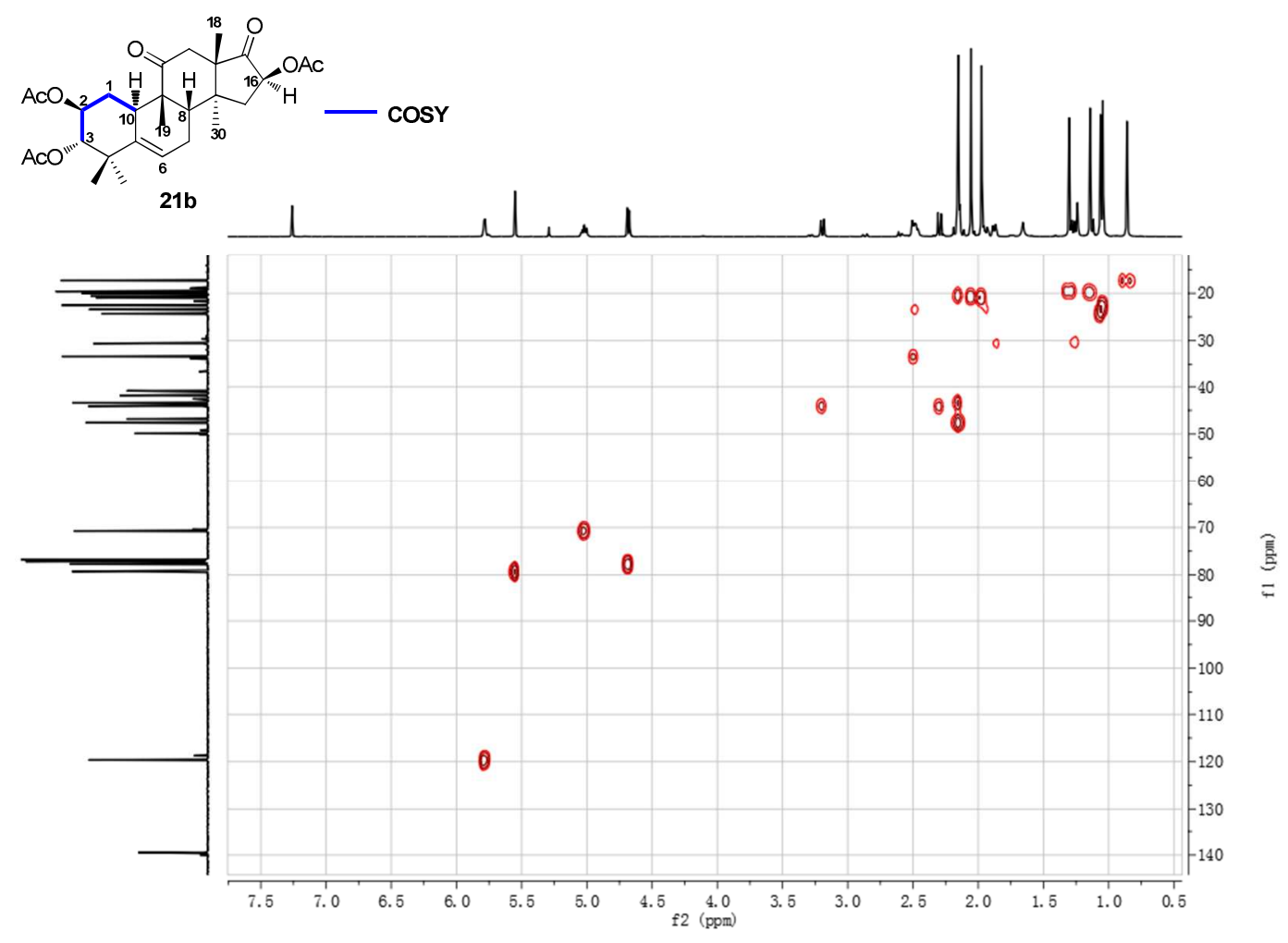




\section{Supporting Information}

HMBC spectrum of Compund 21b

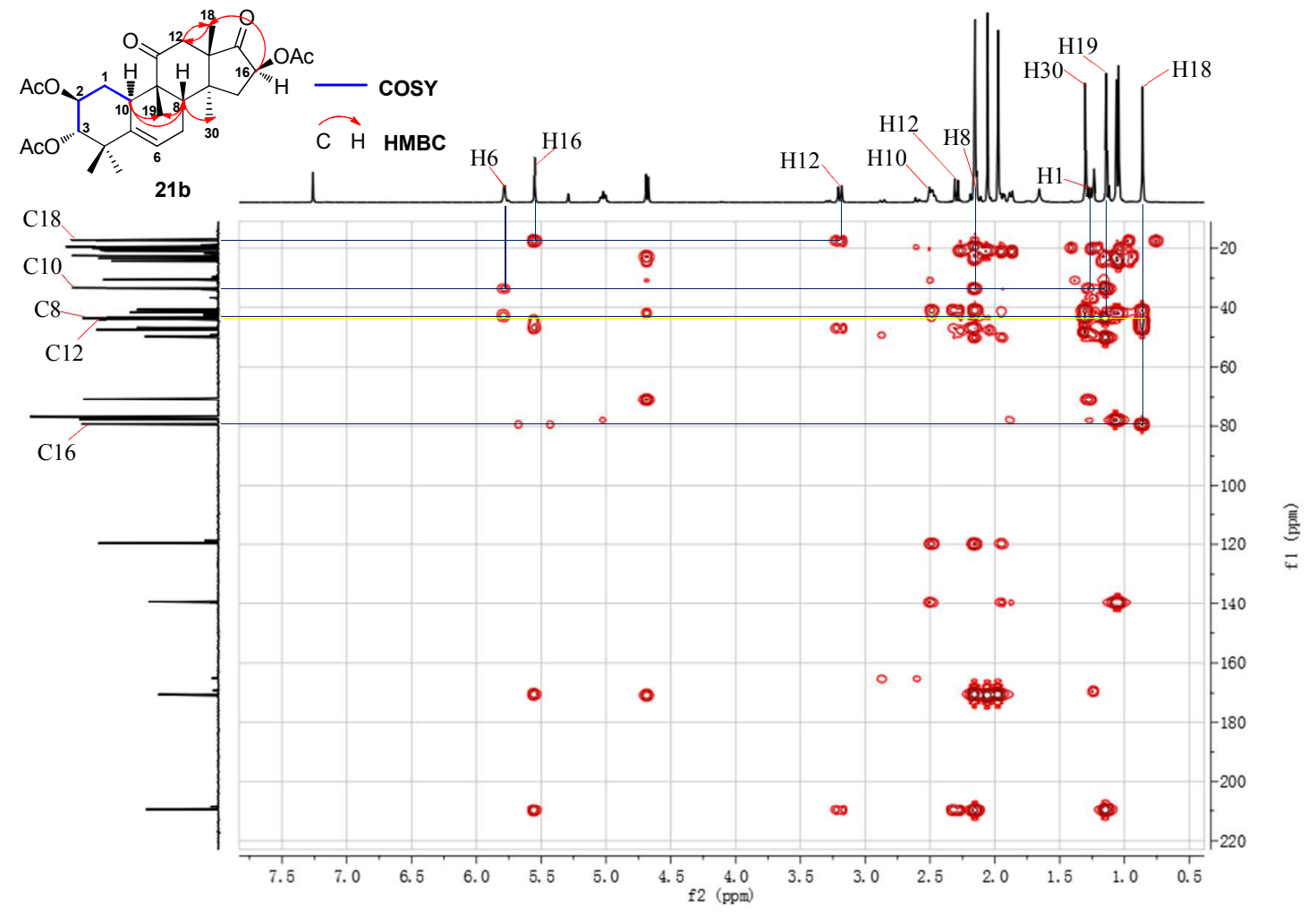

ROESY spectrum of Compund 21b

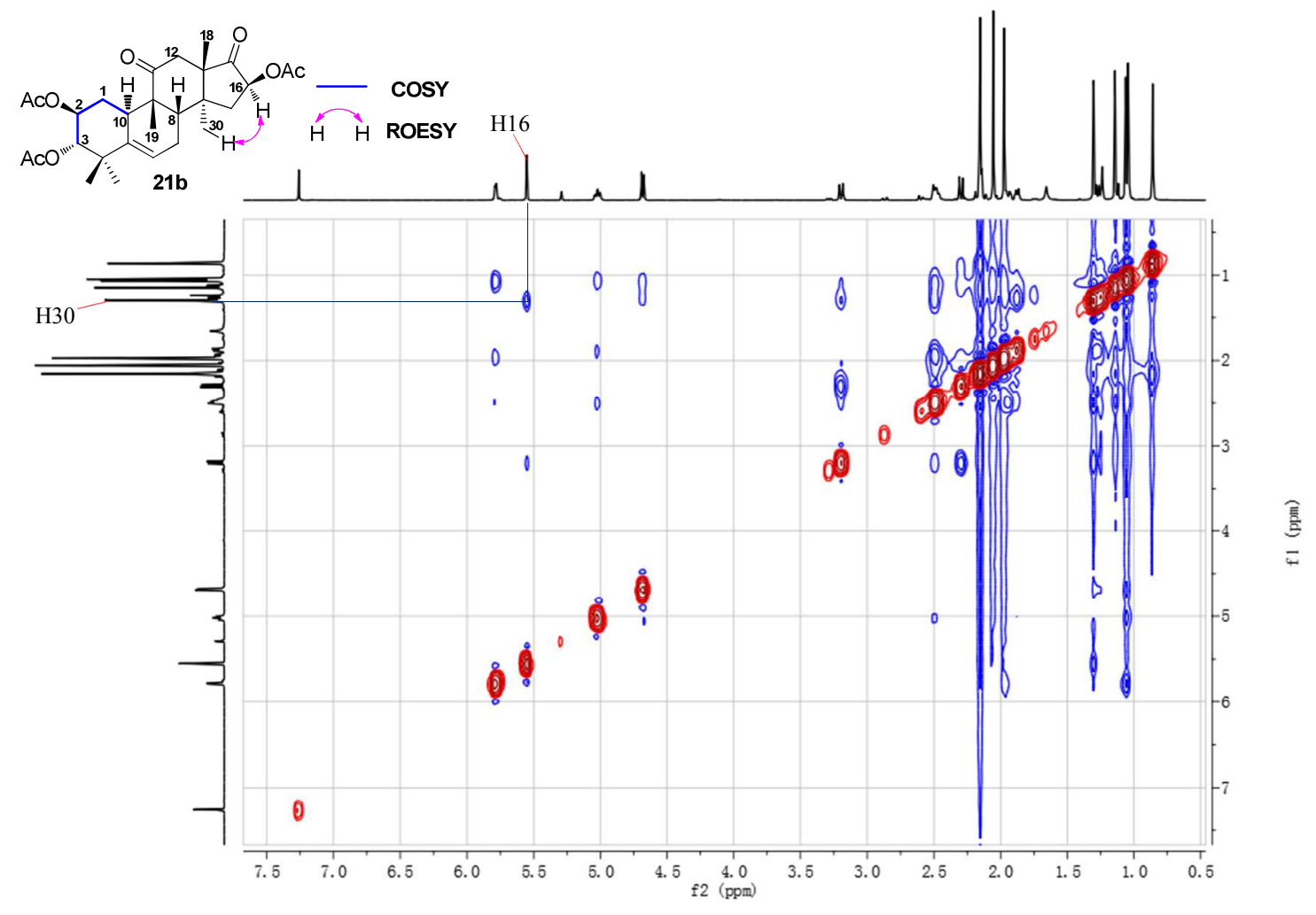




\section{Supporting Information}

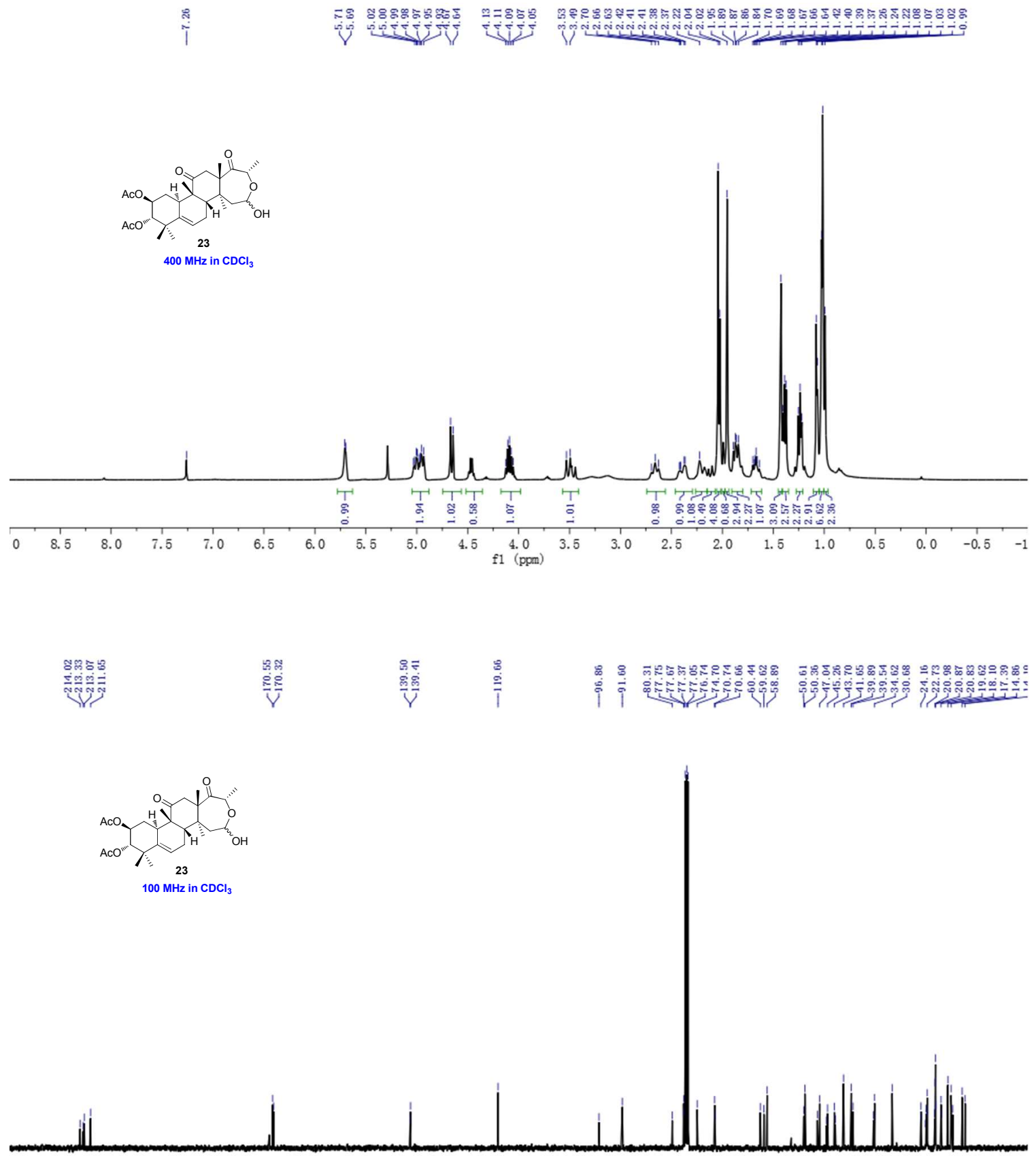

\begin{tabular}{|lllllllllllllllllllllllll}
\hline 30 & 220 & 210 & 200 & 190 & 180 & 170 & 160 & 150 & 140 & 130 & 120 & 110 & 100 & 90 & 80 & 70 & 60 & 50 & 40 & 30 & 20 & 10 & 1
\end{tabular} 

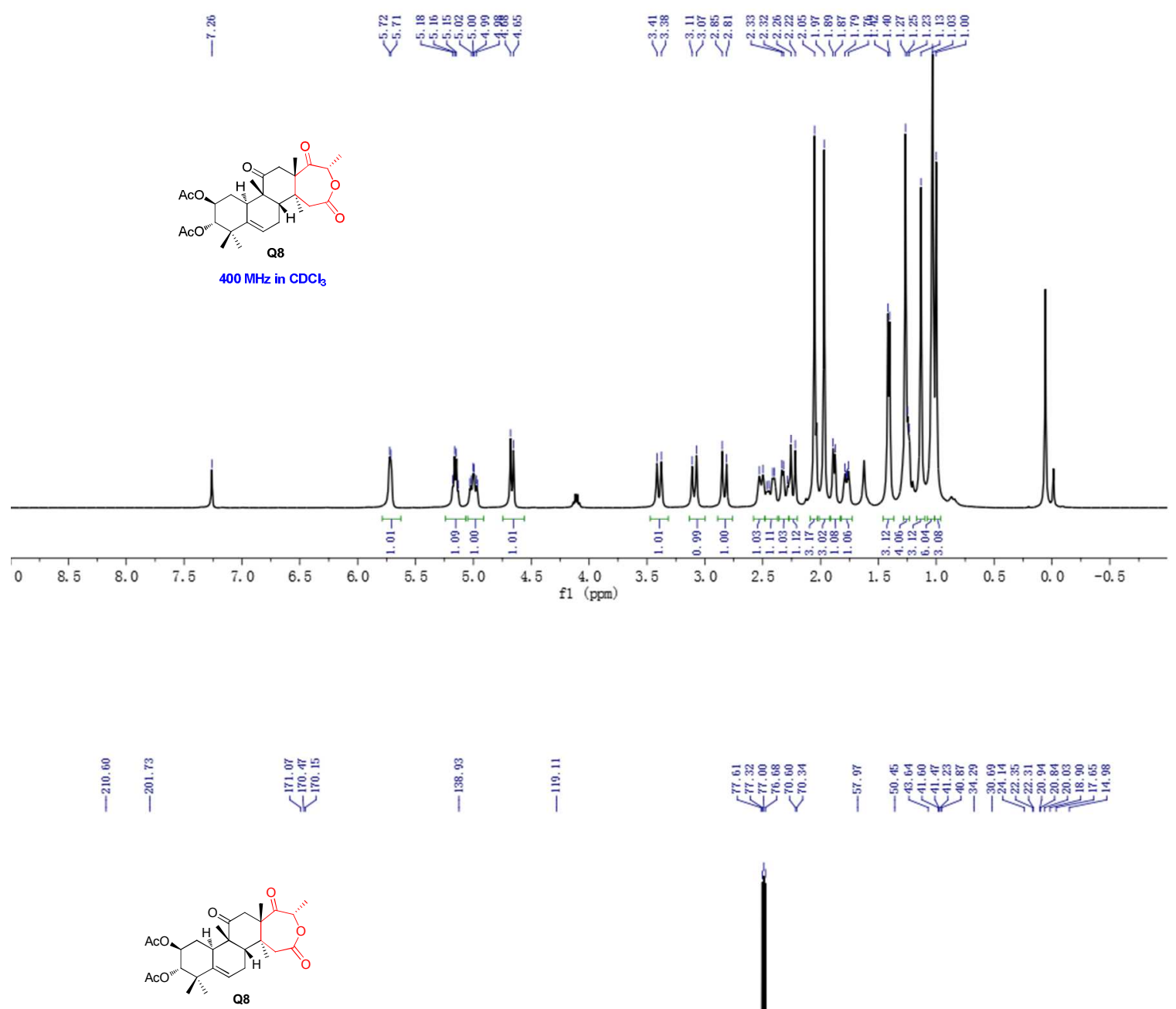

$100 \mathrm{MHz}$ in $\mathrm{CDCl}_{3}$

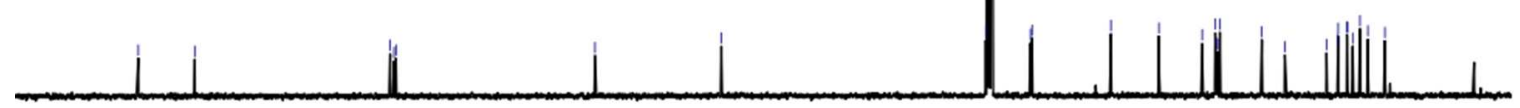

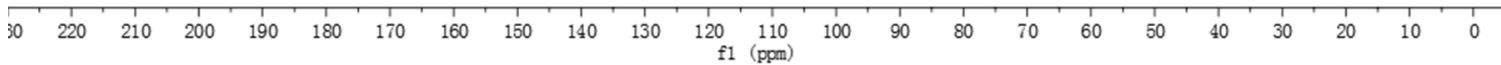




\section{Supporting Information}

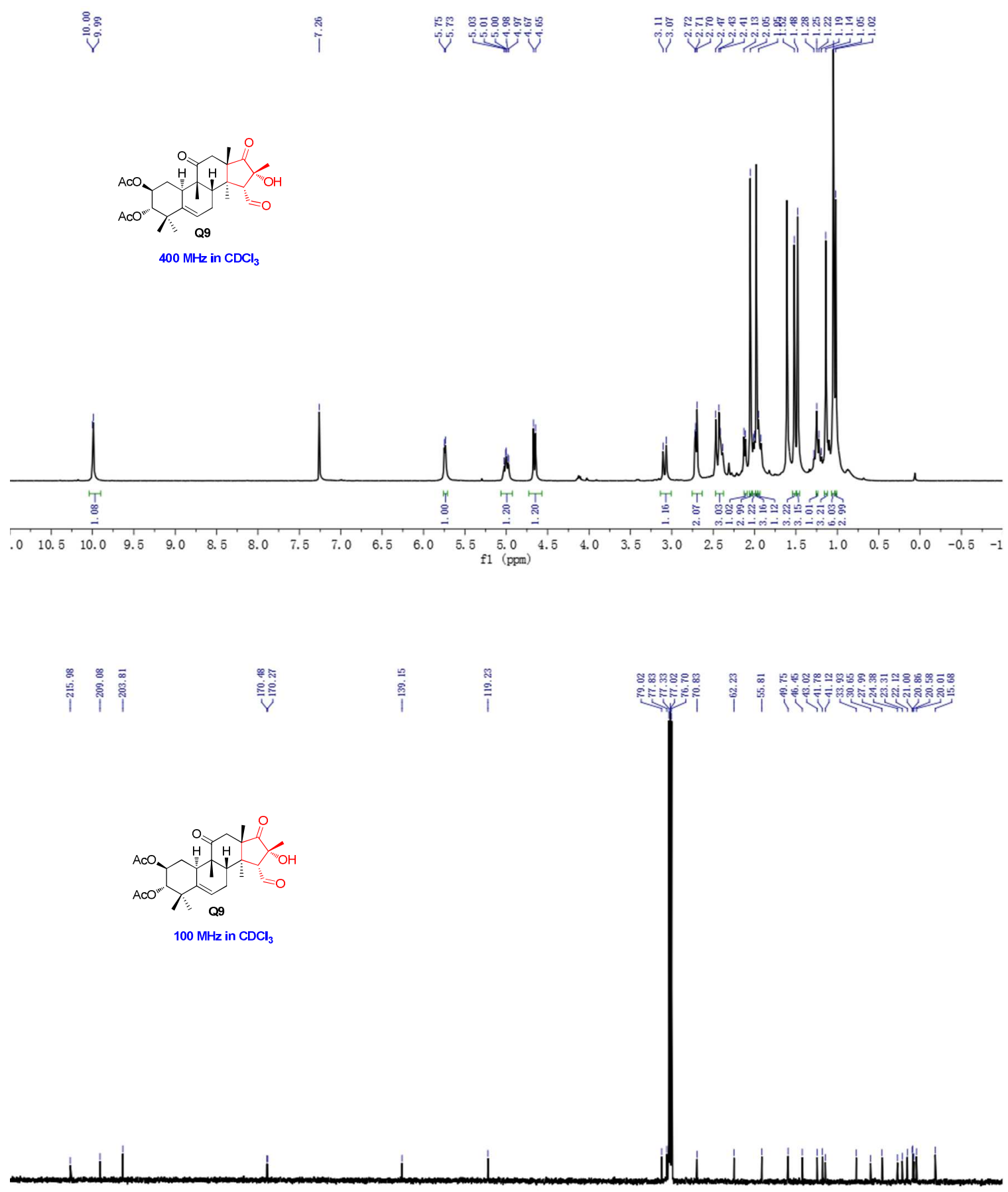

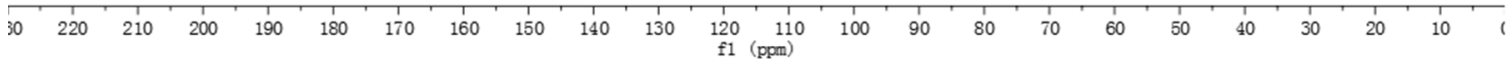




\section{Supporting Information}

\section{X-ray structure of compounds (5, 6, Q2, Q4, Q5, Q6, Q7, Q8, Q9)}

\subsection{X-ray structure of compound 5 (CCDC 1482331)}

Crystal data for mo_5_0m: $\mathrm{C}_{28} \mathrm{H}_{40} \mathrm{O}_{7} \cdot \mathrm{C}_{3} \mathrm{H}_{6} \mathrm{O}, M=546.68, a=7.4728(7) \AA ⿻ 丿$ 11.6974(11) $\AA, c=33.552(3) \AA, \alpha=90^{\circ}, \beta=90^{\circ}, \gamma=90^{\circ}, V=2932.9(5) \AA^{3}, T=100(2)$ $\mathrm{K}$, space group $P 212121, Z=4, \mu(\mathrm{MoK} \alpha)=0.088 \mathrm{~mm}^{-1}, 32695$ reflections measured, 8665 independent reflections $\left(R_{\text {int }}=0.0364\right)$. The final $R_{l}$ values were $0.0621(I>2 \sigma(I))$. The final $w R\left(F^{2}\right)$ values were $0.1857(I>2 \sigma(I))$. The final $R_{l}$ values were 0.0685 (all data). The final $w R\left(F^{2}\right)$ values were 0.1916 (all data). The goodness of fit on $F^{2}$ was 1.039. Flack parameter $=0.1(3)$.

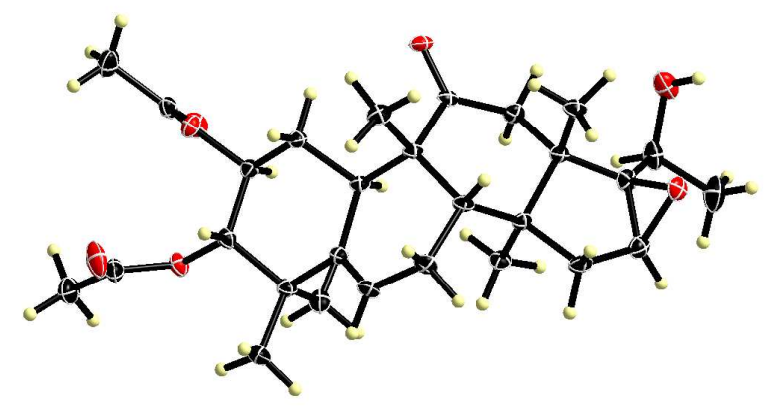

View of the molecules in an asymmetric unit.

Displacement ellipsoids are drawn at the 50\% probability level.

Table 1. Crystal data and structure refinement for mo_5_0m.

Identification code

Empirical formula

Formula weight

Temperature

Wavelength

Crystal system

Space group

Unit cell dimensions mo_5_0m

$\mathrm{C}_{31} \mathrm{H}_{46} \mathrm{O}_{8}$

546.68

100(2) K

$0.71073 \AA$

Orthorhombic

$\mathrm{P} 22_{1} 2_{1}$

$$
\begin{array}{ll}
\mathrm{a}=7.4728(7) \AA & \square \text { alpha }=90^{\circ} . \\
\mathrm{b}=11.6974(11) \AA & \square \text { beta }=90^{\circ} .
\end{array}
$$




\section{Supporting Information}

\begin{tabular}{|c|c|}
\hline & $\mathrm{c}=33.552(3) \AA$ \\
\hline Volume & $2932.9(5) \AA^{3}$ \\
\hline $\mathrm{Z}$ & 4 \\
\hline Density (calculated) & $1.238 \mathrm{Mg} / \mathrm{m}^{3}$ \\
\hline Absorption coefficient & $0.088 \mathrm{~mm}^{-1}$ \\
\hline $\mathrm{F}(000)$ & 1184 \\
\hline Crystal size & $0.580 \times 0.540 \times 0.120 \mathrm{~mm}^{3}$ \\
\hline Theta range for data collection & 1.214 to $31.039^{\circ}$. \\
\hline Index ranges & $-10<=\mathrm{h}<=10,-16<=\mathrm{k}<=16,-40<=1<=46$ \\
\hline Reflections collected & 32695 \\
\hline Independent reflections & $8665[\mathrm{R}(\mathrm{int})=0.0364]$ \\
\hline Completeness to theta $=25.242^{\circ}$ & $99.9 \%$ \\
\hline Absorption correction & Semi-empirical from equivalents \\
\hline Refinement method & Full-matrix least-squares on $\mathrm{F}^{2}$ \\
\hline Data / restraints / parameters & $8665 / 0 / 363$ \\
\hline Goodness-of-fit on $\mathrm{F}^{2}$ & 1.039 \\
\hline Final $R$ indices $[I>2 \operatorname{sigma}(I)]$ & $\mathrm{R} 1=0.0621, \mathrm{wR} 2=0.1857$ \\
\hline $\mathrm{R}$ indices (all data) & $\mathrm{R} 1=0.0685, \mathrm{wR} 2=0.1916$ \\
\hline Absolute structure parameter & $0.1(3)$ \\
\hline Extinction coefficient & $\mathrm{n} / \mathrm{a}$ \\
\hline Largest diff. peak and hole & 0.939 and -0.631 e. $\AA^{-}-3$ \\
\hline
\end{tabular}




\section{Supporting Information}

\subsection{X-ray structure of compound 6 (CCDC 1482479)}

Crystal data for mo_6_0m: $\mathrm{C}_{28} \mathrm{H}_{40} \mathrm{O}_{7}, M=488.60$, orthorhombic, $a=13.3481(11) \AA ̊ ., b$ $=15.2780(13) \AA, c=36.973(3) \AA, \alpha=90.00^{\circ}, \beta=90.00^{\circ}, \gamma=90.00^{\circ}, V=7539.9(11) \AA^{3}$, $T=100(2) \mathrm{K}$, space group $P 212121, Z=12, \mu(\mathrm{MoK} \alpha)=0.091 \mathrm{~mm}^{-1}, 81376$ reflections measured, 21702 independent reflections $\left(R_{\text {int }}=0.0383\right)$. The final $R_{l}$ values were 0.0429 $(I>2 \sigma(I))$. The final $w R\left(F^{2}\right)$ values were $0.0984(I>2 \sigma(I))$. The final $R_{I}$ values were 0.0528 (all data). The final $w R\left(F^{2}\right)$ values were 0.1037 (all data). The goodness of fit on $F^{2}$ was 1.044. Flack parameter $=0.2(4)$.

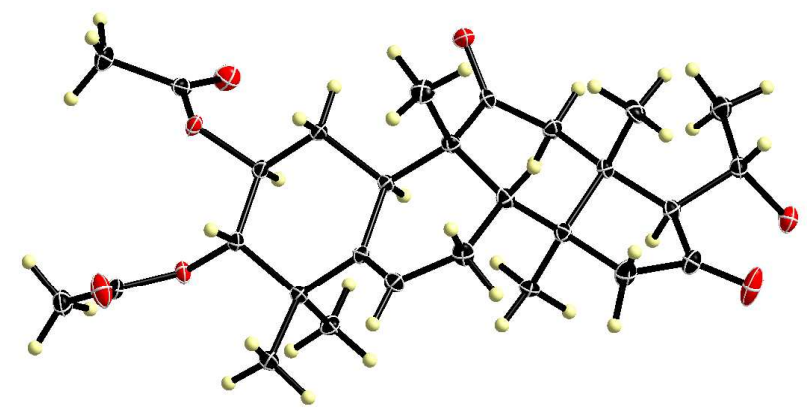

View of the molecules in an asymmetric unit.

Displacement ellipsoids are drawn at the $50 \%$ probability level.

Table 1. Crystal data and structure refinement for 6 .

Identification code

Empirical formula

Formula weight

Temperature

Wavelength

Crystal system, space group

Unit cell dimensions

Volume mo_6_0m

$\mathrm{C}_{28} \mathrm{H}_{40} \mathrm{O}_{7}$

488.60

100(2) K

$0.71073 \mathrm{~A}$

Orthorhombic, P 212121

$$
\begin{aligned}
& \mathrm{a}=13.3481(11) \mathrm{A} \quad \text { alpha }=90 \mathrm{deg} . \\
& \mathrm{b}=15.2780(13) \mathrm{A} \quad \text { beta }=90 \mathrm{deg} . \\
& \mathrm{c}=36.973(3) \mathrm{A} \quad \text { gamma }=90 \mathrm{deg} .
\end{aligned}
$$$$
\text { 7539.9(11) A^3 }
$$ 


\section{Supporting Information}

Z, Calculated density

Absorption coefficient

$\mathrm{F}(000)$

Crystal size

Theta range for data collection

Limiting indices

Reflections collected / unique

Completeness to theta $=30.68$

Absorption correction

Max. and min. transmission

Refinement method

Data / restraints / parameters

Goodness-of-fit on $\mathrm{F}^{\wedge} 2$

Final $\mathrm{R}$ indices [I $>2 \operatorname{sigma}(\mathrm{I})]$

$\mathrm{R}$ indices (all data)

Absolute structure parameter

Largest diff. peak and hole
12, $\quad 1.291 \mathrm{Mg} / \mathrm{m}^{\wedge} 3$

$0.091 \mathrm{~mm}^{\wedge}-1$

3168

$0.50 \times 0.35 \times 0.30 \mathrm{~mm}$

1.10 to $30.68 \mathrm{deg}$.

$-17<=\mathrm{h}<=18,-21<=\mathrm{k}<=20,-52<=\mathrm{l}<=52$

$81376 / 21702[\mathrm{R}(\mathrm{int})=0.0383]$

$95.1 \%$

Semi-empirical from equivalents

0.9731 and 0.9557

Full-matrix least-squares on $\mathrm{F}^{\wedge} 2$

21702 / 0 / 973

1.044

$\mathrm{R} 1=0.0429, \mathrm{wR} 2=0.0984$

$\mathrm{R} 1=0.0528, \mathrm{wR} 2=0.1037$

$0.2(4)$

0.420 and -0.247 e. $\mathrm{A}^{\wedge}-3$ 


\section{Supporting Information}

\subsection{X-ray structure of compound Q2 (CCDC 1482480)}

Crystal data for mo_Q2_0m: $\mathrm{C}_{28} \mathrm{H}_{40} \mathrm{O}_{7} \cdot 2\left(\mathrm{H}_{2} \mathrm{O}\right), M=524.63$, orthorhombic, $a=$ 9.3211(16) $\AA, b=11.4032(19) \AA, c=26.089(4) \AA, \alpha=90.00^{\circ}, \beta=90.00^{\circ}, \gamma=90.00^{\circ}, V$ $=2773.0(8) \AA^{3}, T=100(2) \mathrm{K}$, space group $P 212121, Z=4, \mu(\mathrm{MoK} \alpha)=0.093 \mathrm{~mm}^{-1}$, 27051 reflections measured, 6895 independent reflections $\left(R_{\text {int }}=0.0563\right)$. The final $R_{1}$ values were $0.0383(I>2 \sigma(I))$. The final $w R\left(F^{2}\right)$ values were $0.0921(I>2 \sigma(I))$. The final $R_{l}$ values were 0.0532 (all data). The final $w R\left(F^{2}\right)$ values were 0.0984 (all data). The goodness of fit on $F^{2}$ was 1.029. Flack parameter $=0.9(7)$.

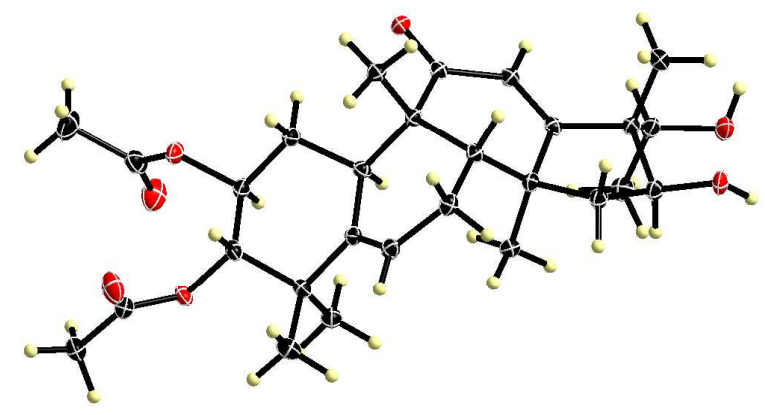

View of the molecules in an asymmetric unit.

Displacement ellipsoids are drawn at the $50 \%$ probability level.

Table 1. Crystal data and structure refinement for $\mathbf{Q 2}$.

Identification code

Empirical formula

Formula weight

Temperature

Wavelength

Crystal system, space group

Unit cell dimensions

Volume

$$
\begin{gathered}
\text { mo_Q2_0m } \\
\mathrm{C}_{28} \mathrm{H}_{44} \mathrm{O}_{9}
\end{gathered}
$$

524.63

$$
\text { 100(2) K }
$$

$0.71073 \mathrm{~A}$

Orthorhombic, P 212121

$$
\begin{aligned}
& \mathrm{a}=9.3211(16) \mathrm{A} \quad \text { alpha }=90 \mathrm{deg} . \\
& \mathrm{b}=11.4032(19) \mathrm{A} \quad \text { beta }=90 \mathrm{deg} . \\
& \mathrm{c}=26.089(4) \mathrm{A} \quad \text { gamma }=90 \mathrm{deg} .
\end{aligned}
$$$$
\text { 2773.0(8) } \mathrm{A}^{\wedge} 3
$$ 


\section{Supporting Information}

Z, Calculated density

Absorption coefficient

$\mathrm{F}(000)$

Crystal size

Theta range for data collection

Limiting indices

Reflections collected / unique

Completeness to theta $=28.35$

Absorption correction

Max. and min. transmission

Refinement method

Data / restraints / parameters

Goodness-of-fit on $\mathrm{F}^{\wedge} 2$

Final $\mathrm{R}$ indices [I $>2 \operatorname{sigma}(\mathrm{I})]$

$\mathrm{R}$ indices (all data)

Absolute structure parameter

Largest diff. peak and hole
4, $\quad 1.257 \mathrm{Mg} / \mathrm{m}^{\wedge} 3$

$0.093 \mathrm{~mm}^{\wedge}-1$

1136

$1.00 \times 0.30 \times 0.04 \mathrm{~mm}$

1.95 to $28.35 \mathrm{deg}$.

$-10<=\mathrm{h}<=12,-15<=\mathrm{k}<=15,-34<=\mathrm{l}<=34$

$27051 / 6895[\mathrm{R}(\mathrm{int})=0.0563]$

$99.5 \%$

Semi-empirical from equivalents

0.9963 and 0.9131

Full-matrix least-squares on $\mathrm{F}^{\wedge} 2$

6895 / 0 / 344

1.029

$\mathrm{R} 1=0.0383, \mathrm{wR} 2=0.0921$

$\mathrm{R} 1=0.0532, \mathrm{wR} 2=0.0984$

$0.9(7)$

0.315 and -0.226 e. $\mathrm{A}^{\wedge}-3$ 


\section{Supporting Information}

\subsection{X-ray structure of compound Q4 (CCDC 1482333)}

Crystal data for mo_Q4_0m: $\mathrm{C}_{26} \mathrm{H}_{34} \mathrm{O}_{4}, M=410.53, a=9.4038(10) \AA, b=23.797(3)$ $\AA, c=9.9633(11) \AA, \alpha=90^{\circ}, \beta=90.656(2)^{\circ}, \gamma=90^{\circ}, V=2229.5(4) \AA^{3}, T=100(2) \mathrm{K}$, space group $P 21, Z=4, \mu(\mathrm{MoK} \alpha)=0.081 \mathrm{~mm}^{-1}, 24850$ reflections measured, 12536 independent reflections $\left(R_{\text {int }}=0.0285\right)$. The final $R_{l}$ values were $0.0394(I>2 \sigma(I))$. The final $w R\left(F^{2}\right)$ values were $0.0963(I>2 \sigma(I))$. The final $R_{l}$ values were 0.0441 (all data). The final $w R\left(F^{2}\right)$ values were 0.0992 (all data). The goodness of fit on $F^{2}$ was 1.028 . Flack parameter $=0.0(3)$.

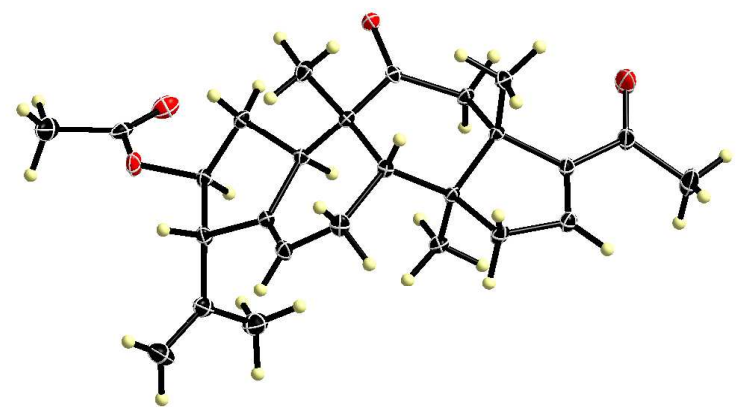

View of the molecules in an asymmetric unit.

Displacement ellipsoids are drawn at the 50\% probability level.

Table 1. Crystal data and structure refinement for mo_Q4_0m.

Identification code

Empirical formula

Formula weight

Temperature

Wavelength

Crystal system

Space group

Unit cell dimensions

$$
\begin{aligned}
& \text { mo_Q4_0m } \\
& \mathrm{C}_{26} \mathrm{H}_{34} \mathrm{O}_{4}
\end{aligned}
$$

410.53

100(2) K

$0.71073 \AA$

Monoclinic

P21

$$
\begin{array}{ll}
\mathrm{a}=9.4038(10) \AA & \mathrm{a}=90^{\circ} . \\
\mathrm{b}=23.797(3) \AA & \mathrm{b}=90.656(2)^{\circ} . \\
\mathrm{c}=9.9633(11) \AA & \mathrm{g}=90^{\circ} .
\end{array}
$$

Volume 


\section{Supporting Information}

Z

Density (calculated)

Absorption coefficient

$\mathrm{F}(000)$

Crystal size

Theta range for data collection

Index ranges

Reflections collected

Independent reflections

Completeness to theta $=25.242^{\circ}$

Absorption correction

Refinement method

Data / restraints / parameters

Goodness-of-fit on $\mathrm{F}^{2}$

Final $\mathrm{R}$ indices [I $>2 \operatorname{sigma}(\mathrm{I})]$

$\mathrm{R}$ indices (all data)

Absolute structure parameter

Extinction coefficient

Largest diff. peak and hole
4

$1.223 \mathrm{Mg} / \mathrm{m}^{3}$

$0.081 \mathrm{~mm}^{-1}$

888

$1.700 \times 0.210 \times 0.120 \mathrm{~mm}^{3}$

1.711 to $30.994^{\circ}$.

$-13<=\mathrm{h}<=13,-34<=\mathrm{k}<=32,-14<=1<=14$

24850

$12536[\mathrm{R}(\mathrm{int})=0.0285]$

$99.8 \%$

Semi-empirical from equivalents

Full-matrix least-squares on $\mathrm{F}^{2}$

$12536 / 1 / 553$

1.028

$\mathrm{R} 1=0.0394, \mathrm{wR} 2=0.0963$

$\mathrm{R} 1=0.0441, \mathrm{wR} 2=0.0992$

$0.0(3)$

$\mathrm{n} / \mathrm{a}$

0.317 and -0.192 e. $\AA^{-3}$ 


\section{Supporting Information}

\subsection{X-ray structure of compound Q5 (CCDC 1482337)}

Crystal data for mo_Q5_0m: $\mathrm{C}_{24} \mathrm{H}_{32} \mathrm{O}_{3}, M=368.49, a=7.9418(8) \AA, b=9.0278(9) \AA$, $c=28.012(3) \AA, \alpha=90^{\circ}, \beta=90^{\circ}, \gamma=90^{\circ}, V=2008.4(3) \AA^{3}, T=100(2) \mathrm{K}$, space group $P 212121, Z=4, \mu(\mathrm{MoK} \alpha)=0.078 \mathrm{~mm}^{-1}, 22355$ reflections measured, 5928 independent reflections $\left(R_{\text {int }}=0.0262\right)$. The final $R_{l}$ values were $0.0346(I>2 \sigma(I))$. The final $w R\left(F^{2}\right)$ values were $0.0875(I>2 \sigma(I))$. The final $R_{l}$ values were 0.0369 (all data). The final $w R\left(F^{2}\right)$ values were 0.0891 (all data). The goodness of fit on $F^{2}$ was 1.073. Flack parameter $=0.0(3)$.

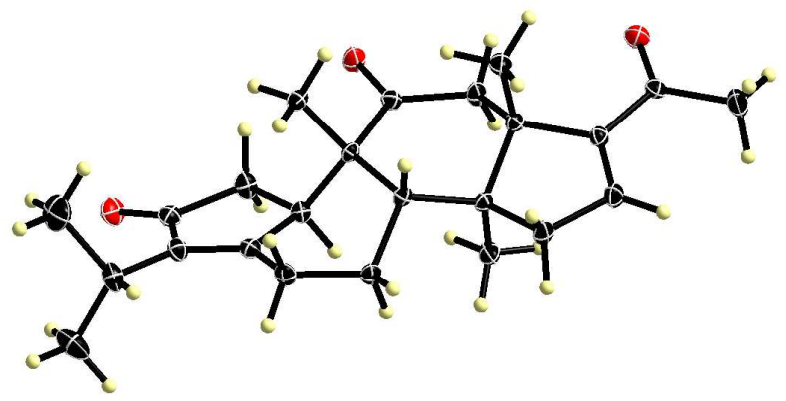

View of the molecules in an asymmetric unit.

Displacement ellipsoids are drawn at the $50 \%$ probability level.

Table 1. Crystal data and structure refinement for mo_Q5_0m.

Identification code

Empirical formula

Formula weight

Temperature

Wavelength

Crystal system

Space group

Unit cell dimensions

Volume

$$
\text { mo_Q5_0m }
$$

$\mathrm{C}_{24} \mathrm{H}_{32} \mathrm{O}_{3}$

368.49

100(2) K

$0.71073 \AA$

Orthorhombic

$\mathrm{P} 2{ }_{1} 2_{1} 2_{1}$

$$
\begin{array}{ll}
\mathrm{a}=7.9418(8) \AA & \mathrm{a}=90^{\circ} . \\
\mathrm{b}=9.0278(9) \AA & \mathrm{b}=90^{\circ} . \\
\mathrm{c}=28.012(3) \AA & \mathrm{g}=90^{\circ} .
\end{array}
$$

2008.4(3) $\AA^{3}$ 


\section{Supporting Information}

Z

Density (calculated)

Absorption coefficient

$\mathrm{F}(000)$

Crystal size

Theta range for data collection

Index ranges

Reflections collected

Independent reflections

Completeness to theta $=25.242^{\circ}$

Absorption correction

Refinement method

Data / restraints / parameters

Goodness-of-fit on $\mathrm{F}^{2}$

Final $\mathrm{R}$ indices [I $>2 \operatorname{sigma}(\mathrm{I})]$

$\mathrm{R}$ indices (all data)

Absolute structure parameter

Extinction coefficient

Largest diff. peak and hole
4

$1.219 \mathrm{Mg} / \mathrm{m}^{3}$

$0.078 \mathrm{~mm}^{-1}$

800

$1.080 \times 0.540 \times 0.100 \mathrm{~mm}^{3}$

1.454 to $30.924^{\circ}$.

$-11<=\mathrm{h}<=11,-12<=\mathrm{k}<=12,-37<=\mathrm{l}<=38$

22355

$5928[\mathrm{R}(\mathrm{int})=0.0262]$

$100.0 \%$

Semi-empirical from equivalents

Full-matrix least-squares on $\mathrm{F}^{2}$

$5928 / 0 / 250$

1.073

$\mathrm{R} 1=0.0346, \mathrm{wR} 2=0.0875$

$\mathrm{R} 1=0.0369, \mathrm{wR} 2=0.0891$

$0.0(3)$

$\mathrm{n} / \mathrm{a}$

0.335 and -0.166 e. $\AA^{-3}$ 


\section{Supporting Information}

\subsection{X-ray structure of compound Q6 (CCDC 1482338)}

Crystal data for mo_Q6_0m: $\mathrm{C}_{24} \mathrm{H}_{30} \mathrm{O}_{3}, M=366.48, a=6.2298(14) \AA, \quad b=12.745(3)$ $\AA, c=12.605(3) \AA, \alpha=90^{\circ}, \beta=99.799(3)^{\circ}, \gamma=90^{\circ}, V=986.3(4) \AA^{3}, T=100(2) \mathrm{K}$, space group $P 21, Z=2, \mu(\mathrm{MoK} \alpha)=0.080 \mathrm{~mm}^{-1}, 10207$ reflections measured, 5191 independent reflections $\left(R_{\text {int }}=0.0324\right)$. The final $R_{l}$ values were $0.0415(I>2 \sigma(I))$. The final $w R\left(F^{2}\right)$ values were $0.1064(I>2 \sigma(I))$. The final $R_{l}$ values were 0.0496 (all data). The final $w R\left(F^{2}\right)$ values were 0.1118 (all data). The goodness of fit on $F^{2}$ was 1.020 . Flack parameter $=-0.2(6)$.

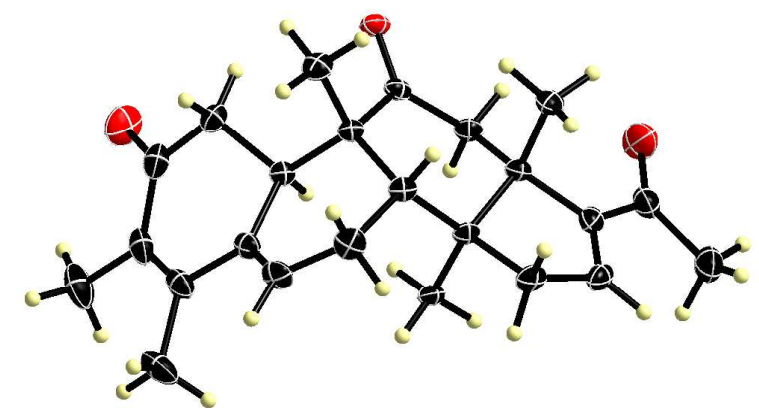

View of the molecules in an asymmetric unit.

Displacement ellipsoids are drawn at the 50\% probability level.

Table 1. Crystal data and structure refinement for mo_Q6_0m.

Identification code

Empirical formula

Formula weight

Temperature

Wavelength

Crystal system

Space group

Unit cell dimensions

$$
\begin{aligned}
& \text { mo_Q6_0m } \\
& \mathrm{C}_{24} \mathrm{H}_{30} \mathrm{O}_{3}
\end{aligned}
$$

366.48

100(2) K

$0.71073 \AA$

Monoclinic

$\mathrm{P} 2_{1}$

$$
\begin{array}{ll}
\mathrm{a}=6.2298(14) \AA & \mathrm{a}=90^{\circ} . \\
\mathrm{b}=12.745(3) \AA & \mathrm{b}=99.799(3)^{\circ} . \\
\mathrm{c}=12.605(3) \AA & \mathrm{g}=90^{\circ} .
\end{array}
$$

Volume 


\section{Supporting Information}

Z

Density (calculated)

Absorption coefficient

$\mathrm{F}(000)$

Crystal size

Theta range for data collection

Index ranges

Reflections collected

Independent reflections

Completeness to theta $=25.242^{\circ}$

Absorption correction

Refinement method

Data / restraints / parameters

Goodness-of-fit on $\mathrm{F}^{2}$

Final $\mathrm{R}$ indices [I $>2 \operatorname{sigma}(\mathrm{I})]$

$\mathrm{R}$ indices (all data)

Absolute structure parameter

Extinction coefficient

Largest diff. peak and hole
2

$1.234 \mathrm{Mg} / \mathrm{m}^{3}$

$0.080 \mathrm{~mm}^{-1}$

396

$1.000 \times 0.400 \times 0.070 \mathrm{~mm}^{3}$

1.639 to $29.119^{\circ}$.

$-8<=\mathrm{h}<=8,-17<=\mathrm{k}<=17,-17<=1<=14$

10207

$5191[\mathrm{R}(\mathrm{int})=0.0324]$

$99.5 \%$

Semi-empirical from equivalents

Full-matrix least-squares on $\mathrm{F}^{2}$

$5191 / 1 / 250$

1.020

$\mathrm{R} 1=0.0415, \mathrm{wR} 2=0.1064$

$\mathrm{R} 1=0.0496, \mathrm{wR} 2=0.1118$

$-0.2(6)$

$\mathrm{n} / \mathrm{a}$

0.320 and -0.195 e. $\AA^{-3}$ 


\section{Supporting Information}

\subsection{X-ray structure of compound Q7 (CCDC 1482481)}

Crystal data for mo_Q7_0m: $\mathrm{C}_{28} \mathrm{H}_{38} \mathrm{O}_{8}, M=502.58$, orthorhombic, $a=8.3520(9) \AA, \quad b$

$=14.9946(17) \AA, c=40.870(5) \AA, \alpha=90.00^{\circ}, \beta=90.00^{\circ}, \gamma=90.00^{\circ}, V=5118.3(10) \AA^{3}$, $T=100(2) \mathrm{K}$, space group $P 212121, Z=8, \mu(\mathrm{MoK} \alpha)=0.095 \mathrm{~mm}^{-1}, 50733$ reflections measured, 12644 independent reflections $\left(R_{\text {int }}=0.0537\right)$. The final $R_{l}$ values were 0.0463 $(I>2 \sigma(I))$. The final $w R\left(F^{2}\right)$ values were $0.1112(I>2 \sigma(I))$. The final $R_{l}$ values were 0.0593 (all data). The final $w R\left(F^{2}\right)$ values were 0.1193 (all data). The goodness of fit on $F^{2}$ was 1.069. Flack parameter $=-0.2(6)$.

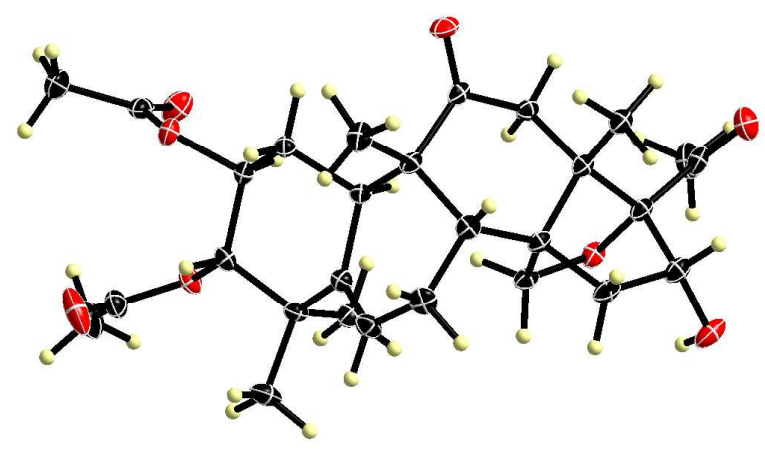

View of the molecules in an asymmetric unit.

Displacement ellipsoids are drawn at the $50 \%$ probability level.

Table 1. Crystal data and structure refinement for Q7.

Identification code

Empirical formula

Formula weight

Temperature

Wavelength

Crystal system, space group

Unit cell dimensions

Volume

Z, Calculated density

$$
\begin{gathered}
\text { mo_Q7_0m } \\
\mathrm{C}_{28} \mathrm{H}_{38} \mathrm{O}_{8} \\
502.58 \\
100(2) \mathrm{K} \\
0.71073 \mathrm{~A}
\end{gathered}
$$

Orthorhombic, P 212121

$$
\begin{aligned}
& \mathrm{a}=8.3520(9) \text { A } \quad \text { alpha }=90 \mathrm{deg} . \\
& \mathrm{b}=14.9946(17) \text { A } \quad \text { beta }=90 \mathrm{deg} . \\
& \mathrm{c}=40.870(5) \text { A } \quad \text { gamma }=90 \mathrm{deg} .
\end{aligned}
$$

5118.3(10) $\mathrm{A}^{\wedge} 3$

$8, \quad 1.304 \mathrm{Mg} / \mathrm{m}^{\wedge} 3$ 


\section{Supporting Information}

Absorption coefficient

$\mathrm{F}(000)$

Crystal size

Theta range for data collection

Limiting indices

Reflections collected / unique

Completeness to theta $=28.28$

Absorption correction

Max. and min. transmission

Refinement method

Data / restraints / parameters

Goodness-of-fit on $\mathrm{F}^{\wedge} 2$

Final $\mathrm{R}$ indices $[\mathrm{I}>2 \operatorname{sigma}(\mathrm{I})]$

$\mathrm{R}$ indices (all data)

Absolute structure parameter

Largest diff. peak and hole
$0.095 \mathrm{~mm}^{\wedge}-1$

2160

$0.96 \times 0.42 \times 0.08 \mathrm{~mm}$

1.00 to $28.28 \mathrm{deg}$.

$-11<=\mathrm{h}<=10,-19<=\mathrm{k}<=19,-54<=\mathrm{l}<=54$

$50733 / 12644[\mathrm{R}(\mathrm{int})=0.0537]$

$99.8 \%$

Semi-empirical from equivalents

0.9925 and 0.9146

Full-matrix least-squares on $\mathrm{F}^{\wedge} 2$

12644 / 0 / 665

1.069

$\mathrm{R} 1=0.0463, \mathrm{wR} 2=0.1112$

$\mathrm{R} 1=0.0593, \mathrm{wR} 2=0.1193$

$-0.2(6)$

0.323 and -0.275 e. $A^{\wedge}-3$ 


\section{Supporting Information}

\subsection{X-ray structure of compound Q8 (CCDC 1482340)}

Crystal data for mo_Q8_0m: $\mathrm{C}_{28} \mathrm{H}_{38} \mathrm{O}_{8} \cdot \mathrm{CH}_{2} \mathrm{Cl}_{2}, M=587.51, a=7.6253(10) \AA, b=$ 11.8707(16) $\AA, c=16.229(2) \AA, \alpha=90^{\circ}, \beta=90.932(2)^{\circ}, \gamma=90^{\circ}, V=1468.8(3) \AA^{3}, T=$ $100(2) \mathrm{K}$, space group $P 21, Z=2, \mu(\mathrm{MoK} \alpha)=0.269 \mathrm{~mm}^{-1}, 16251$ reflections measured, 8373 independent reflections $\left(R_{\text {int }}=0.0261\right)$. The final $R_{l}$ values were $0.0318(I>2 \sigma(I))$.

The final $w R\left(F^{2}\right)$ values were $0.0822(I>2 \sigma(I))$. The final $R_{l}$ values were 0.0368 (all data). The final $w R\left(F^{2}\right)$ values were 0.0849 (all data). The goodness of fit on $F^{2}$ was 1.021. Flack parameter $=-0.009(18)$.

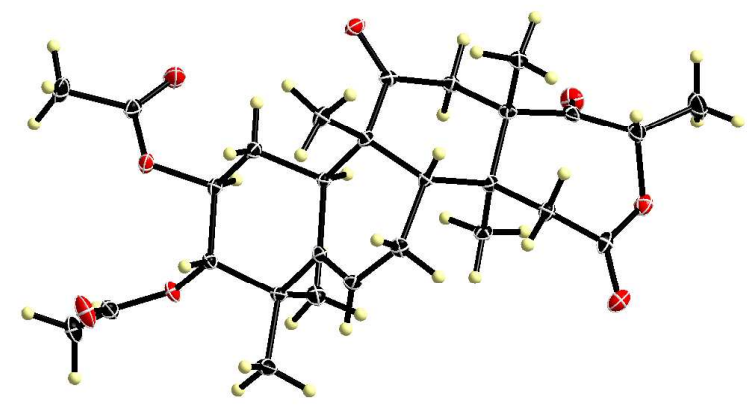

View of the molecules in an asymmetric unit.

Displacement ellipsoids are drawn at the 50\% probability level.

Table 1. Crystal data and structure refinement for mo_Q8_0m.

Identification code

Empirical formula

Formula weight

Temperature

Wavelength

Crystal system

Space group

Unit cell dimensions
mo_Q8_0m

$\mathrm{C}_{29} \mathrm{H}_{40} \mathrm{Cl}_{2} \mathrm{O}_{8}$

587.51

100(2) K

$0.71073 \AA$

Monoclinic

$\mathrm{P} 2_{1}$

$$
\begin{array}{ll}
\mathrm{a}=7.6253(10) \AA & \mathrm{a}=90^{\circ} . \\
\mathrm{b}=11.8707(16) \AA & \mathrm{b}=90.932(2)^{\circ} . \\
\mathrm{c}=16.229(2) \AA & \mathrm{g}=90^{\circ} .
\end{array}
$$

Volume

1468.8(3) $\AA^{3}$ 


\section{Supporting Information}

Z

Density (calculated)

Absorption coefficient

$\mathrm{F}(000)$

Crystal size

Theta range for data collection

Index ranges

Reflections collected

Independent reflections

Completeness to theta $=25.242^{\circ}$

Absorption correction

Refinement method

Data / restraints / parameters

Goodness-of-fit on $\mathrm{F}^{2}$

Final $\mathrm{R}$ indices [I $>2 \operatorname{sigma}(\mathrm{I})]$

$\mathrm{R}$ indices (all data)

Absolute structure parameter

Extinction coefficient

Largest diff. peak and hole
2

$1.328 \mathrm{Mg} / \mathrm{m}^{3}$

$0.269 \mathrm{~mm}^{-1}$

624

$1.120 \times 0.900 \times 0.060 \mathrm{~mm}^{3}$

2.126 to $30.969^{\circ}$.

$-10<=\mathrm{h}<=10,-16<=\mathrm{k}<=16,-22<=1<=22$

16251

$8373[\mathrm{R}(\mathrm{int})=0.0261]$

$99.8 \%$

Semi-empirical from equivalents

Full-matrix least-squares on $\mathrm{F}^{2}$

$8373 / 1 / 360$

1.021

$\mathrm{R} 1=0.0318, \mathrm{wR} 2=0.0822$

$\mathrm{R} 1=0.0368, \mathrm{wR} 2=0.0849$

$-0.009(18)$

$\mathrm{n} / \mathrm{a}$

0.316 and -0.235 e. $\AA^{-3}$ 


\section{Supporting Information}

\subsection{X-ray structure of compound Q9 (CCDC 1482332)}

Crystal data for mo_Q9_0m-sr: $\mathrm{C}_{28} \mathrm{H}_{38} \mathrm{O}_{8} \cdot \mathrm{H}_{2} \mathrm{O}, M=520.60, a=26.073(6) \AA, b=$ 7.8003(19) $\AA, c=29.094(7) \AA, \alpha=90^{\circ}, \beta=91.171(4)^{\circ}, \gamma=90^{\circ}, V=5916(2) \AA^{3}, T=$ $100(2) \mathrm{K}$, space group $C 2, Z=8, \mu(\mathrm{MoK} \alpha)=0.086 \mathrm{~mm}^{-1}, 31206$ reflections measured, 15773 independent reflections $\left(R_{\text {int }}=0.0613\right)$. The final $R_{I}$ values were $0.1209(I>2 \sigma(I))$. The final $w R\left(F^{2}\right)$ values were $0.3192(I>2 \sigma(I))$. The final $R_{I}$ values were 0.1352 (all data). The final $w R\left(F^{2}\right)$ values were 0.3280 (all data). The goodness of fit on $F^{2}$ was 1.073. Flack parameter $=0.5(5)$.

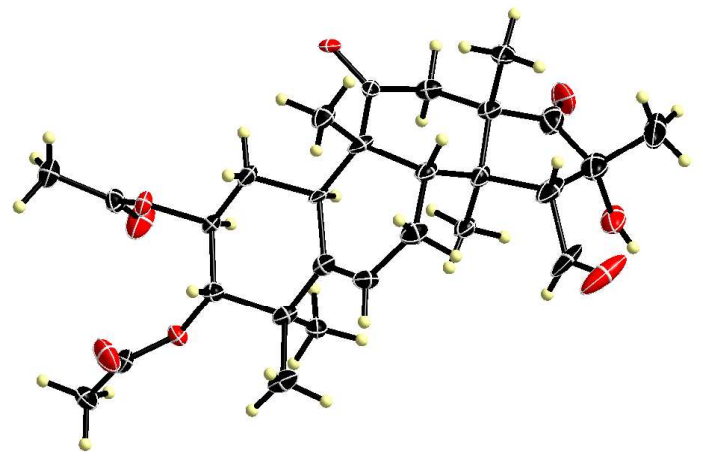

View of the molecules in an asymmetric unit.

Displacement ellipsoids are drawn at the $50 \%$ probability level.

Table 1. Crystal data and structure refinement for mo_Q9_0m-sr.

Identification code

Empirical formula

Formula weight

Temperature

Wavelength

Crystal system

Space group

Unit cell dimensions
mo_Q9_0m-sr

$\mathrm{C}_{28} \mathrm{H}_{40} \mathrm{O}_{9}$

520.60

100(2) K

$0.71073 \AA$

Monoclinic

C2

$$
\begin{array}{ll}
\mathrm{a}=26.073(6) \AA & \text { alfa }=90^{\circ} . \\
\mathrm{b}=7.8003(19) \AA & \text { beta }=91.171(4)^{\circ} . \\
\mathrm{c}=29.094(7) \AA & \text { gamma }=90^{\circ} .
\end{array}
$$




\section{Supporting Information}

\begin{tabular}{ll} 
Volume & $5916(2) \AA^{3}$ \\
$Z$ & 8 \\
Density (calculated) & $1.169 \mathrm{Mg} / \mathrm{m}^{3}$ \\
Absorption coefficient & $0.086 \mathrm{~mm}^{-1}$ \\
$\mathrm{~F}(000)$ & 2240 \\
Crystal size & $0.670 \times 0.350 \times 0.280 \mathrm{~mm}^{3}$ \\
Theta range for data collection & 0.700 to $29.963^{\circ}$. \\
Index ranges & $-34<=\mathrm{h}<=36,-10<=\mathrm{k}<=10,-40<=1<=40$ \\
Reflections collected & 31206 \\
Independent reflections & $15773[\mathrm{R}(\mathrm{int})=0.0613]$ \\
Completeness to theta $=25.242^{\circ}$ & $99.2 \%$ \\
Absorption correction & Semi-empirical from equivalents \\
Refinement method & Full-matrix least-squares on $\mathrm{F}^{2}$ \\
Data / restraints / parameters & $15773 / 693 / 684$ \\
Goodness-of-fit on F 2 & 1.073 \\
Final R indices [I 2 sigma(I)] & $\mathrm{R} 1=0.1209, \mathrm{wR} 2=0.3192$ \\
R indices (all data) & $\mathrm{R} 1=0.1352, \mathrm{wR} 2=0.3280$ \\
Absolute structure parameter & $0.5(5)$ \\
Extinction coefficient & $\mathrm{n} / \mathrm{a}$ \\
Largest diff. peak and hole & 1.008 and $-0.585 \mathrm{e} . \AA^{-3}$ \\
\hline
\end{tabular}

